مجلة كلية التربية، جامعة الأزهر، العدد: (183، الجزء الأول) يوليو لسنة 2019م

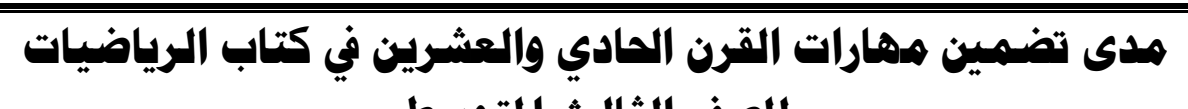
للصف الثالث المتوسط

مستخلص الاراسة:

هدفت الاراسة الحالية تعرف مدى تضمين مهارات القرن الحادي والعشرين في كتاب

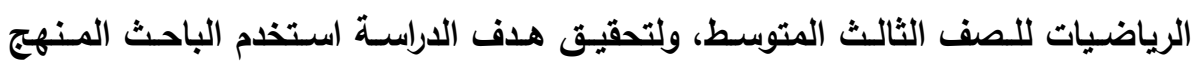

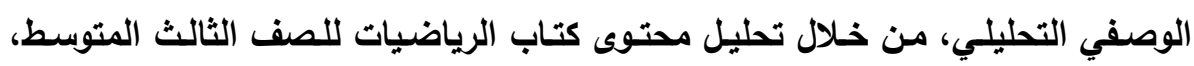
باستخدام بطاقة تحليل المحتوى التي تم بناؤها في ضوء مهارات القرن الحادي والعثرين، حيث اشتملت على (3) مجـالات، و(10) مهارات رئيسة، و (22) مهارة فرعيـة، و(73)

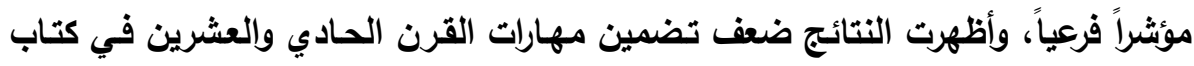
الرياضيات للصف الثالث المتوسط للمجالات الثلاثة، وكذلك ضعف تضمين المهارات

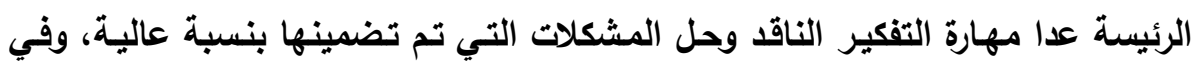
ضوء نتائج الدراسة أوصى الباحث بوضـع تصور موحد من قبل وزارة التعليم ومسؤولي لوني

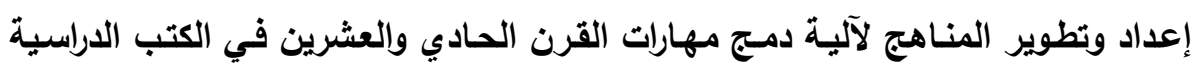
عامـة، وفي كتب الرياضيات على وجهه الخصوص لتوحيد الجهود والعدل، وعقد دورات

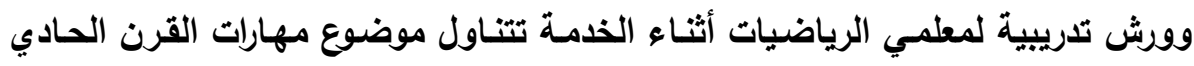
والعشرين وكيفية تضمينها في مناهج الرياضيات. 
مجلة كلية التريبة، جامعة الأزهر ، العدد: (183، الجزء الأول) يوليو لسنة 2019م

The Extent to Which the 21st Century Skills Are Included in the Mathematics Book of the Third Year Preparatory Stage.

BY:

\author{
Dr. Ibrahim bin Sulayem R ezeeq Al- H arby \\ Associate Professor of Curriculum and Instruction \\ (Mathematics) Faculty of Education - Um Al- Q ura University
}

\title{
ABST RACT:
}

The current study aimed to define the extent to which the 21st century skills are included in the mathematics book of the third year preparatory stage pupils. For achieving such objective, the study made use of the analytical descriptive method via analyzing the content of the mathematics book of the third year preparatory stage pupils utilizing the content analysis form, which was developed in the light of the 21 st century skills, namely, three domains, 10 main skills, 22 sub-skills and 73 sub-indicators. The results of the study showed limited inclusion of the 21st century skills in the mathematics book of the third year preparatory stage pupils concerning the three domains, as well as limited inclusion of the main skills apart from the skills of critical thinking and problem solving which was included on a large scale. In the light of the results attained, the researcher recommended developing unified perspective by the Ministry of Education and those responsible for developing curricula concerning the mechanisms of including the skills of the 21st century into textbooks in general and in mathematics books in particular to unite efforts and work. The study also recommended holding training workshops for the in-service mathematics teachers concerning how are the $21 \mathrm{st}$ century skills incorporated into the mathematics curricula. 
يتسم القرن الحادي والعشرون بتطورات علمية سريعة ومتجددة أثرت على كافة

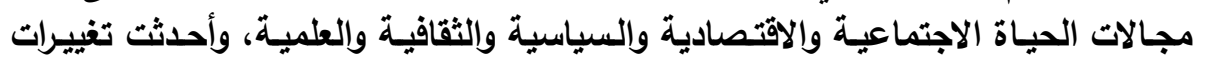

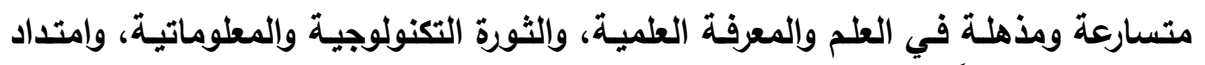

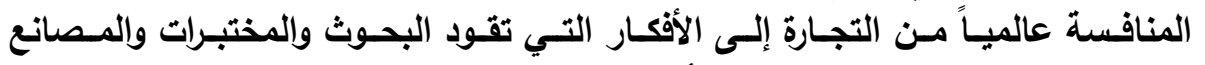

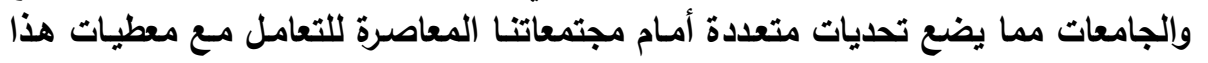

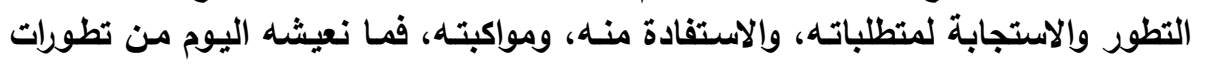

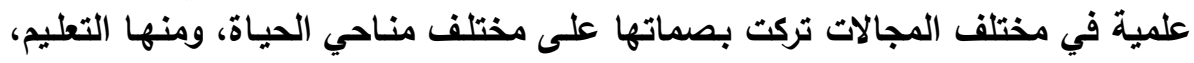

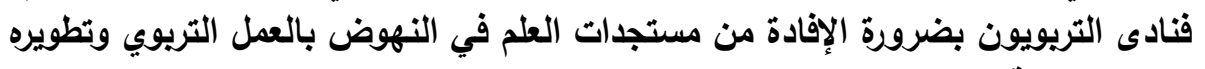

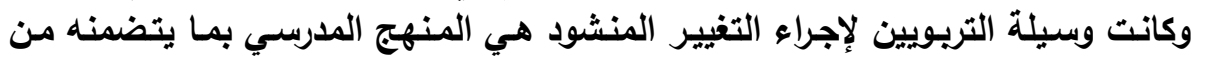

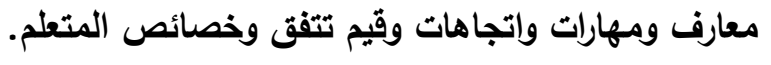

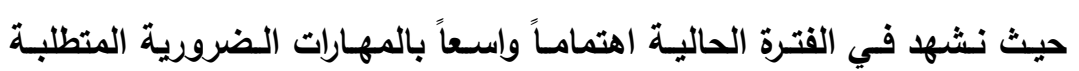

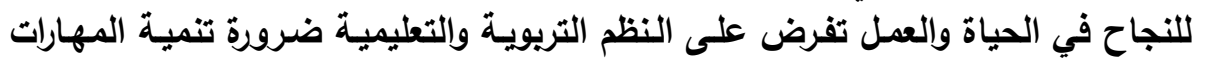

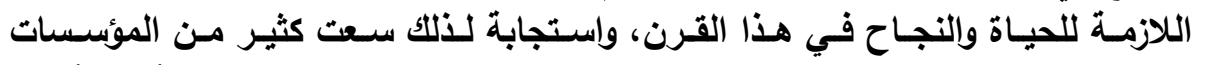

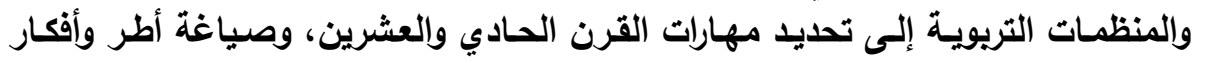

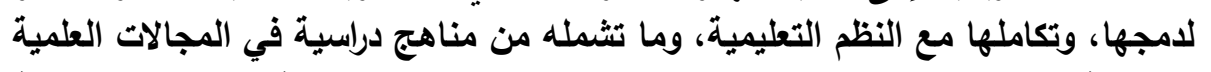

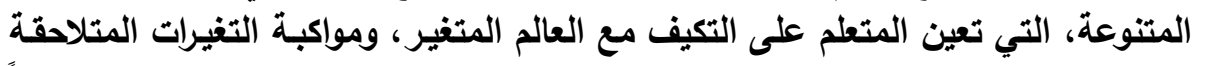

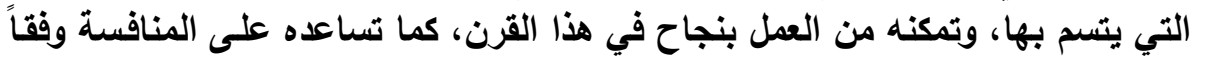

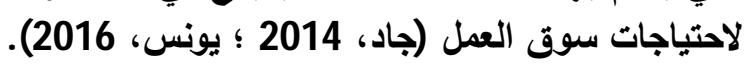

ويعد توجه مهارات القرن الواحد والعشرين من التوجهات التي بدأت تنال اهتماماً

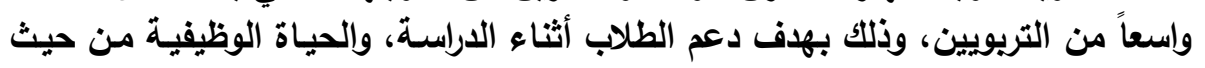

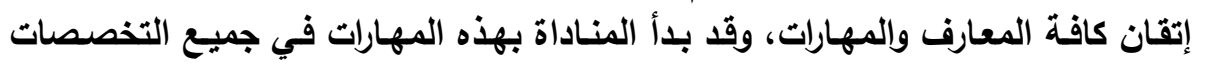

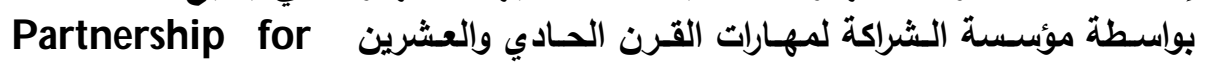
21Century Skills

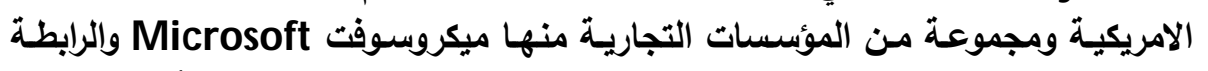

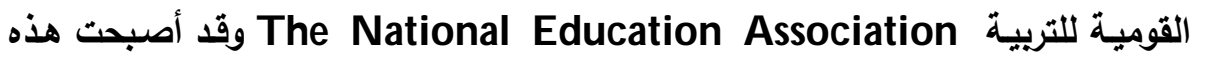

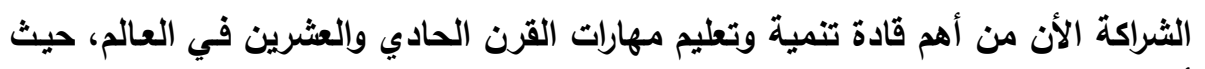

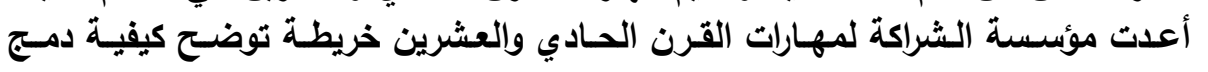

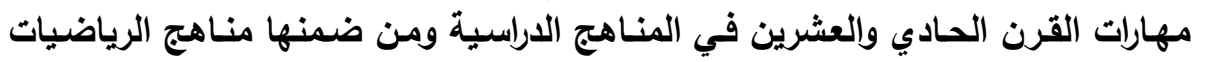

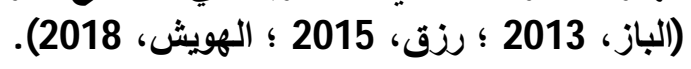

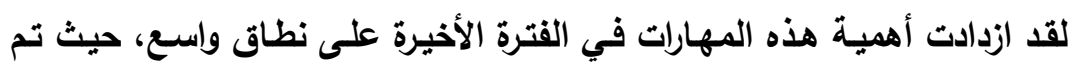

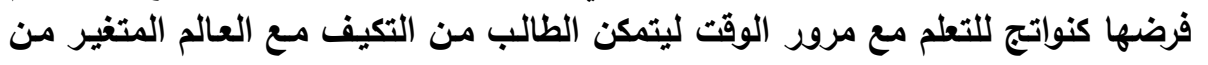




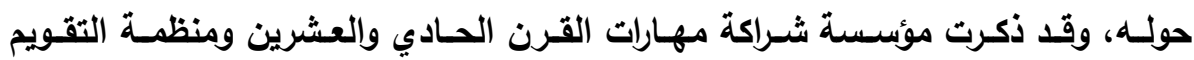

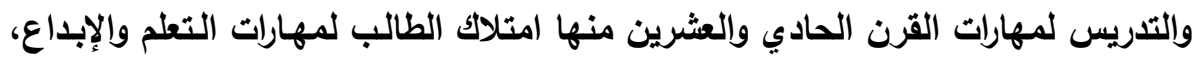

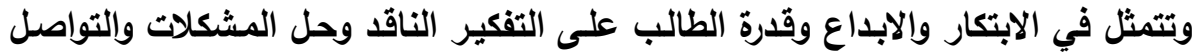

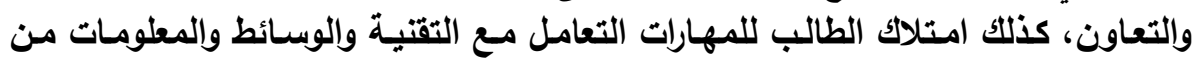

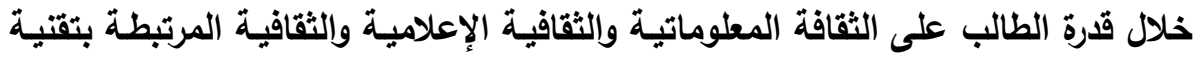

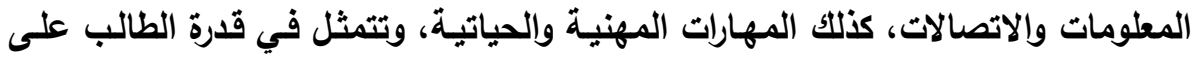
المرونة والقدرة على التكيف والمبادرة والتوجيه الذاتي، والقدرة على الإنتاج والقيادة وتحمل التانية

المسئولية ( السعيد، 2018)

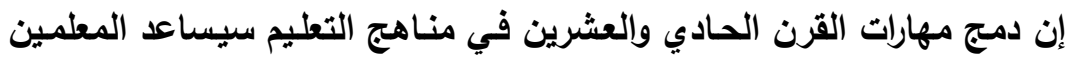

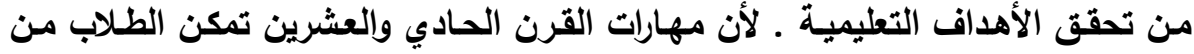

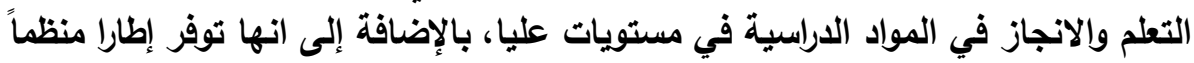

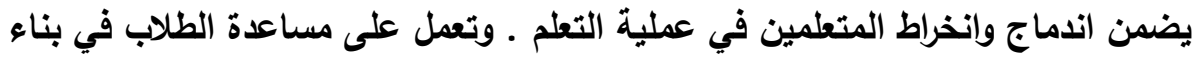

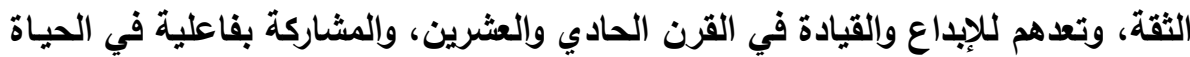

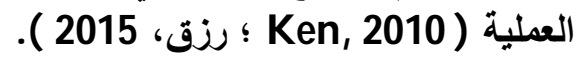

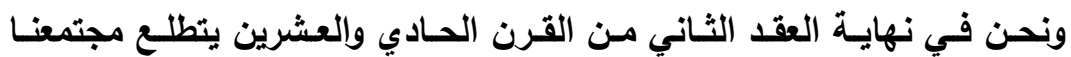

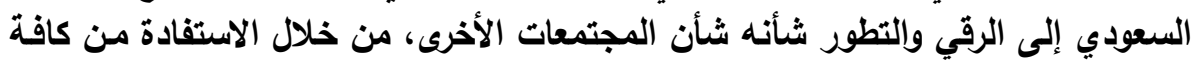

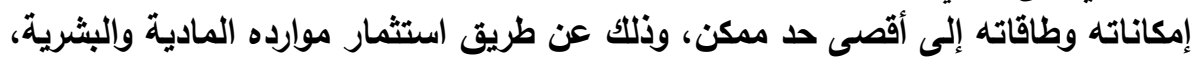

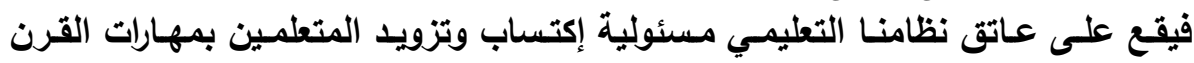

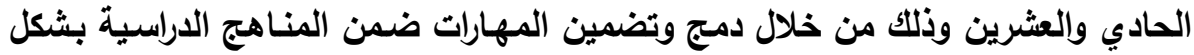

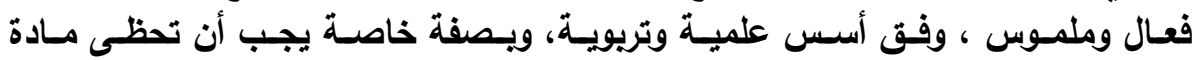

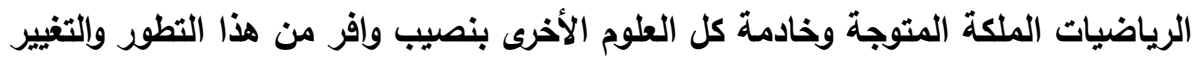

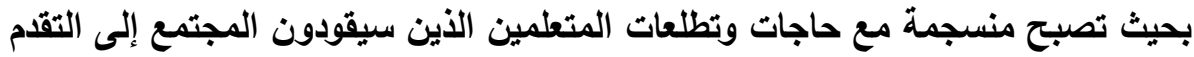

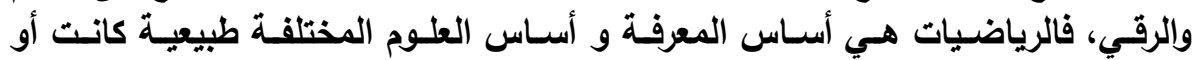

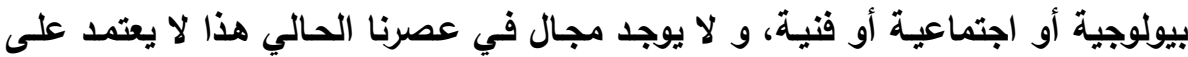

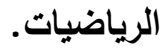

كما أن هناك اتفاق بين التريويين على أن المناهج الحالية لم تعد كافيـة لإعداد

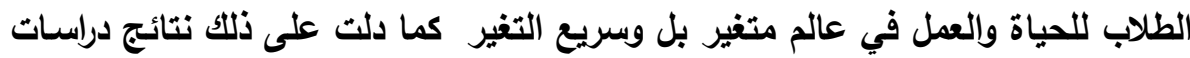

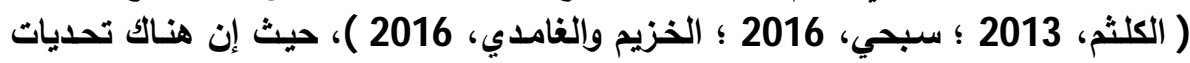
تواجه هولاء الطلاب تستوجب أن يكون تعلم اليوم مختلف عن تعلم الأمس، فمن الأهمية

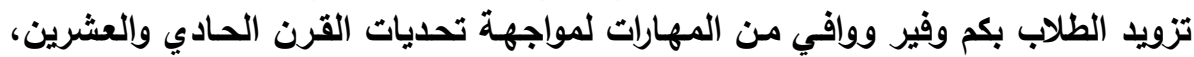

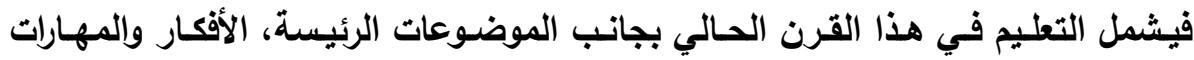


مجلة كلية التزبية، جامعة الأزهر، العدد: (183، الجزء الأول) يوليو لسنة 2019م

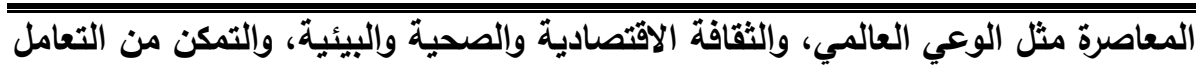

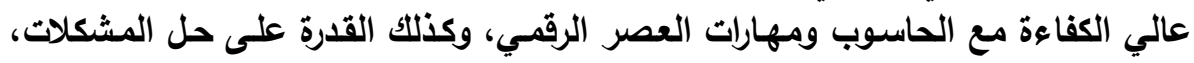

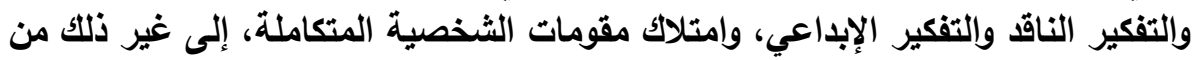
مهارات التعلم في القرن الحادي والعشرين.

لذا يجب على القائمين على بناء وتصميم المناهج مراعاة تضمين مهارات القرن

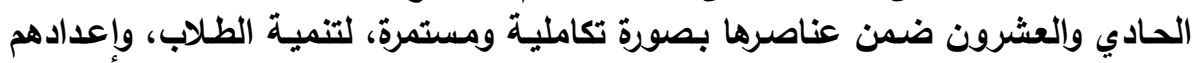

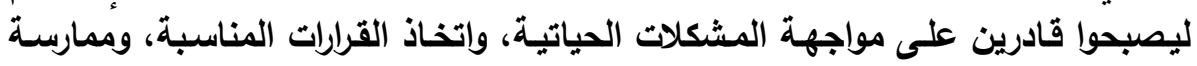

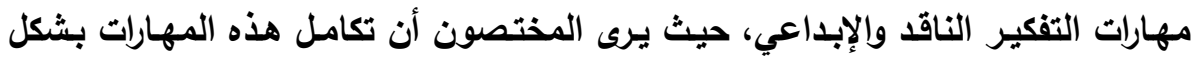

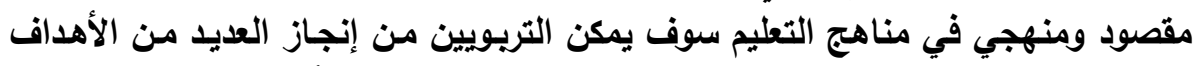

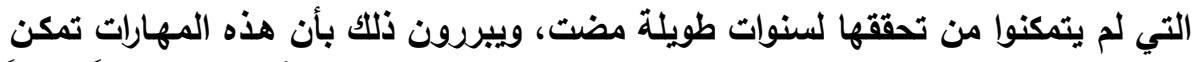

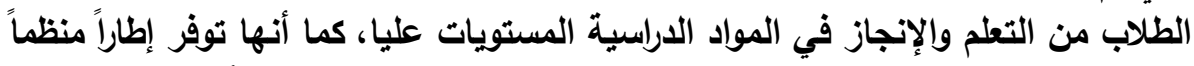

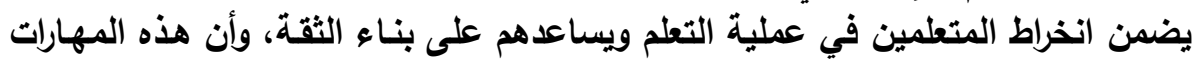
تعد الطلاب للابتكار، والقيادة في القرن الحادي والعة والعشرين والمشاركة بفاعلية في الحياة .

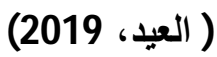

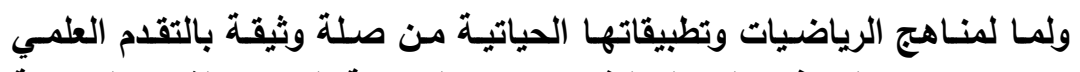

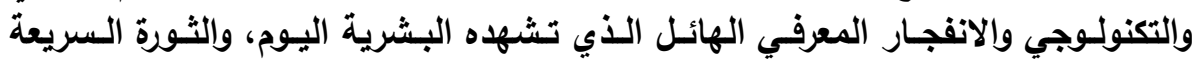

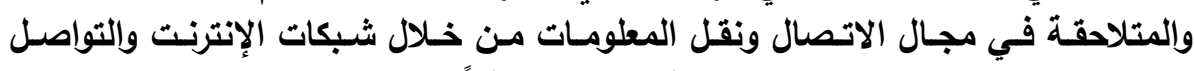

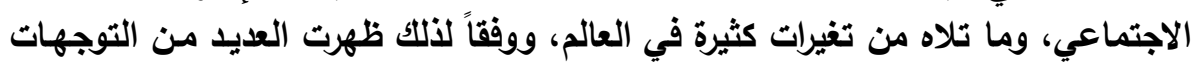

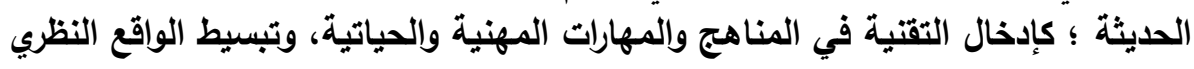

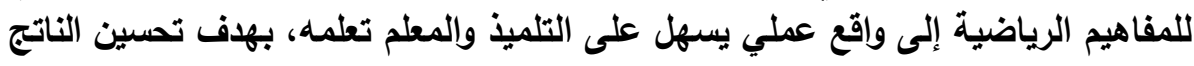

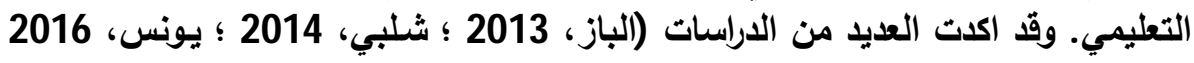

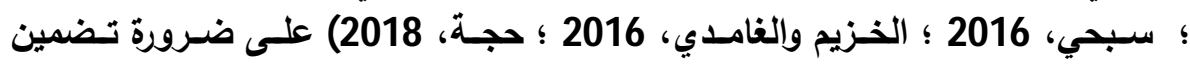
مهارات القرن الحادي والعشرين في محتوى مقرراتها الدراسية. مشكلة الدراسة وتساؤلاتها: بالرغم من أن المملكة العربية السعودية قد حققت قفزات كبيرة في مجال التعليم

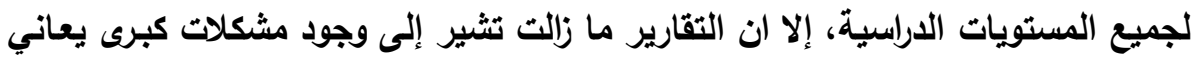

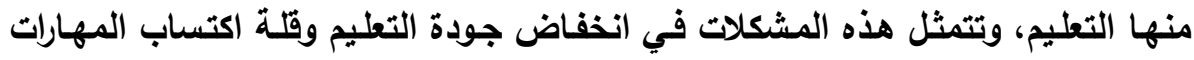

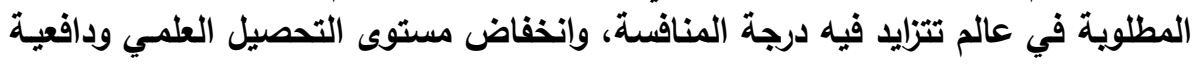

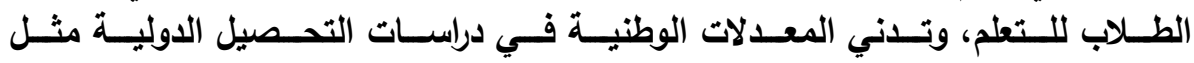

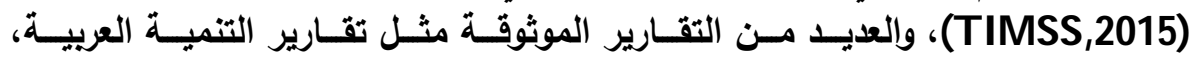

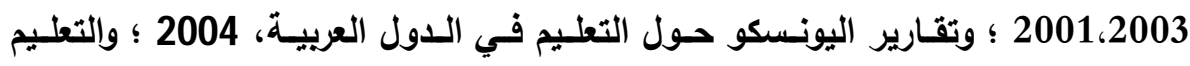




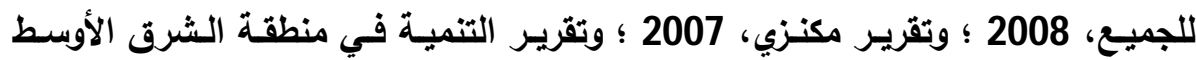
وشمال افريقيا الصادر عن البنك الدولي، 2008 و 2007 (الهويش، 2007 2018).

فالعديد من المتخصصين في التربية والتعليم يتفقون فيما بينهم على وجود فجوة

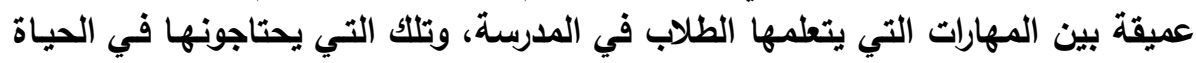

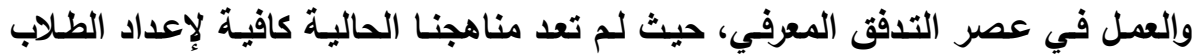

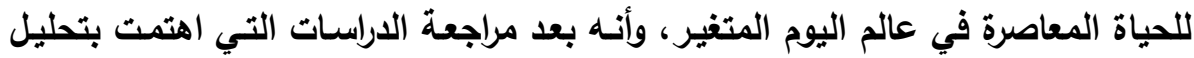

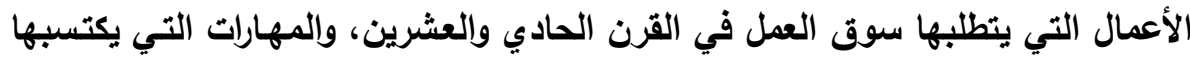

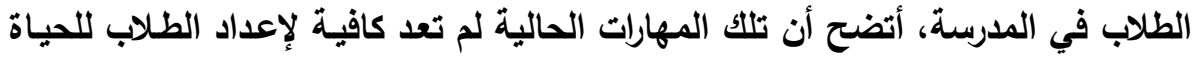

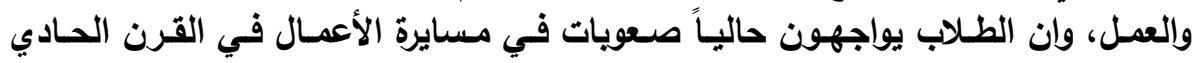
والعشرين وأنهم يعدون لأعمال اختفت أو مرشحة للاختفاء في هذا القرن (شلبي، 2014؛ راشدد، 2017).

إن مجتمعنا يواجه العديد من التحديات خلال القرن الحادي والعشرين، على الصعيد

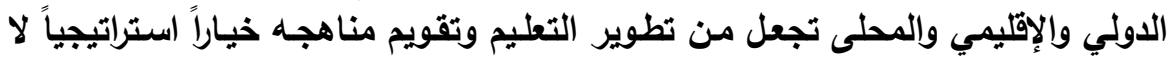

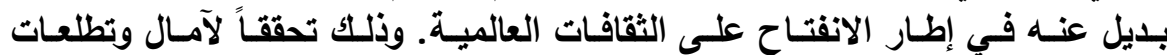

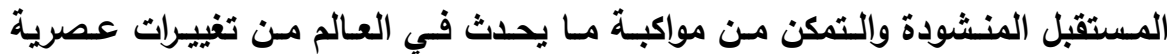

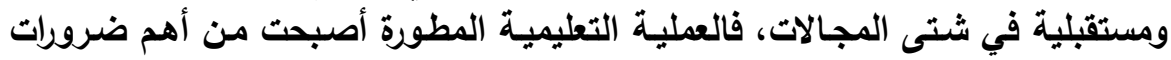

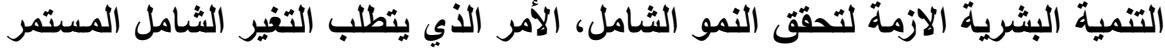

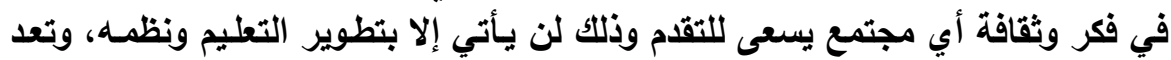

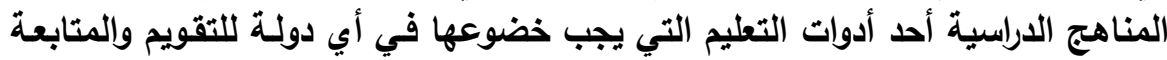

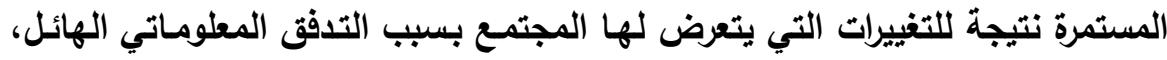

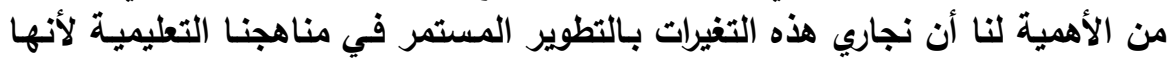

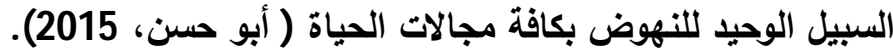

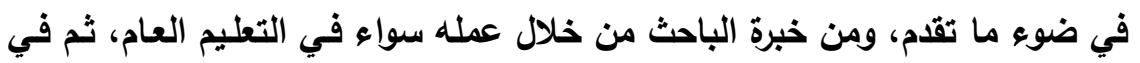

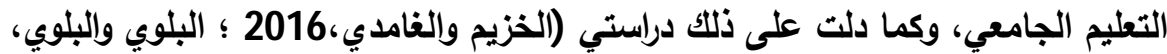

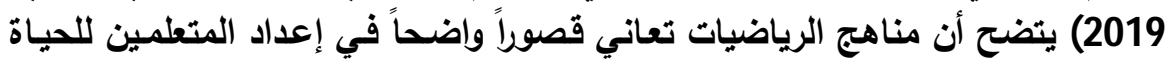

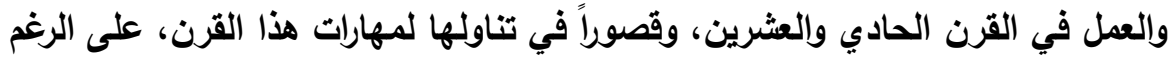

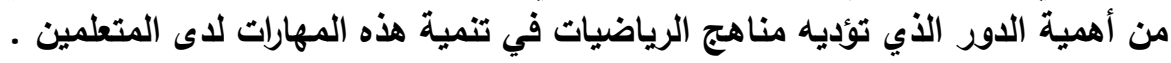
ولندرة الدراسات التي تناولت مدى تضمين مهارات القرن الحادي والعشرين في كتاب الرياضيات للصف الثالث المتوسط -بحدود معرفة واطلاع الباحث - ولكون مرحلة التعليم

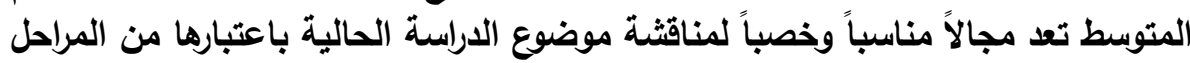

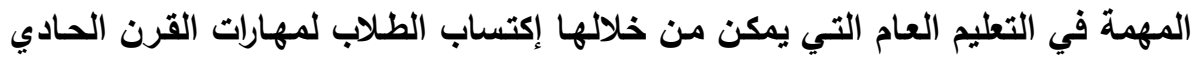


مجلة كلية التربية، جامعة الأزهر، العدد: (183، الجزء الأول) يوليو لسنة 2019م

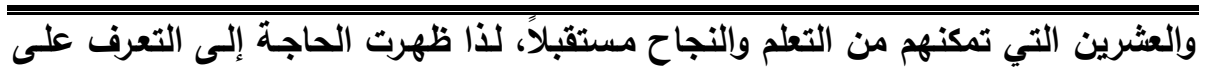

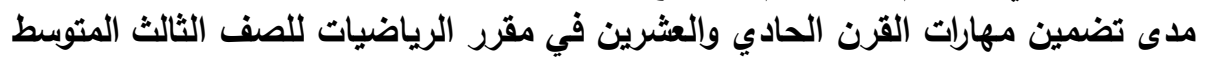

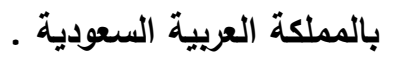

لذا فقا سعت الاراسة الحالية إلى الإجابة عن السؤال الرئيس التالي: مـا مدى تضمين مهارات القرن الحادي والعشرين في كتاب الرياضيات للصف الثالث

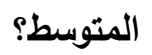

ويتفرع منه الأسئلة التالية:

1 - مـا مهارات القرن الحسادي والعشرين المتطلب تضمينها في كتـاب الرياضيات

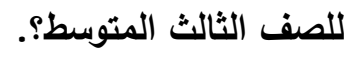

2 - ما مدى تضمين مهارات القرن الحادي والعشرين في كتاب الرياضيات للصف

الثالث المتوسط؟.

هدف الدراسة: - م

التعرف على مدى تضمين مهارات القرن الحادي والعشرين في كتاب الرياضيات

للصف الثالث المتوسط.

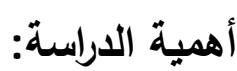

1 - تأتي هذه الدراسة استجابة للتوجهات العالمية التي تنادي بأهمية تضمين مهارات

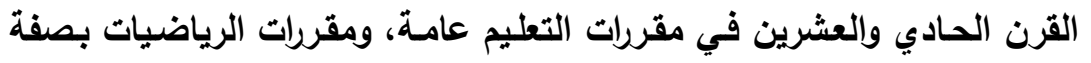

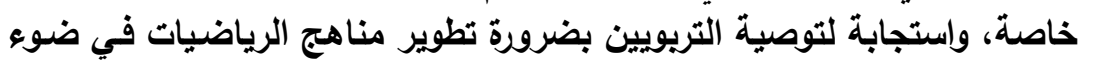

$$
\text { المستجدات التريوية. }
$$

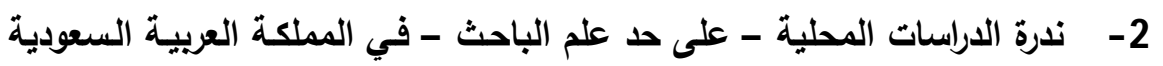

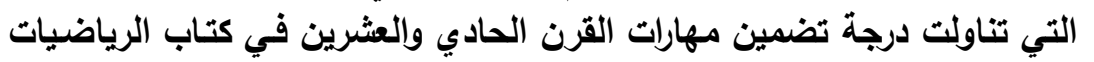
في مراحل التعليم المختلفة.

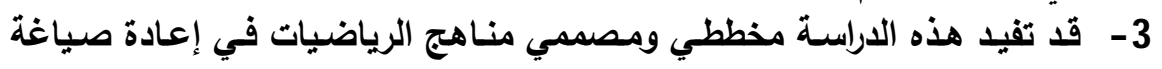

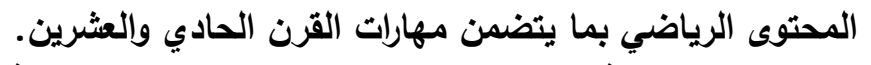

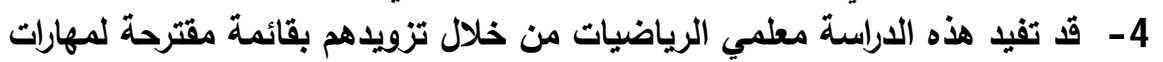

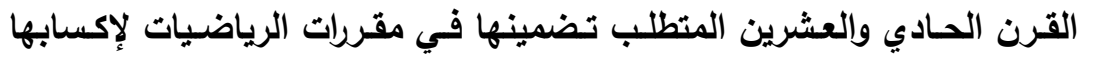

$$
\text { الطلاب. القن }
$$




\footnotetext{
حدود الاراسة: الحدود الموضوعية:

اقتصرت الدراسـة على مهارات القرن الحـادي والعشرين المتطلب تضمينها في كتاب الرياضيات - كتاب الطالب - للصف الثالث المتوسط. الحدود الزماتية:

طبقت الاراسة على كتاب الرياضيات للصف الثالث المتوسط بالمملكة العربية السعودية طبعة 1438 -1439هـ

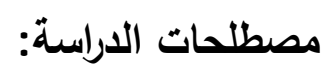
مهارات القرن الحادي والعشرين:

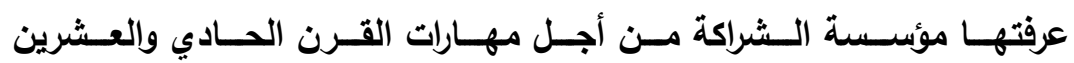
Partnership for 21Century Skills

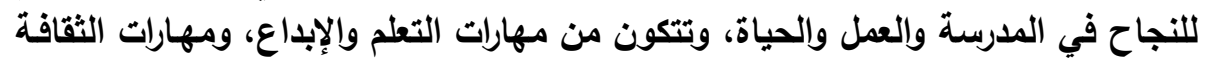

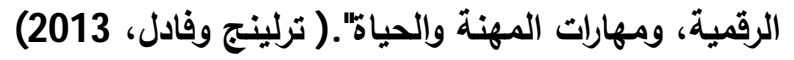
وتُعرف إجرائياً في هذه الدراسة بأنها مجموعة مهارات التعلم والعمل والحياة التي

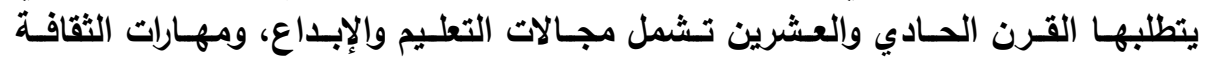

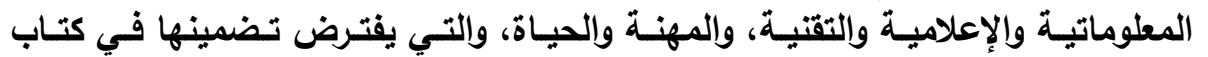
الرياضيات للصف الثالث المتوسط. مدى تضمين: نسبة تشبع المهارة الفرعية ويقاس بعدد مؤشرات مهارات القرن الحادي والعشرين التي تحققت وتم تضمينها في كتاب الرياضيات للصف الثالث المتوسط.

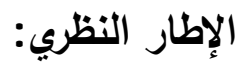
فيما يلي يتم تناول الإطار النظري للاراسـة من خلال تناول مهارات القرن الحادي والعشرين من حيث مفهومها وماهيتها، ومجالاتها، وتضمينها في الرياض فياضيات المدرسية. مفهوم مهارات القرن الحادي والعشرين:

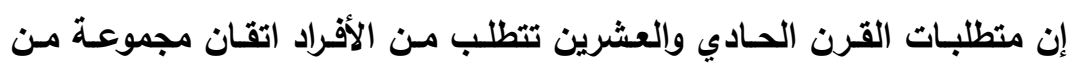
المهارات التي ترتكز على مجموعة من الدعائم، حيث يستخدم هذا المفهوم عادة لتحديد 
مجلة كلية التريبة، جامعة الأزهر ، العدد: (183، الجزء الأول) يوليو لسنة 2019م

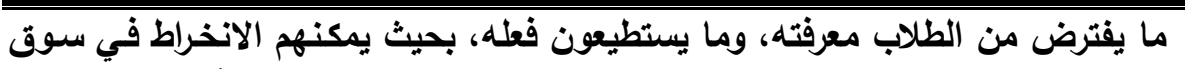

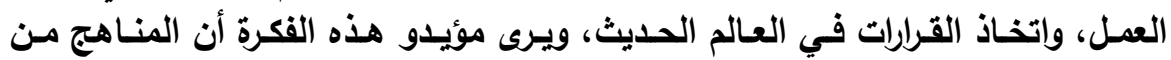

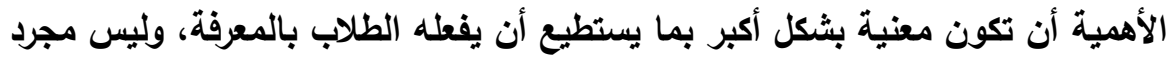

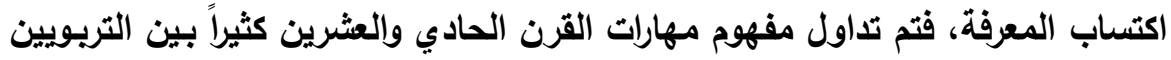

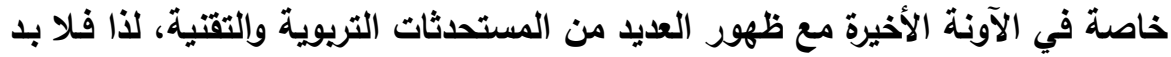

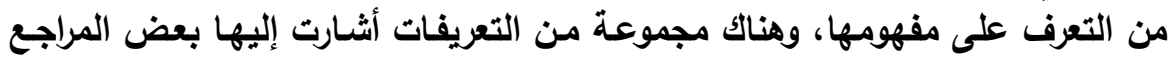
والاراسات والبحوث الأجنبية والعربية.

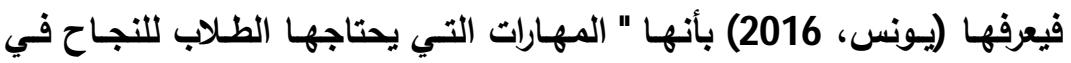

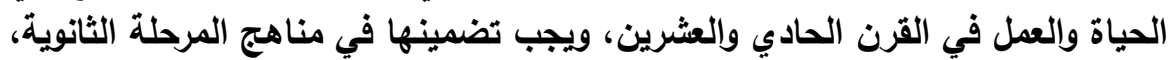

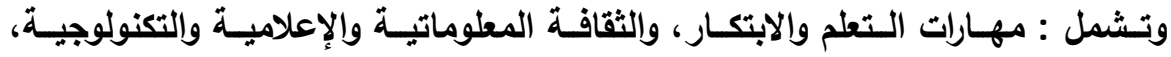

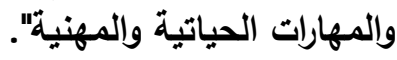

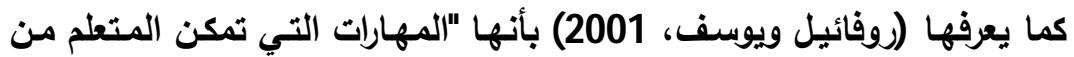

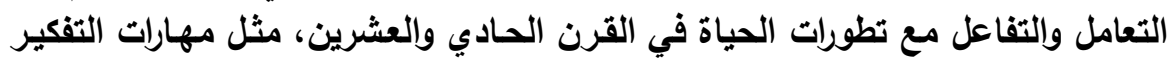

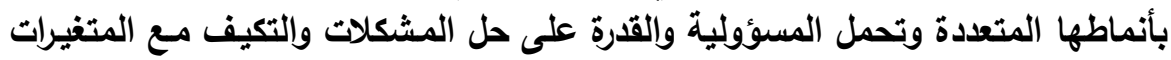

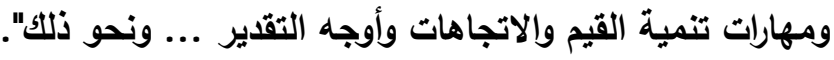

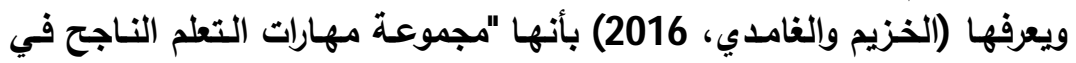

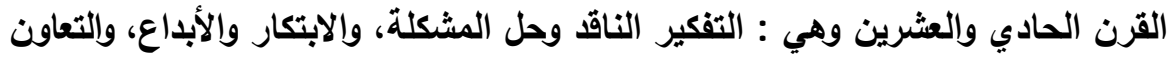

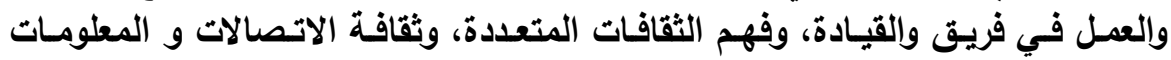

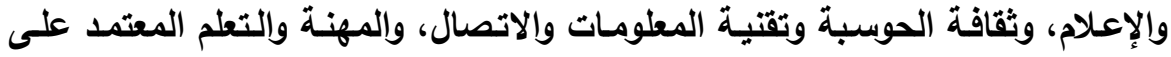

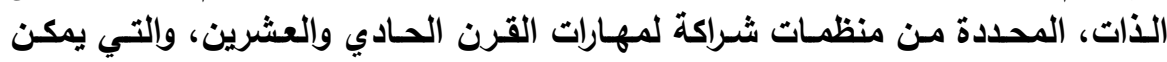

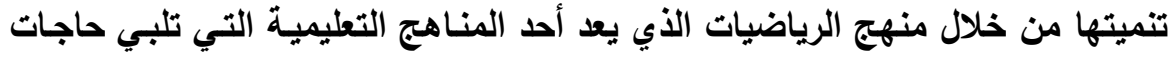

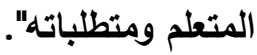

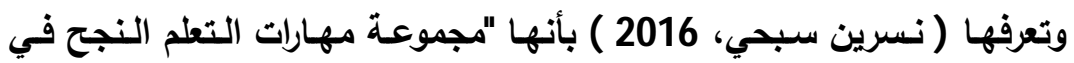

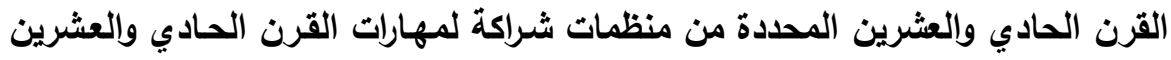

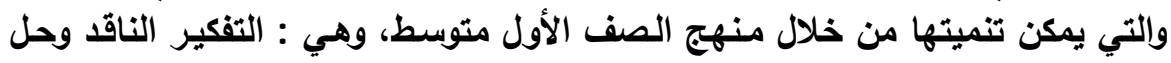

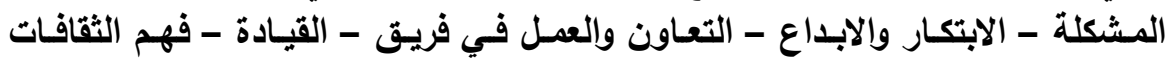

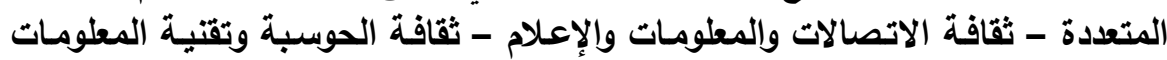
والاتصال - المهنة والتعلم المعتمد على الأتات".

في حين يعرفها ( السعيد، 2018 ) بأنها "مهارات التعلم الحياتية والأكاديمية

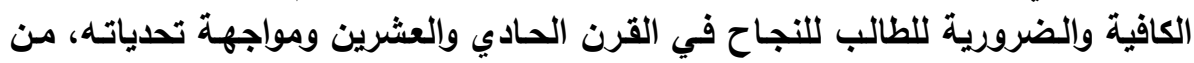

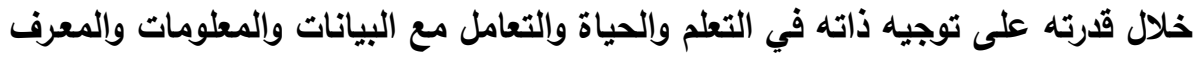

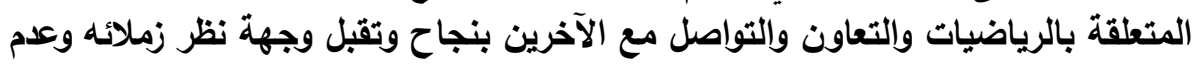

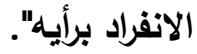




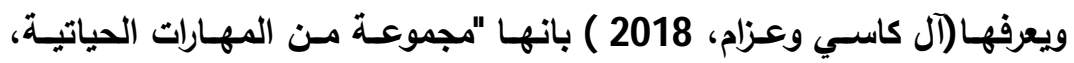

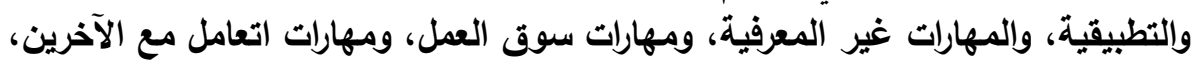

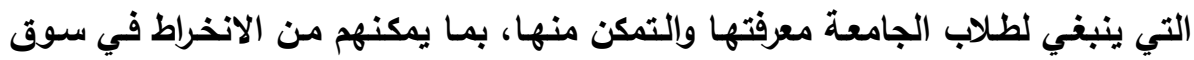

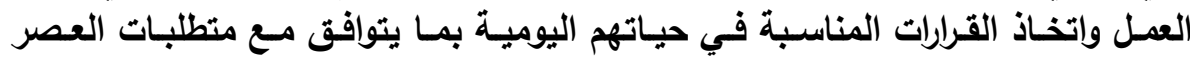

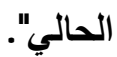

ويعرفها (Scott,2015) بأنها الكفاءات والمهارات الأساسية للنجاح في العمل

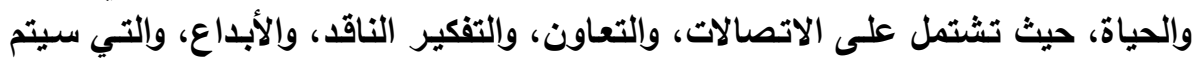

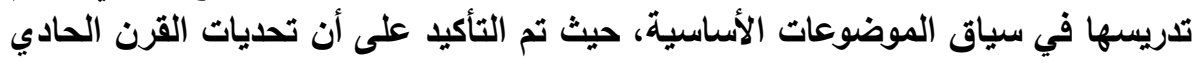

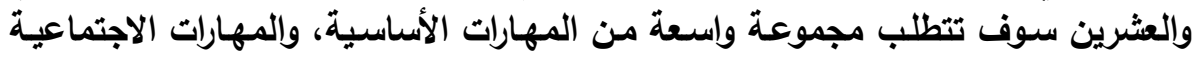

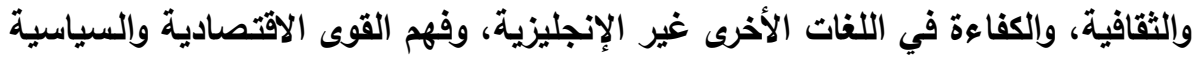
التي تتؤثر على المجتمعات .

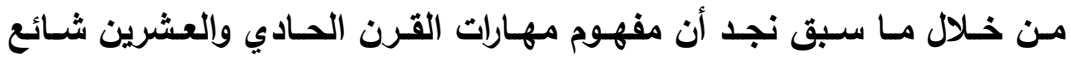

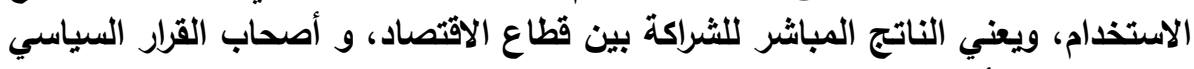

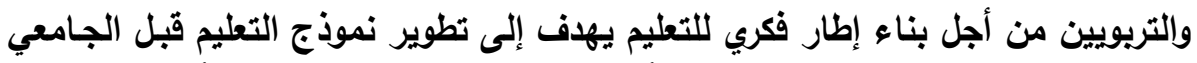

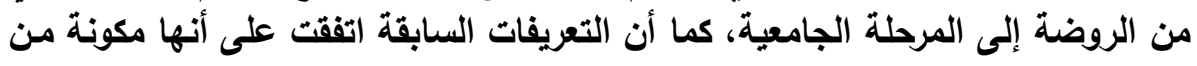

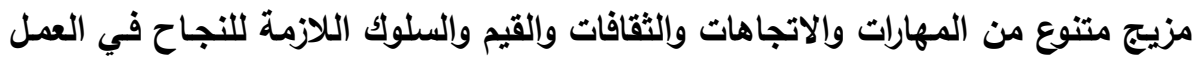

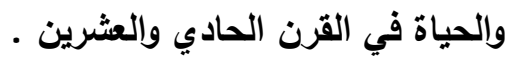

بينما نجد أن الاختلاف بين التعريفات السابقة لمهارات القرن الحادي والعشرين

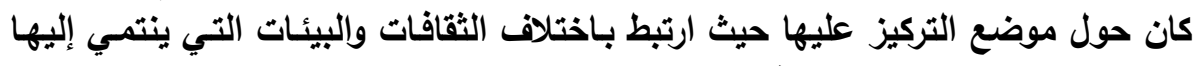

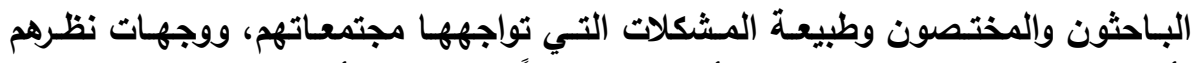

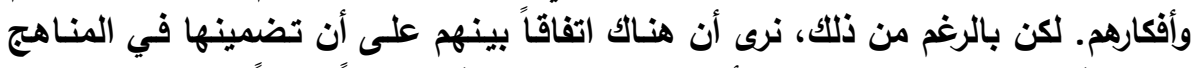

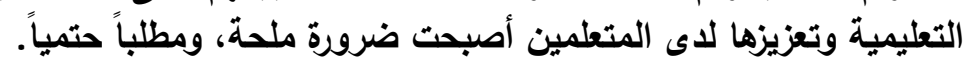
المجالات الرئيسة لمهارات القرن الحادي والعشرين: اختلف الخبراء والتريويون في تحديد مهارات القرن الحادي والعشرين تحديداً

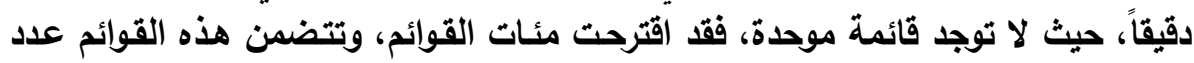

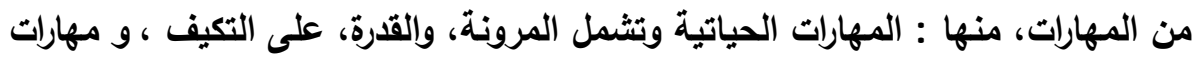

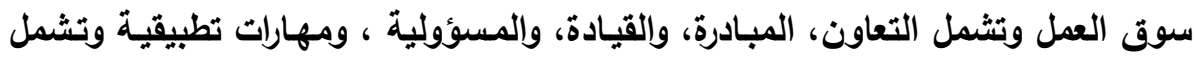

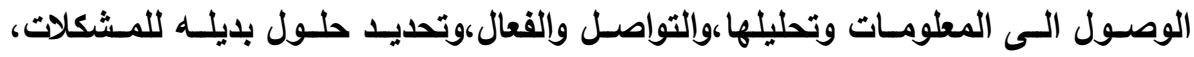

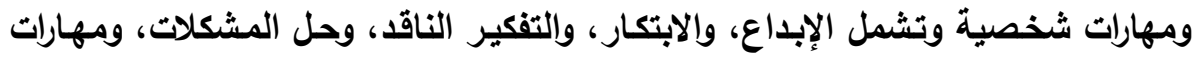

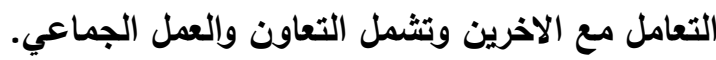


مجلة كلية التربية، جامعة الأزهر، العدد: (183، الجزء الأول) يوليو لسنة 2019م

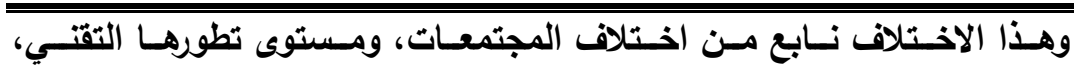

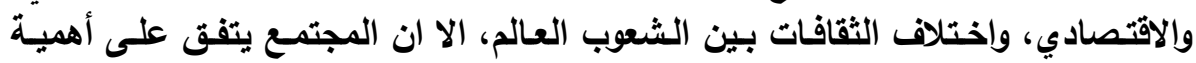

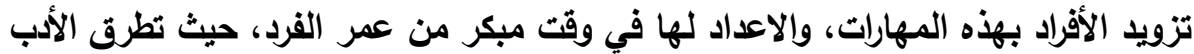

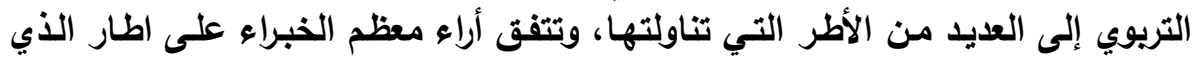
أعدته الشراكة من أجل مهارات القرن الحادي والعشرين Century Skills

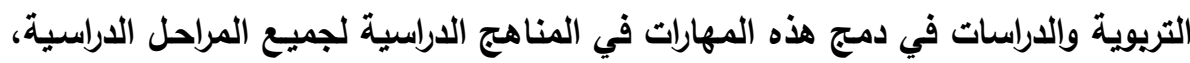

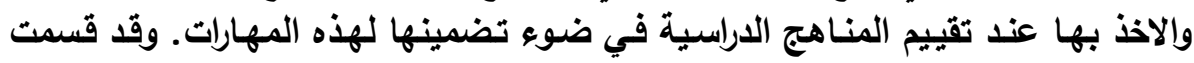

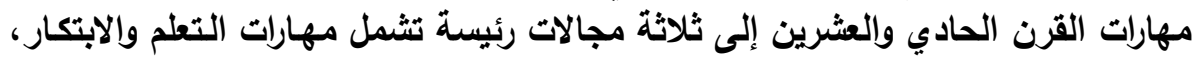

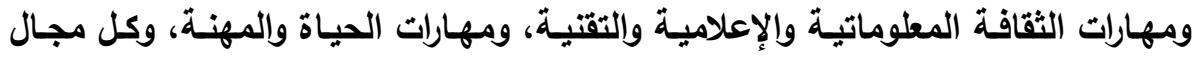

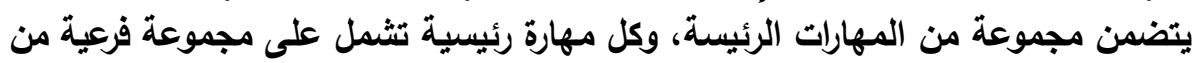

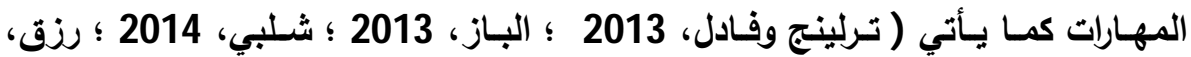

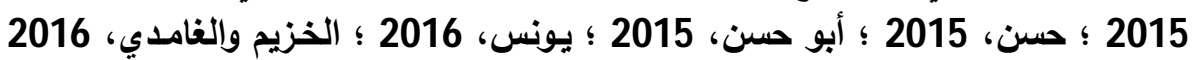
؛ سبحي، 2016 ؛ راثد، 2017 ؛ حجة، 2018 ؛ ؛ المنصور ، 2018 ؛ ؛ العيد، 2019) .

$$
\text { أولاً :مهارات التعلم والابتكار : }
$$

وفقاً للشراكة من أجل مهارات القرن الحادي والعشرين فإن مهارات التعلم والابتكار هي

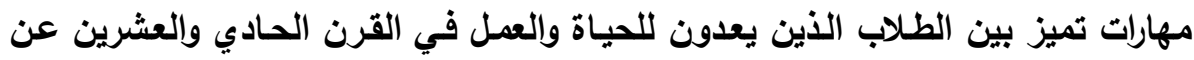

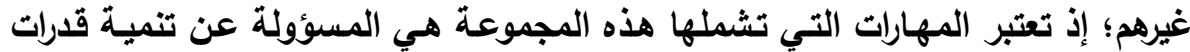

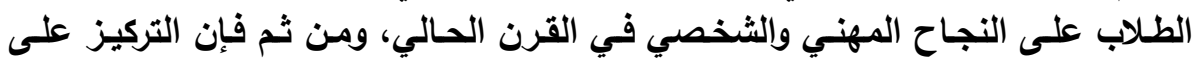
الابتكار، والتفكير الناقد، والتواصل والتعاون ضروري لإعداد الطلاب، وتثثمل مهارات التعلم والابتكار المهارات الفرعية التالية:

1 ـ مهارات التفكير الناقد وحل المشكلات: ويتضمن التفكير الناقد وحل المشكلات المهارات

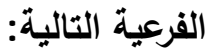

مهارة التفكير بشكل فعال، مهارة استخدام التفكير المنظومي، ومهارة إصدار الأحكام والقرارات، ومهارة حل المشكلات.

2. مهارات الإبداع والابتكار: ويتضمن الإبداع والابتكار عدد من المهارات الفرعية التالية: التفكير الخلاق، والعمل والابتكار، وتنفيذ الابتكار .

3. مهارات التواصل والتعاون: وتتضمن مهارات التواصل والتعاون عدد من المهارات الفرعية التالية: التواصل بوضوح، التعاون مع الآخرين. 


\section{ثانياً : مهارات الثقافة المعلوماتية والإعلامية والتقتية:}

يعيش الأفراد في القرن الحادي والعشرين في بيئة تصطبخ بالتقنية، ويزداد فيها

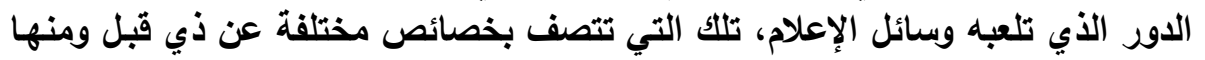

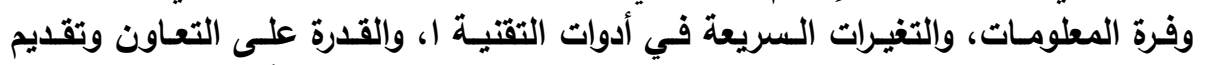

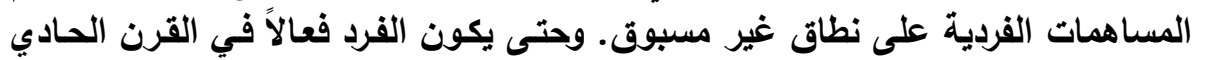

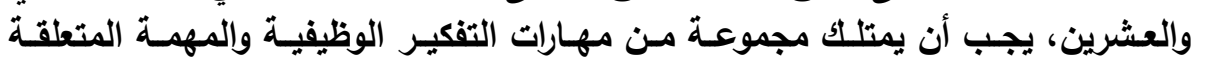

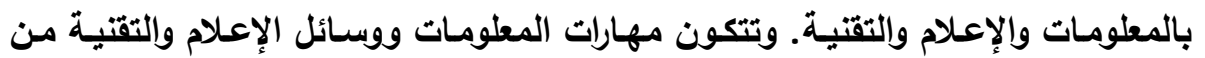
المهارات القرعية التالية:

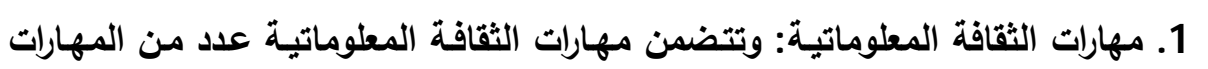
الفرعية التالية: الوصول إلى المعلومات وتقييمها، واستخدام وإدارة المعلومات .

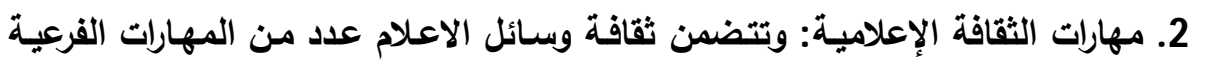

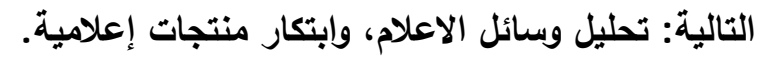

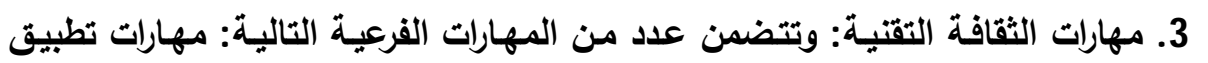

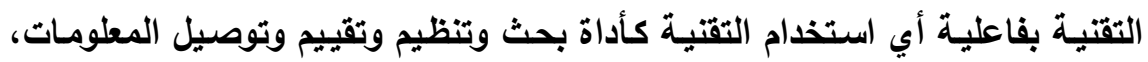

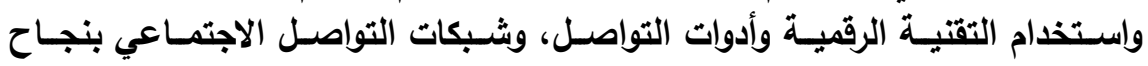

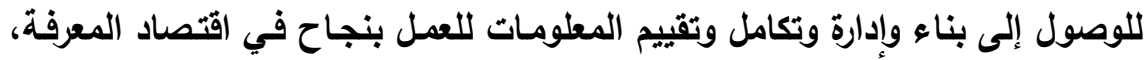

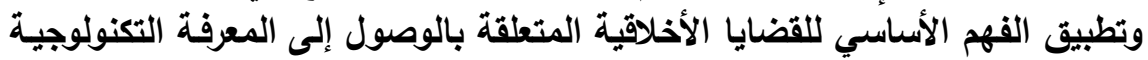

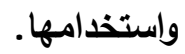

ثالثاً : مهارات الحياة والمهنة:

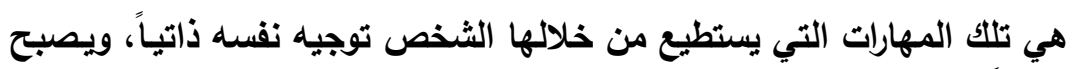

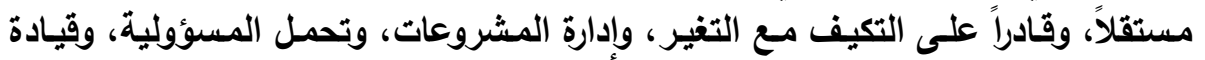
الآخرين. وتثثمل مهارات الحياة والمهنة المهئة المهارات الفرعية التالية:

1 ـ مهارات المرونة والتكيف: وتتضمن مهارات المرونة والتكيف عدد من المهارات الفرعية

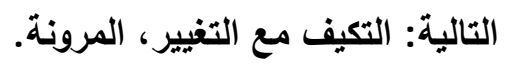

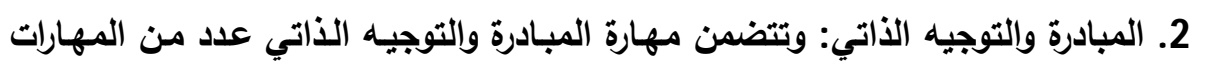
الفرعية التالية: إدارة الوقت والاهداف، التئه العمل المستقل، التعلم الموجه ذاتياً.

3. مهارات الإنتاجية والمساعلة: وتتضمن مهارات الإنتاجية والمساعلة عدد من المهارات

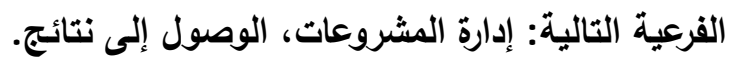


مجلة كلية التربية، جامعة الأزهر، العدد: (183، الجزء الأول) يوليو لسنة 2019م

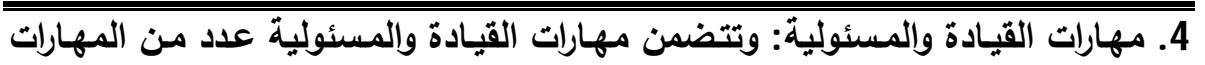
الفرعية التالية: مهارة قيادة وتوجيه الآخرين، مهارة المسئولية عن التهات الآخرين.

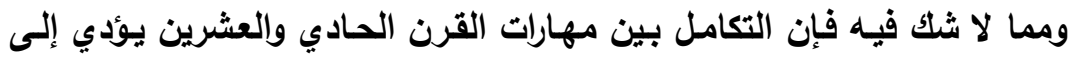

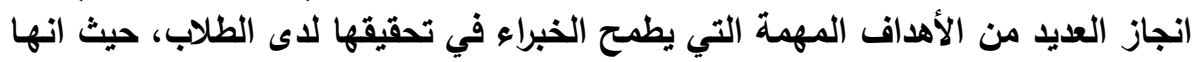

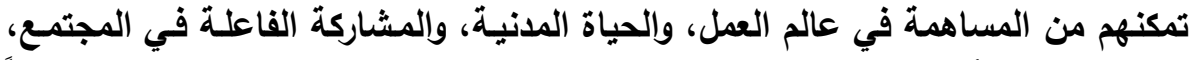

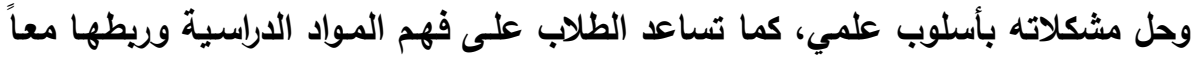
من اجل تنمية التفكير ويناء أفكار جديدة، واستخدم أدوات المعرفة والتقنية لمواتئ لمواصلة التعلم

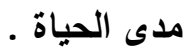

تضمين مهارات التعلم في القرن الحادي والعشرين عند تدريس الرياضيات: اتفق العديد من العلمـاء والتريويين على أن تلدريس الرياضيات وتعلـم مهارات القرن

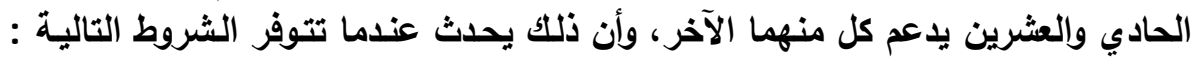

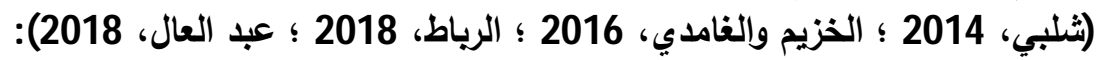

1 -أن يقوم تـدريس الرياضـيات على أسـاس منــاهج جديـدة قائمـة على استـراتيجية

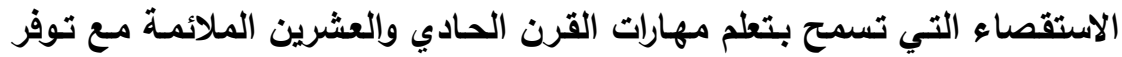

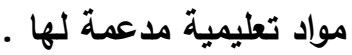

2 -أن يمارس الطلاب مهارات الاستقصاء والتصميم التكنولوجي، ويتاح لهم مدى واسئع

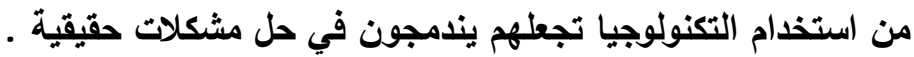

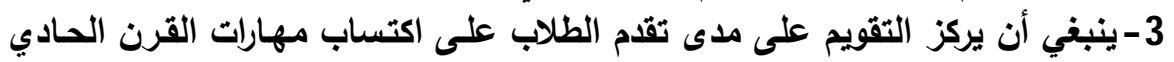

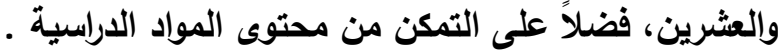

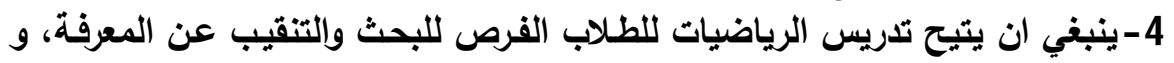

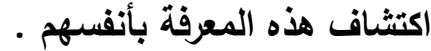

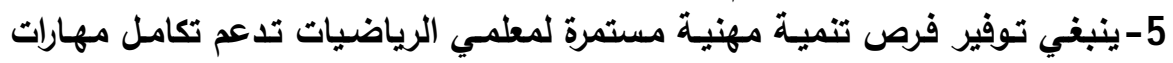

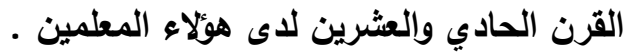

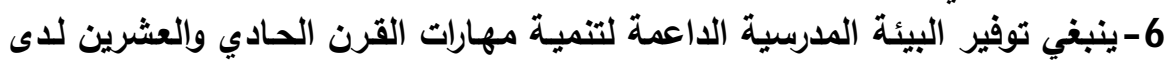

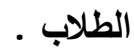

7 -ينبغي أن تتكامل مهارات القرن الحادي والعشرين بشكل هادف ومقصود ومنهجي

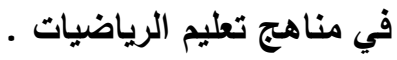

تنمية مهارات القرن الحادي والعشرين وتعليم وتعلم الرياضيات :

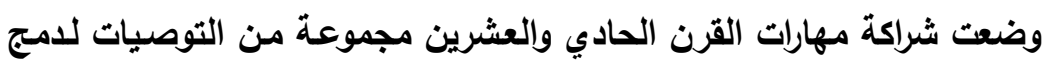

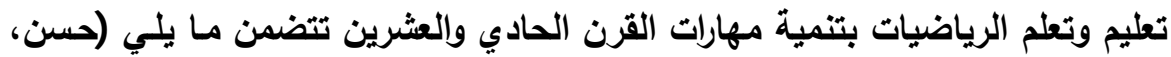

2015 ؛ عبد العال، 2018 ؛ الهويش، 2018 ؛ ؛ البلوي والبلوي، و2019) . : 
- ضرورة تصميم منـاهج الرياضيات في ضوء مهارات القرن الحادي والعشرين،

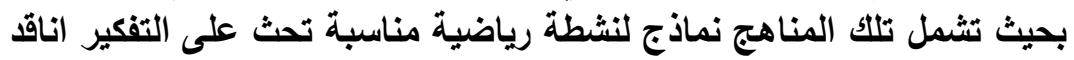

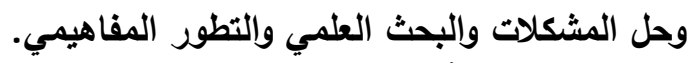

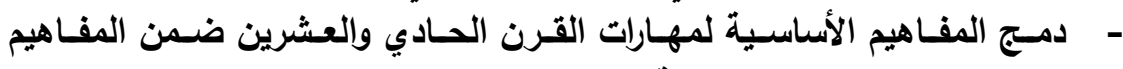

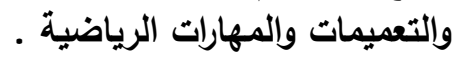

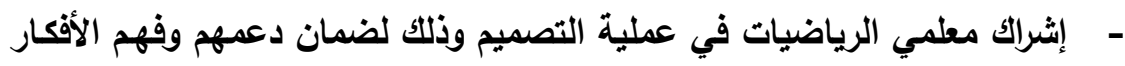

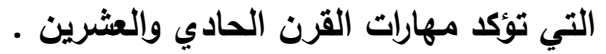
- تقديم الاروس والوحدات التي تتضمن المفاهي والتيم والمهارات الأساسية التي يحتاج

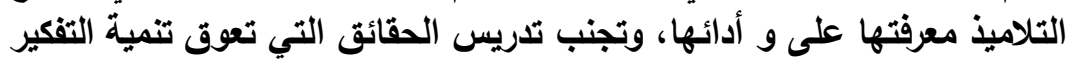

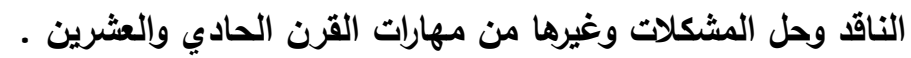

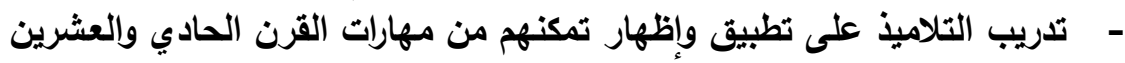

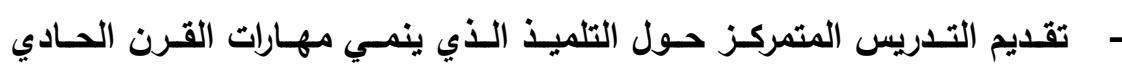

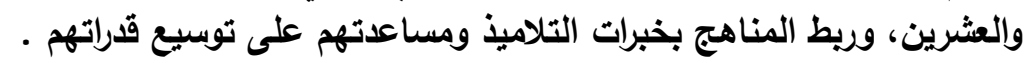

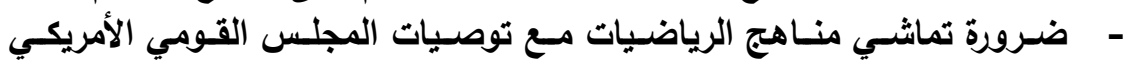

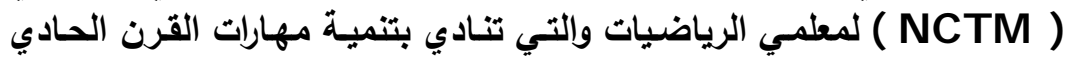
- الاهتمام في برامج التنمية المهنية لمعلمي الرياضيات قبل وأثناء الخدمة بأهمية

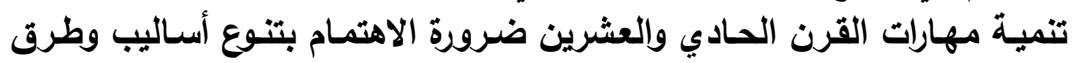
التدريس وأساليب تقويم تعلم التلاميذ. إن تكامل هذه المهارات بشكل مقصود ومنهجي في منـاهج التعليم عامـة، وفي التهي

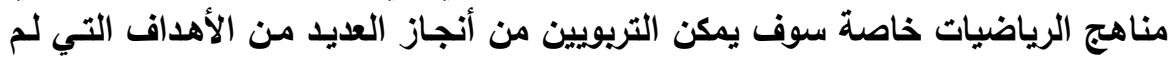

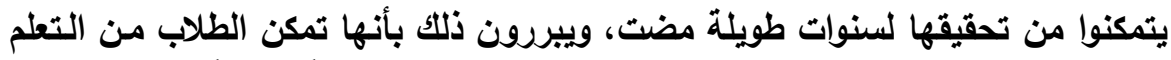

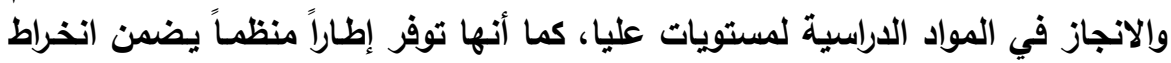

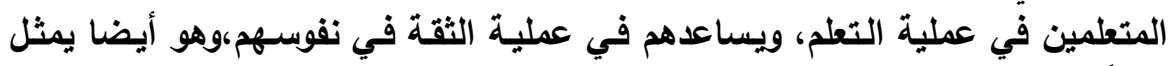

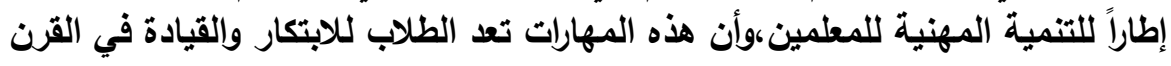

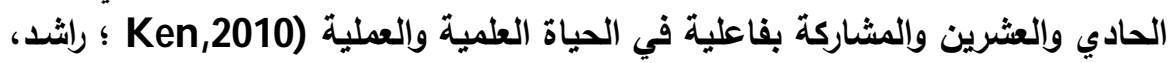

كما يؤدي التكامل بين المهارات القرن الحادي والعشرين إلى انجاز العديد من العناء

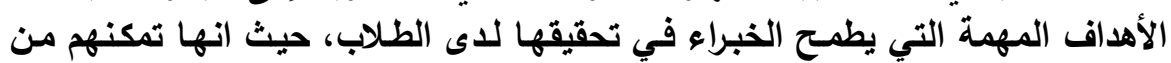

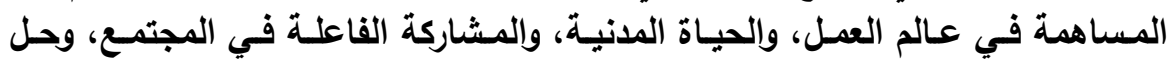

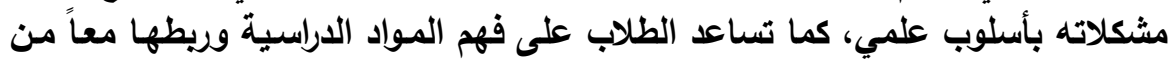


مجلة كلية التربية، جامعة الأزهر، العدد: (183، الجزء الأول) يوليو لسنة 2019م

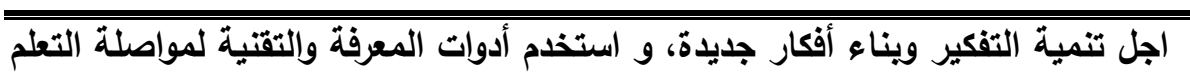
مدى الحياة.

الارراسات السابقة:

استعرض الباحث عددًا من الاراسات السابقة المرتبطة بموضوع ومجال الدراسـة وذلك على النحو التالي:

هدفت دراسـة ( Miller,2009) معرفة مدى نمو مهارات الاتصالات والتعاون

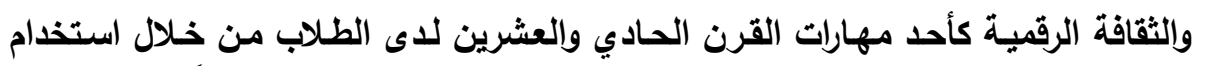

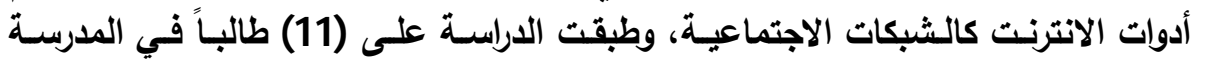

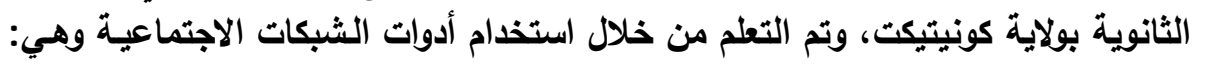

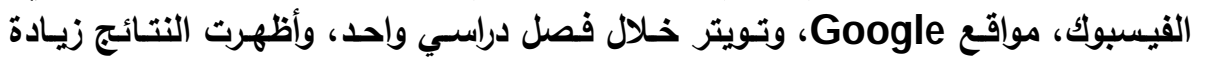

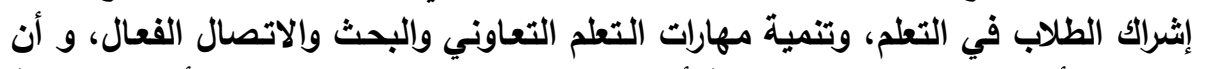

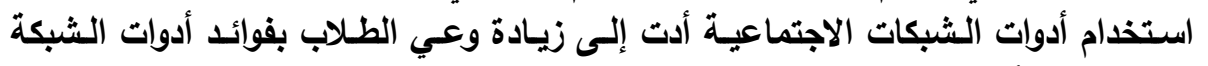

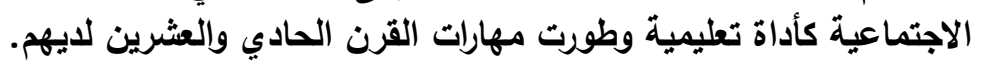

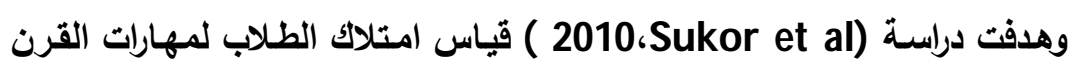

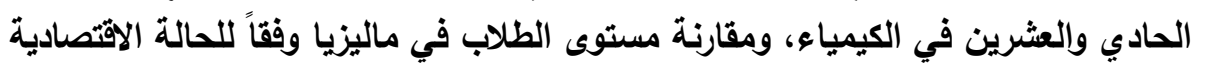

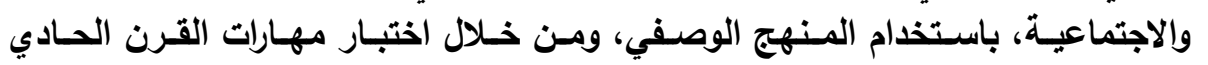

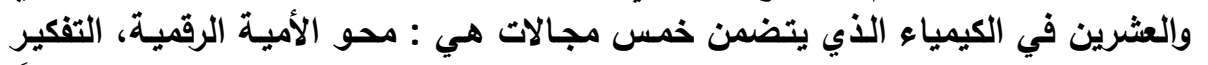

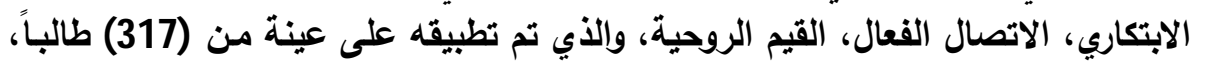

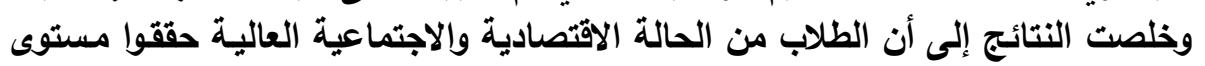

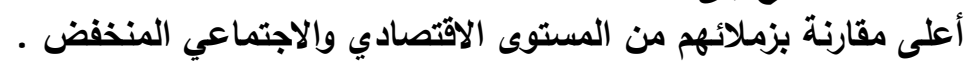

كما هدفت دراسة ( (Vogt \& Robin,2012) مقارنة المناهج التعليمية الدولية

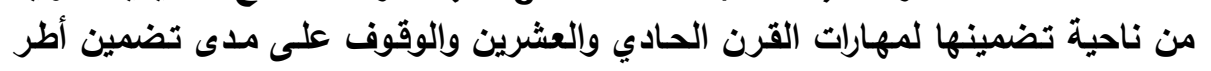

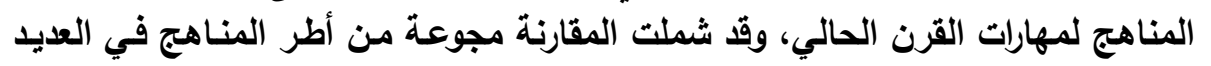

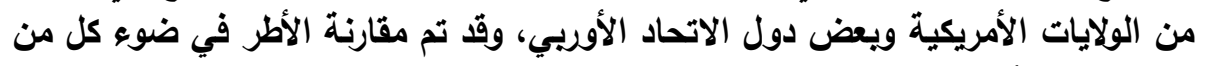

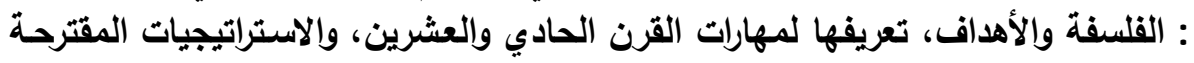

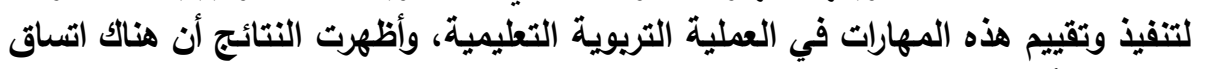

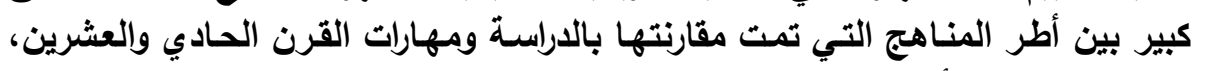
ولكن الممارسات لأي منها لا زالت بعيدة عن التنفيذ.

وهدفت دراسـة ( شلبي، 2014 ) تحديد مهارات القرن الحادي والعشرين التي التي

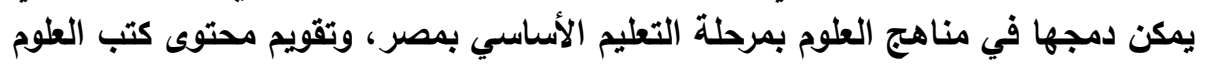

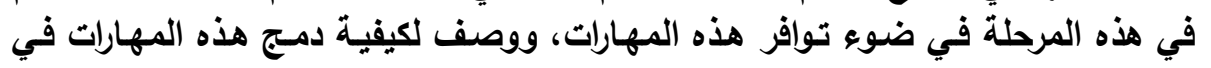




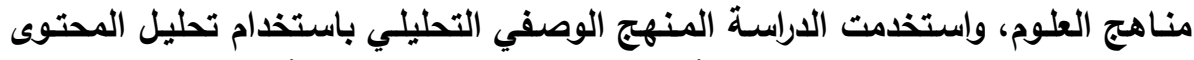

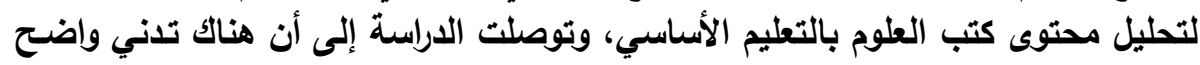
في تناول هذه المهارات في كتب العلوم ل

وهدفت دراسة (حسن، 2015) تعرف مدى توفر مهارات القرن الحادي والعشرين

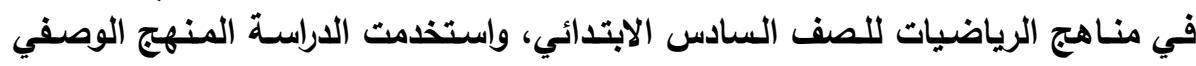

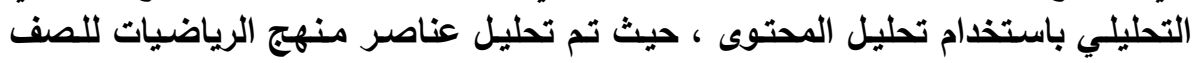

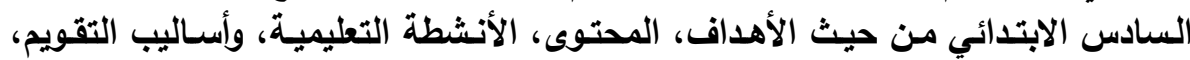

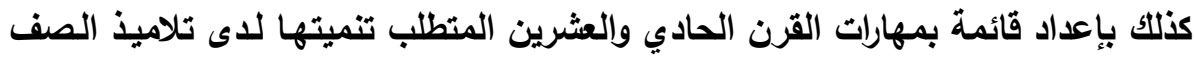

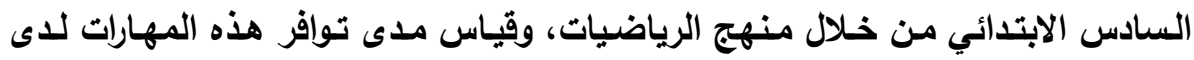

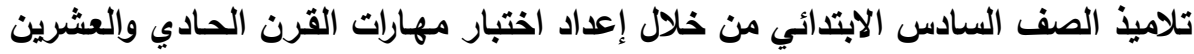

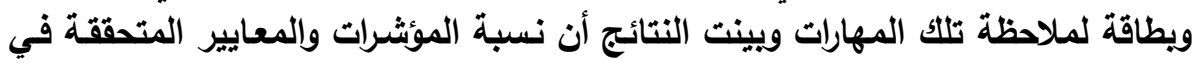

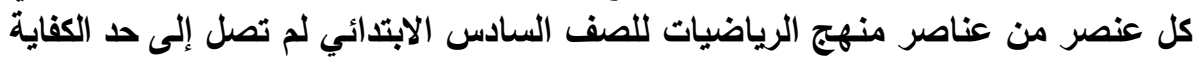

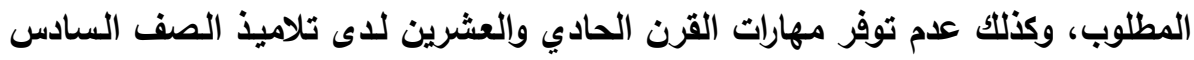

$$
\text { الابتدائي. }
$$

كما هدفت دراسـة (Kayange \& Msiska,2016) تعرف مدى دمـج مهارات

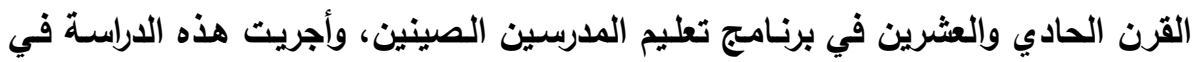

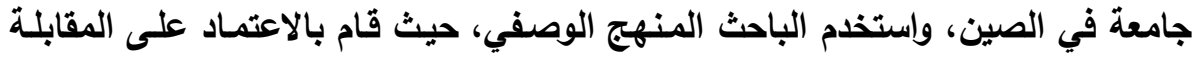

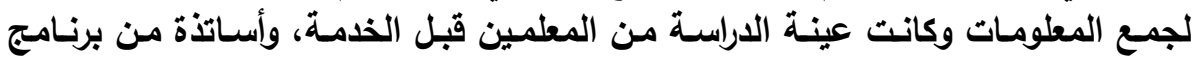

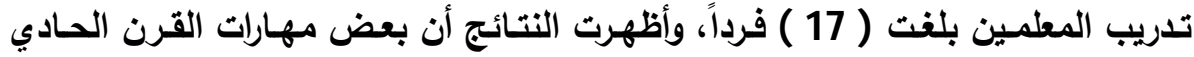

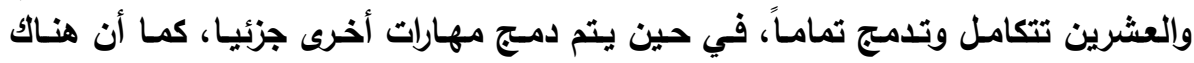
تحديات لامج مهارات القرن الحادي والعشرين. وهدفت دراسـة ( الخزيم و الغامدي، 2016 ) تعرف درجة توفئ توفر مهارات القرن

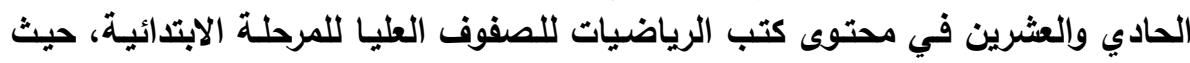

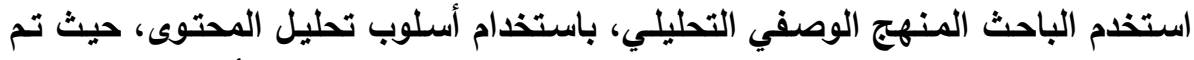

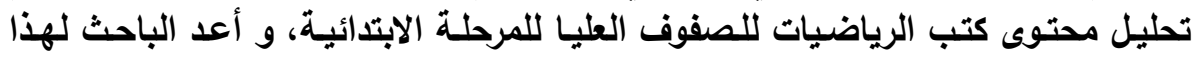

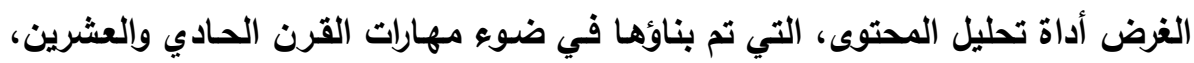

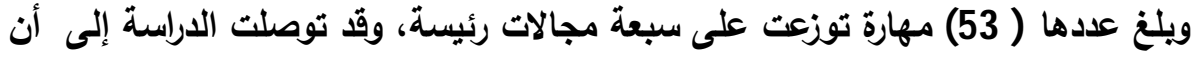

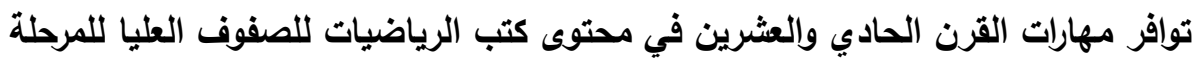
الابتدائية بلرجة متوسطة. وهدفت دراسـة ( سبحي، 2016 ) تعرف مدى تضمين مهارات القرن الحسادي

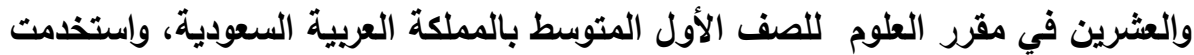


مجلة كلية التريبة، جامعة الأزهر ، العدد: (183، الجزء الأول) يوليو لسنة 2019م

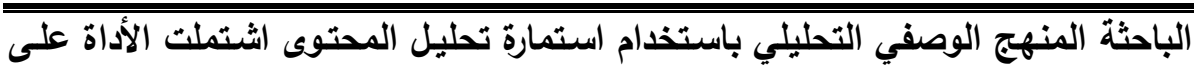

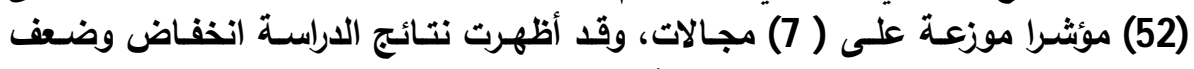

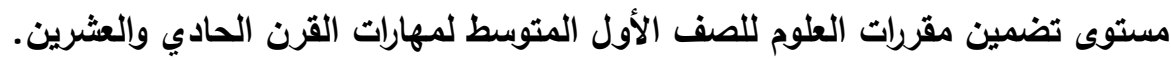
في حين هدفت دراسـة (الحربي والجبر ، 2016) تعرف مستوى وعي معلمسي

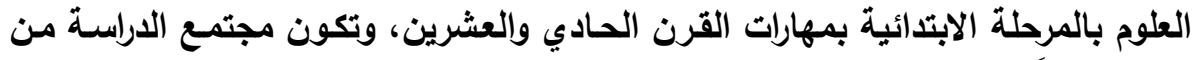

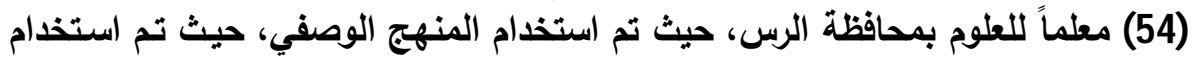

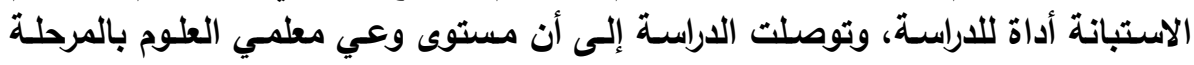

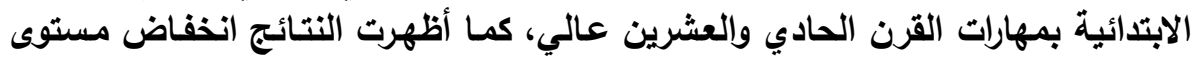
وعي معلمي العلوم بمهارات التفكير عن المتوسط العام لمهارات القرن الحادئ العادي والعشرين. وهدفت دراسة (يونس، 2016) التعرف على درجة تضمين مهارات القرن الحادي

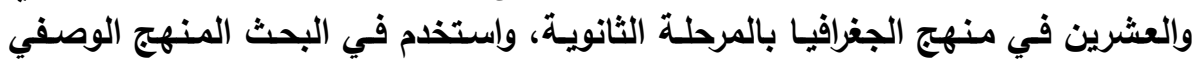

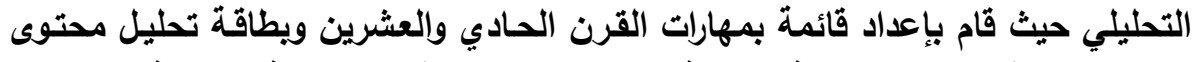

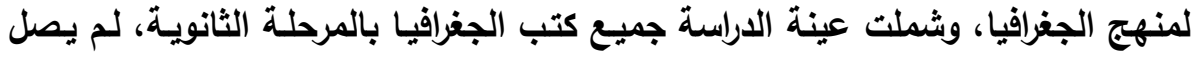

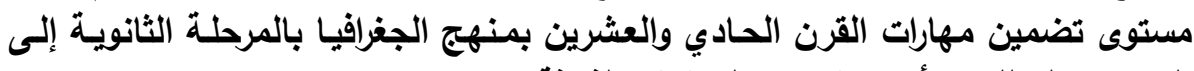
المستوى المطلوب بأي صف من الصفوف الثنلاثة .

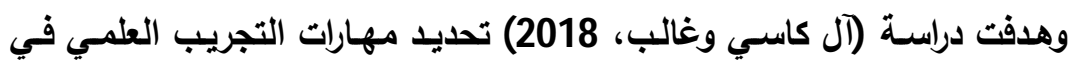

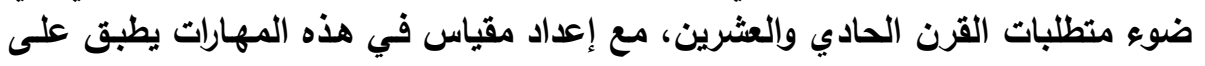

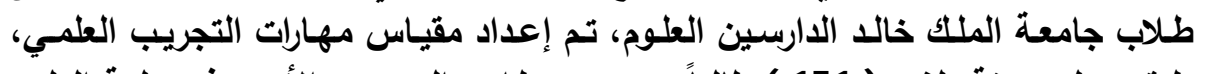

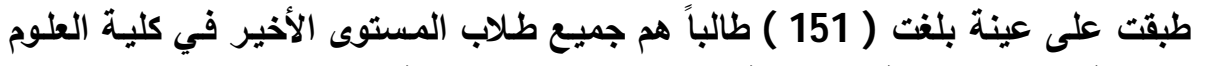

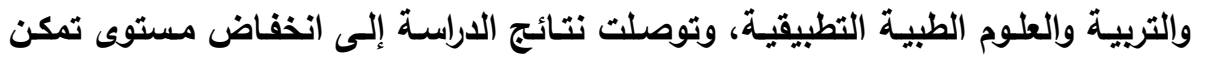
عينة البحث من مهارات التجريب العلمي في ضوء منطلبات القرن الحادي والعشرين .

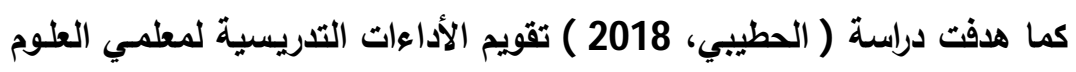

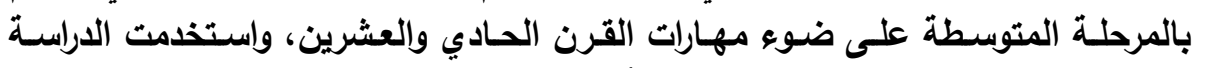

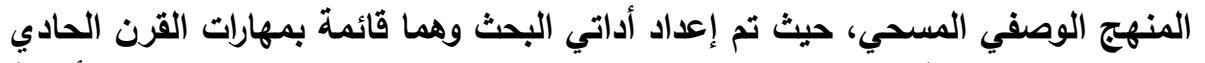

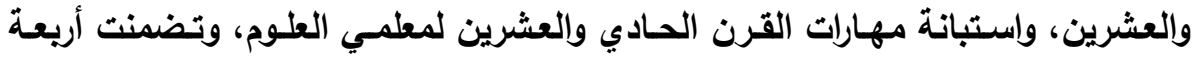

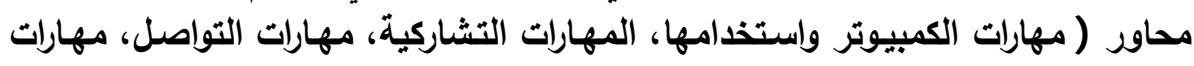

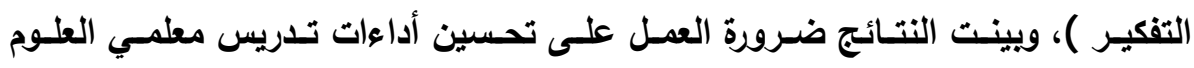

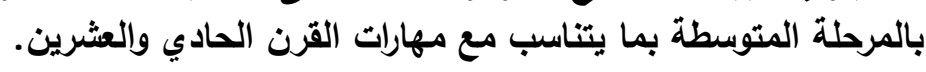

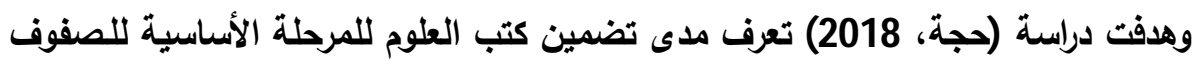

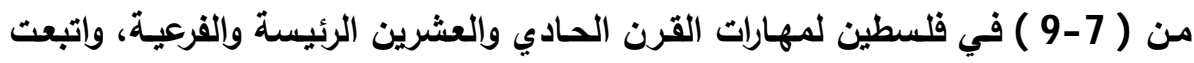

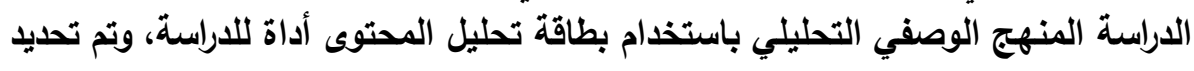


المهارات في المحتوى في ضوء ما تثير إليه كل من الأهداف والمحتوى والأنثطة وأسئلة

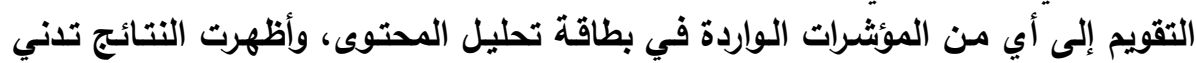
تضمين كتب العلوم لمهارات القرن الحادي والعشرين سواءً الرئيسة أو الفرعية.

$$
\text { التعقيب على الدراسات السابقة: }
$$

من خلال استعراض الاراسات السابقة التي تناولت البراعة الرياضية يمكن

ملاحظة التالي: من خدر:

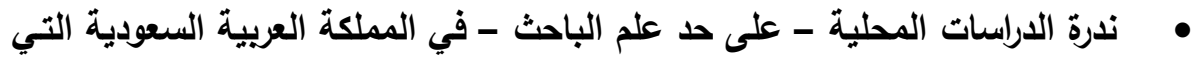

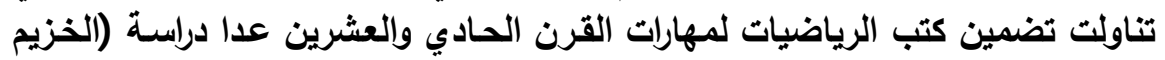
والغامدي، 2016).

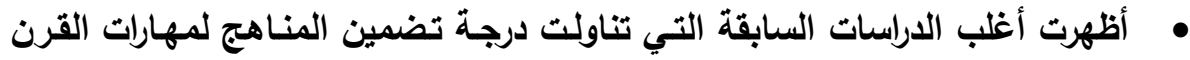

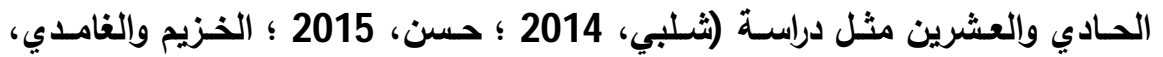
2016 ؛ سبحي، 2016 ؛ يونس، دإن 2016 ؛ حجة، 2018 ) ضعفاً وقصوراً في تضمين المناهج المدرسية لهذه المهارات. • تنوعت الأهداف التي سعت الدراسات السابقة لتحقيقها، حيث هدفت بعض الداراستات (Miller,2009)

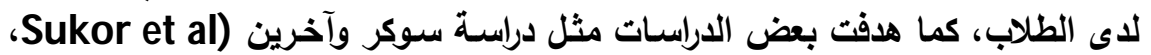

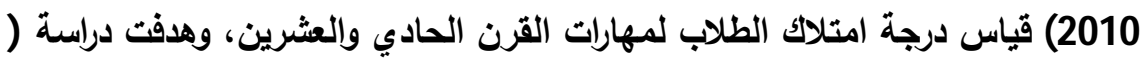

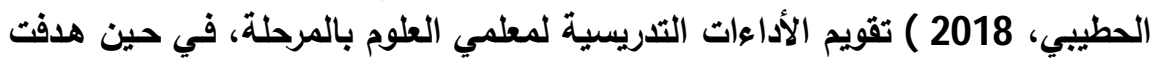

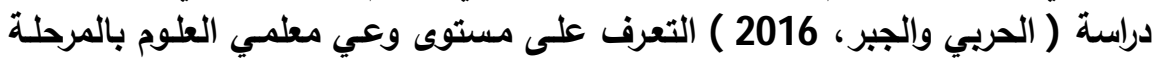

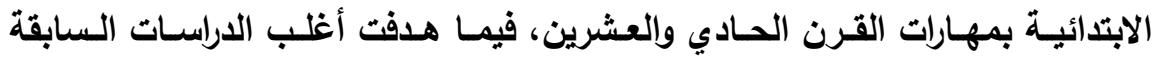

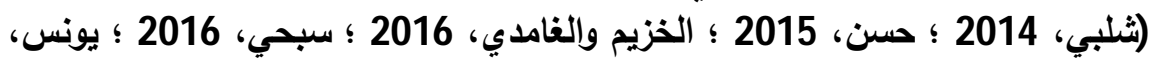
2016 ؛ حجة، 2018 ) التعرف على درجة تضمين المناهج المدرسية لمهارات القرن

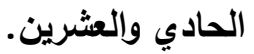
• تنوعت مناهج البحث المستخدمة، حيث استخدمت أغلب الدراسـات السابقة (ثلبي،

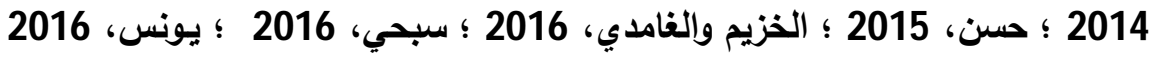

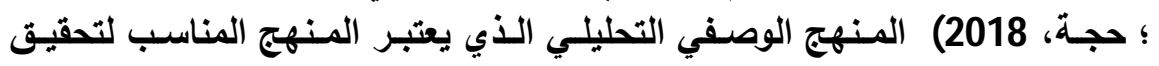

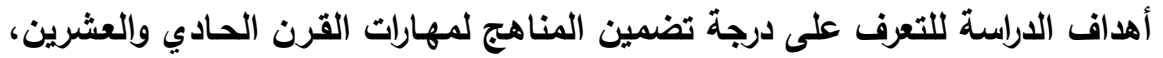

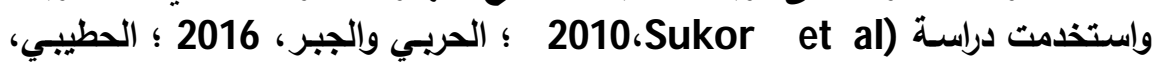
2018) المنهج الوصفي المسحي،، وذلك وفقاً لأهداف الدارية.

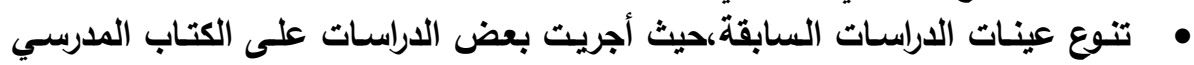
سواء في المرحلة الابتدائية أو المتوسطة أولة أو الثانويـة الطلاب المرحلة الابتدائية مثل الثل 
مجلة كلية التربية، جامعة الأزهر ، العدد: (183، الجزء الأول) يوليو لسنة 2019م

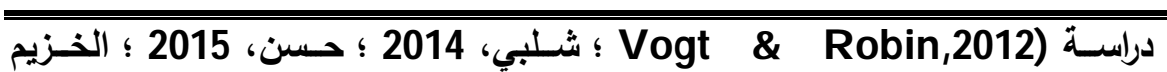

والغامدي، 2016 ؛ سبحي، 2016 ؛ يونس، 2016 ؛ 2016 ؛ حجة، 2018 ) ) ، بينما أجريت

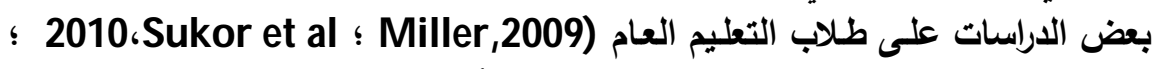

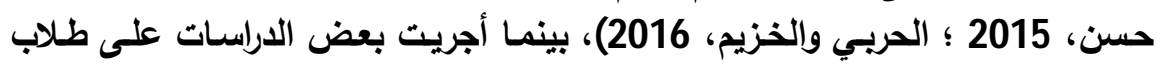
المرحلة الجامعية (آل كاسي وغالب، 2018 المبن، 2018).

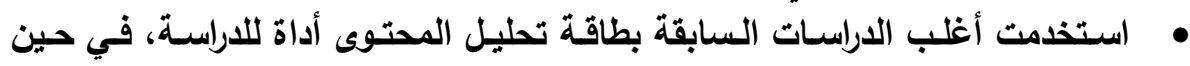

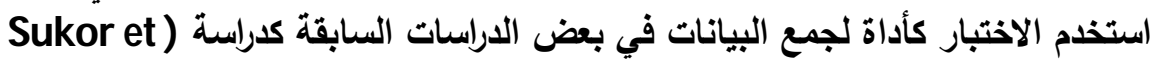
2010،al

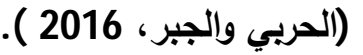

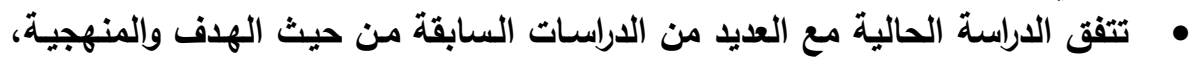

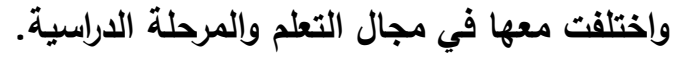

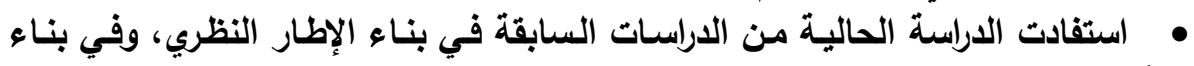

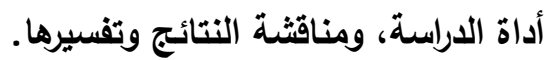

$$
\text { منهج الاراسة: }
$$

اتبعت الدراسة الحالية المنهج الوصفي التحليلي متمثلاً ذلك في أسلوب تحليل

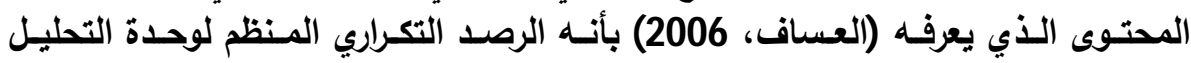

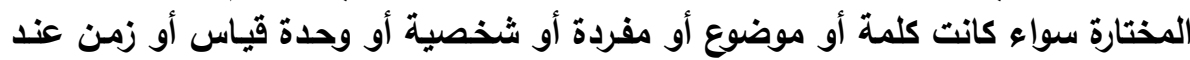

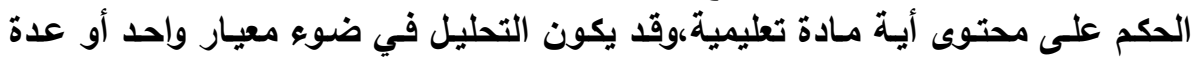

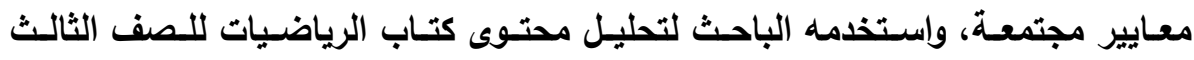
المتوسط، للتعرف على مدى تضمين مهارات القرن الحادي والعشرين في كتاب الرياضيات

للصف الثالث المتوسط.

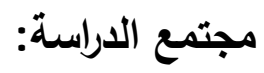

يتمثل مجتمع الاراسـة في كتاب الرياضيات - كتاب الطالب - للصف الثالث

المتوسط بالمملكة العربية السعودية طبعة 1438 ـ1439هـ.

أداة الدراسة: - ماسة

لتنفيــ هذه الدراســة وتحقق أهدافها تـم استخدم بطاقة تحليـل المحتوى أداة

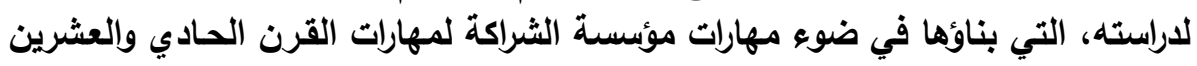

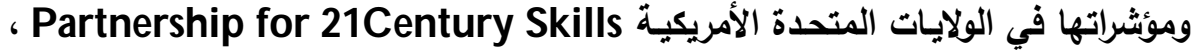

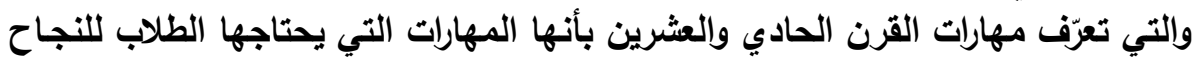

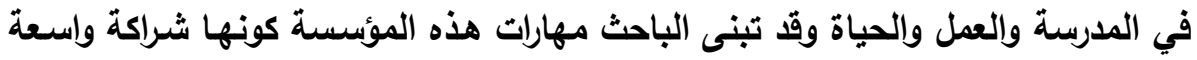




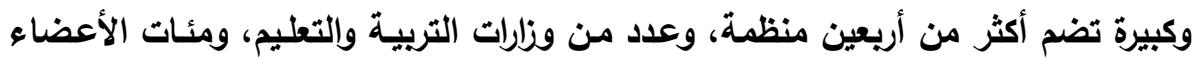

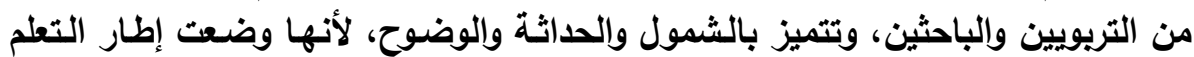

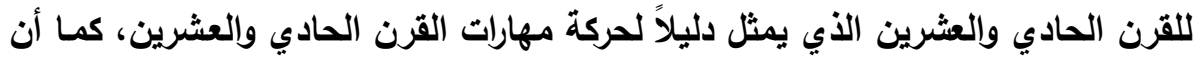

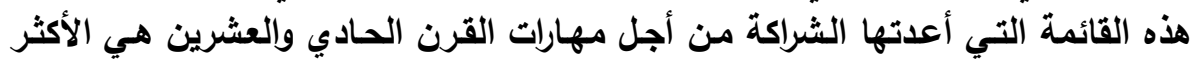

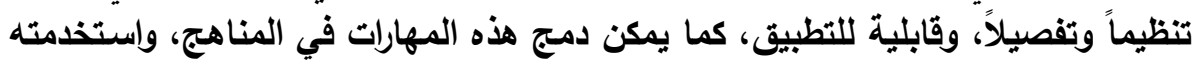

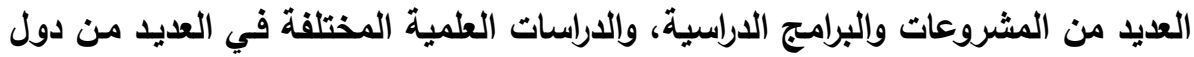

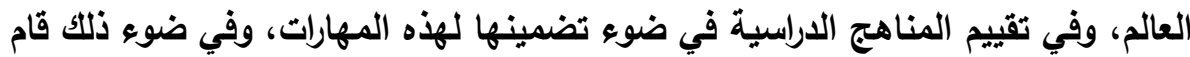

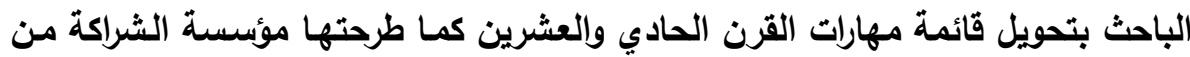

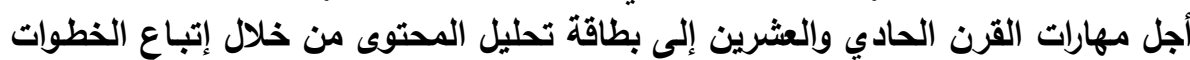

1 - الاطلاع على المراجع العلمية ( ترلينج ونـادل 2013 ؛ روفائيل ويوسف 2001)

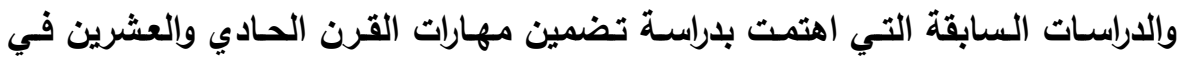

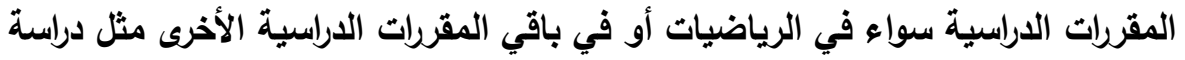

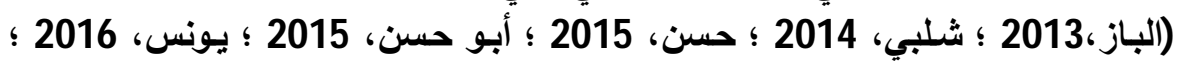

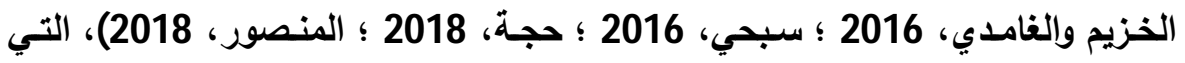
تضمنت قوائم بمهارات القرن الحادي والعشي،

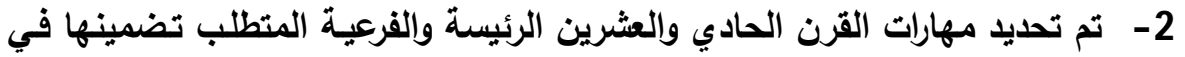

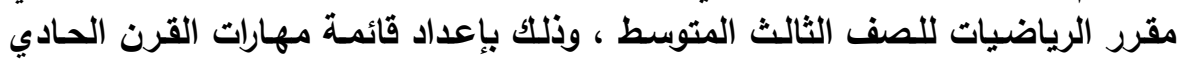

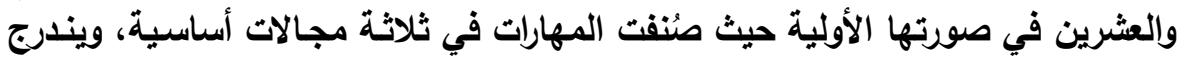

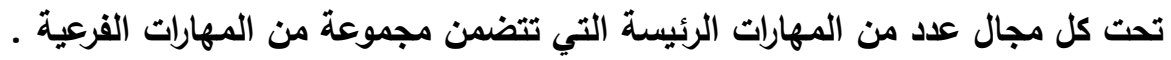

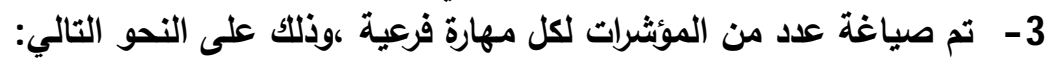

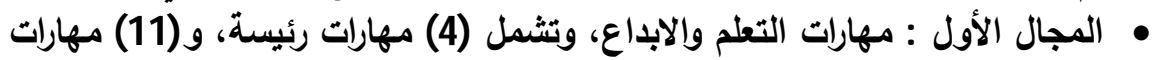

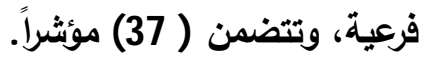

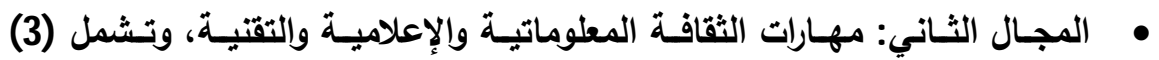
مهارات رئيسة، و(6) مهارات فرعية، وتتضمن (21) مؤشراً.

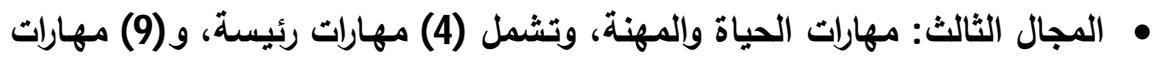

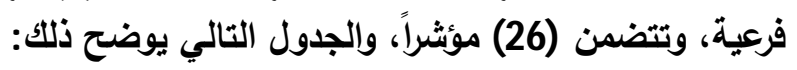


مجلة كلية التريبة، جامعة الأزهر ، العدد: (183، الجزء الأول) يوليو لسنة 2019م

\begin{tabular}{|c|c|c|c|c|}
\hline \multicolumn{5}{|c|}{ في صية لقائمة مهارات القرن الحادي والعشرين ومؤثراتها } \\
\hline المؤثرات & عدد المهارات & عدد المهارات & المجال & p \\
\hline 37 & 11 & 4 & التعلم والإبداع & 1 \\
\hline 21 & 6 & 3 & الإلثقافـــة المعلوماتيـــــــة & 2 \\
\hline 26 & 9 & 4 & الحياة والمهنة & 3 \\
\hline 84 & 26 & 11 & المجموع & \\
\hline
\end{tabular}

ووضعت هذه القائمة في بطاقة لتحليل المحتوى، ويذلك أصبحت بطاقة تحليل

المحتوى في صورتها الأولية.

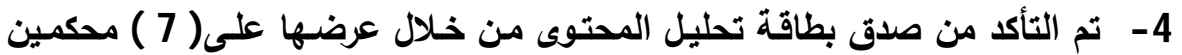

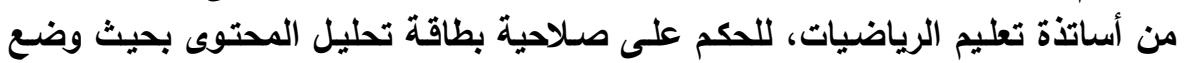

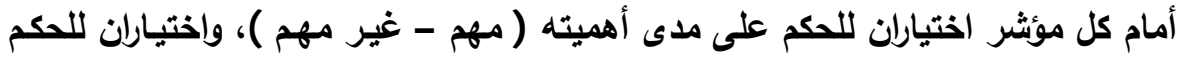

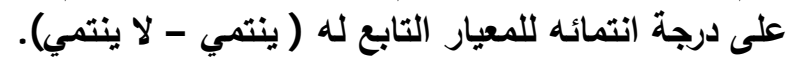

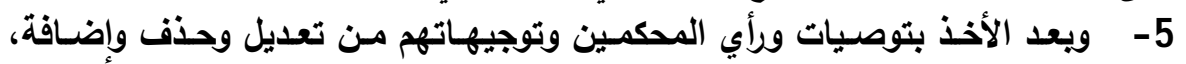

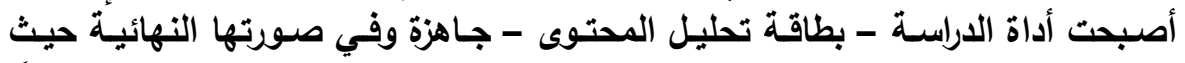
اشتملت على (3) مجالات، و(10) مهارات رئيسة، و (22) مهارة فرعية، وه (73) مؤثشراً،

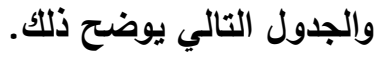

جدول(2) المهارات الرئيسة والفرعية لقائمة مهارات القرن الحادي والعشرين ومؤثراتها في صورتها النهائية

\begin{tabular}{|c|c|c|c|c|}
\hline المؤثرات & عدد المهارات & عدد المهارات & المجال & r \\
\hline 31 & 8 & 3 & التعلم والإبداع & 1 \\
\hline 18 & 6 & 3 & والإعلامية والتقلقة المعلوماتية & 2 \\
\hline 24 & 8 & 4 & الحياة والمهنة & 3 \\
\hline 73 & 22 & 10 & & الم \\
\hline
\end{tabular}


6 - تحديد عينـة التحليل : تمثلت عينة التحليل بجميع الموضوعات الواردة في كتاب الفياب

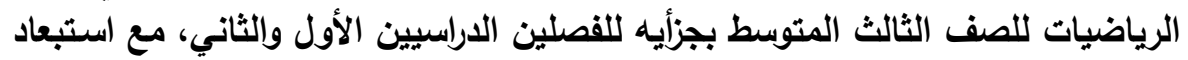
الغلاف ومقدمة الكتاب والفهارس.

7 - تحديد وحدات التحليل : تم استخدام المفردة كوحدة للتحليل والتي تحمل مضمدوناً مرتبطاً بمهارات القرن الحادي والعشرين لملاعمتها طبيعة الدراسـة، باستخدام فئتين (موجود / غير موجود) للحكم على وجود المؤشر في كتاب الرياضيات للصف الثمن الثالث 8 - معيار الحكم على مدى تضمين مهارات القرن الحادي والعشرين في كتاب الرياضيات للصف الثالث المتوسط: تم اعتماد النسب التالية معياراً للحكم على مدى تضمين مهارات القرن الحادي والعشرين في كتاب الرياضيات للصف الثالث المتوسط:

جدول(2) المهارات الرئيسة والفرعية لقائمة مهارات القرن الحادي والعشرين ومؤثراتها في صورتها النهائية

\begin{tabular}{|c|c|c|}
\hline \multirow[t]{2}{*}{ مدى التضمين } & \multicolumn{2}{|c|}{ النسبة المئوية } \\
\hline & إلى & من \\
\hline عالية جـاً & $\% 100$ & أكبر من 90\% \\
\hline عالية & $\% 90$ & أكبر من 70\% \\
\hline متوسطة & $\% 70$ & أكبر من 50\% \\
\hline متدنية & $\% 50$ & أكبر من 30 \% \\
\hline متدنية جدأ & $\% 30$ & أكبر من صفر \% \\
\hline منعدمة & & صفر\%\% \\
\hline
\end{tabular}

ثبات أداة تحليل المحتوى : تم تحليل وحدتين من كتاب الرياضيات للصف الثالث

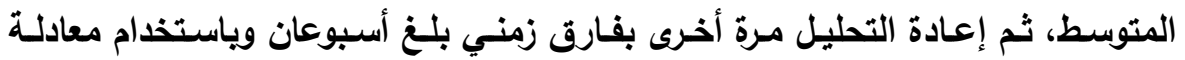
هلوستي Holisti لحساب النسبة المئوية للاتفاق بين التحليليين، والتي بلغت فئن (0,91)،

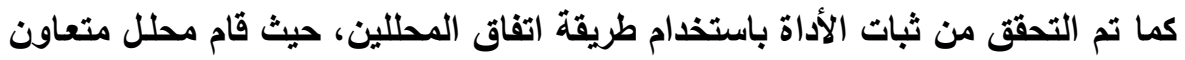

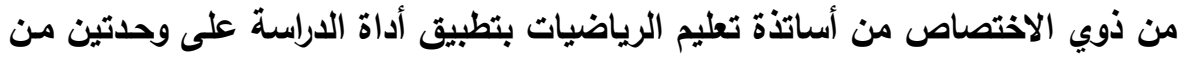

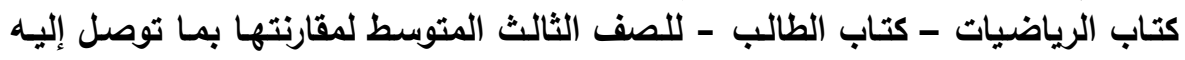

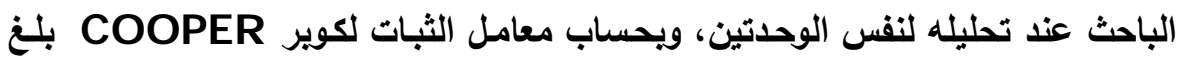

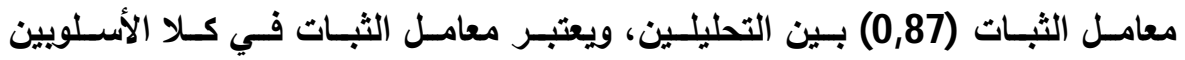


مجلة كلية التربية، جامعة الأزهر ، العدد: (183، الجزء الأول) يوليو لسنة 2019م

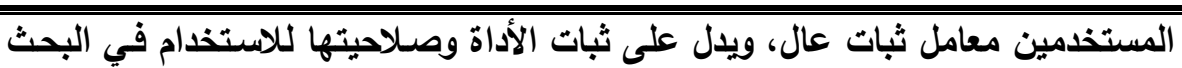

الحالي.

نتائج الاراسة:

إجابة السوأل الأول:

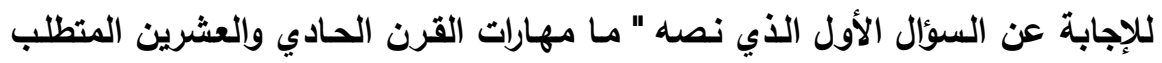

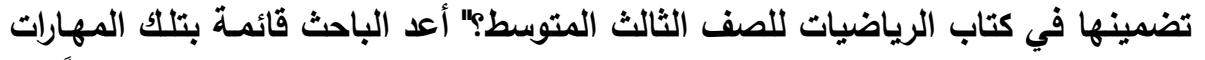

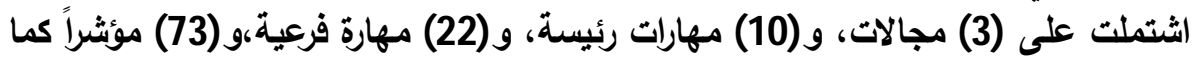

تم توضيحه سابقاً في إجراءات الاراسة ولات

إجابة السؤال الثاني: - إن

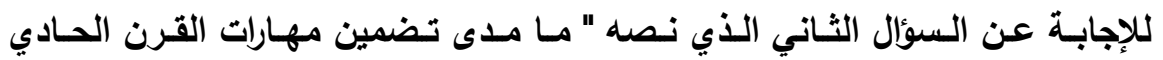

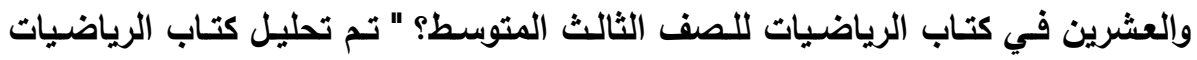

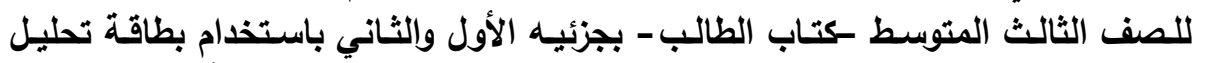

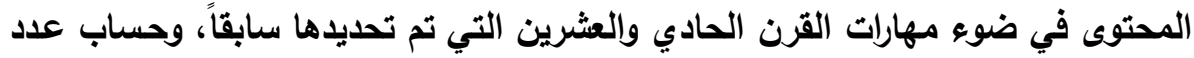

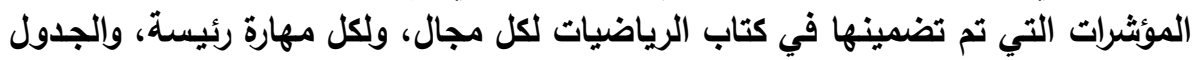

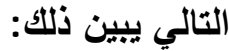

جدول (4) عدد مؤثرات المهارات الرئيسة المضمنة في مقرر الرياضيات للصف الثالث المتوسط المطائ

\begin{tabular}{|c|c|c|c|c|c|c|}
\hline نشبة & نشبة المهارات & المؤشرات & المؤشرات & الرئيسة & المجال & م \\
\hline \multirow[t]{4}{*}{$\% 48,39$} & $\% 75$ & 9 & 12 & التفكير الناقد & \multirow[t]{3}{*}{ والإبداع } & 1 \\
\hline & $\% 18,18$ & 2 & 11 & والإبتكار & & 2 \\
\hline & $\% 50$ & 4 & 8 & الاتصال & & 3 \\
\hline & $\% 50$ & 3 & 6 & المعلوماتية الثقافة & المعلوماتية الثقافة & 4 \\
\hline
\end{tabular}

- 535- 
مجلة كلية التربية، جامعة الأزهر ، العدد: (183، الجزء الأول) يوليو لسنة 2019م

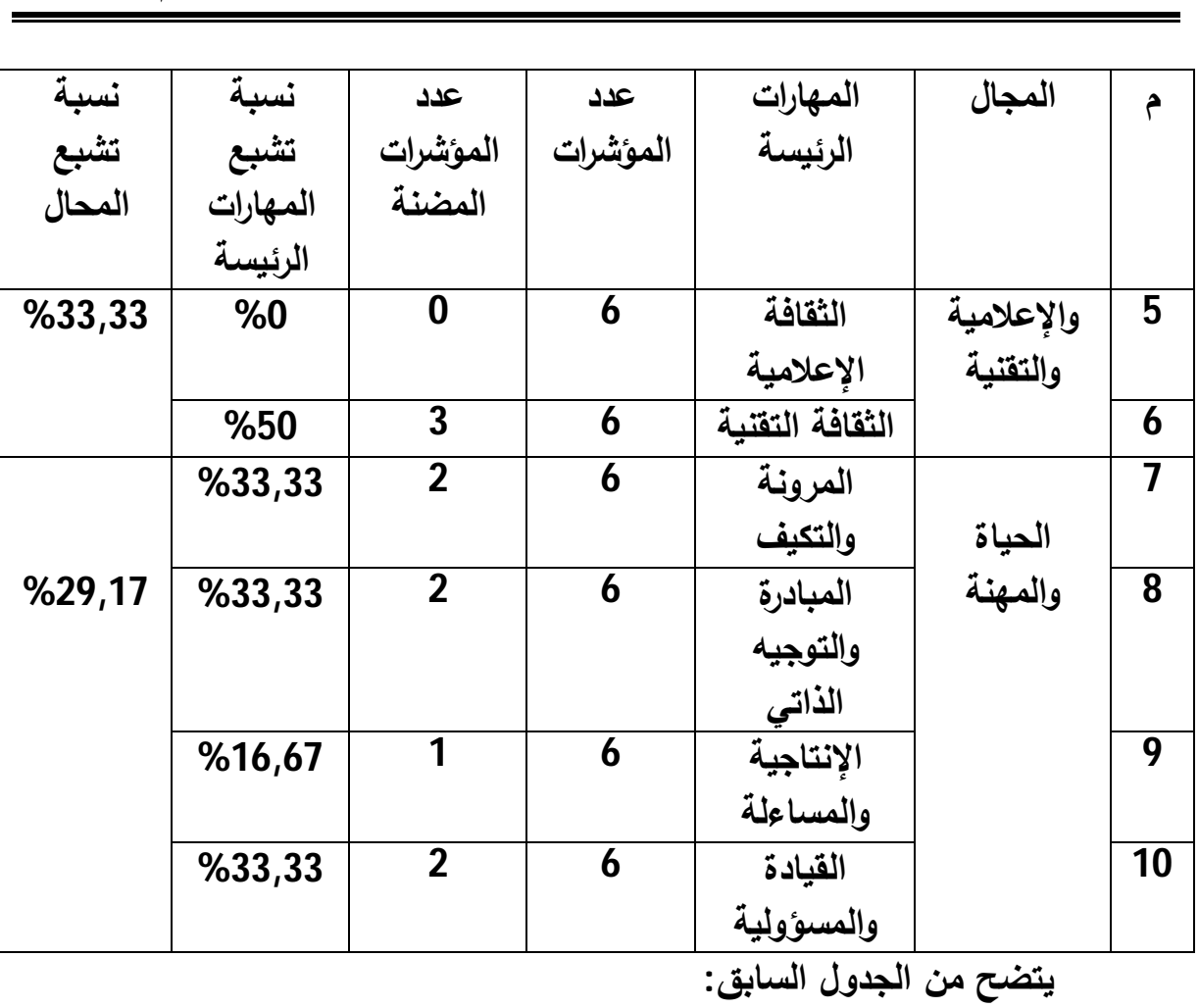

• نسبة تشبع المجالات الرئيسة لمهارات القرن الحادي والعشرين في كتاب الرياضيات

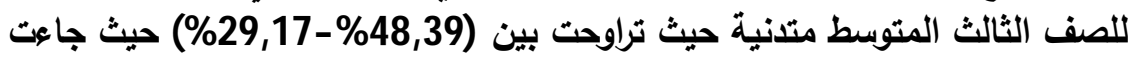

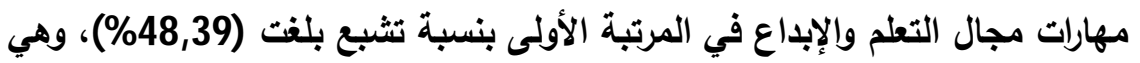

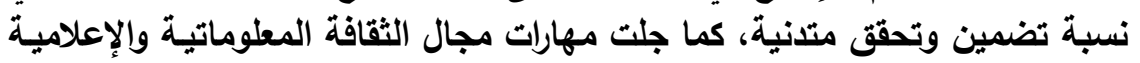

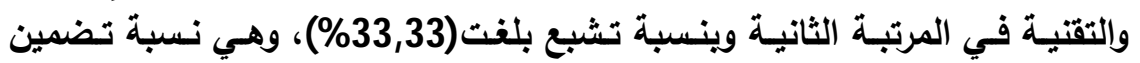

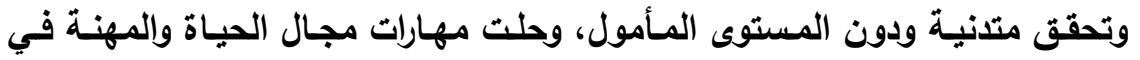

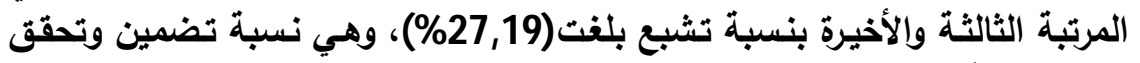

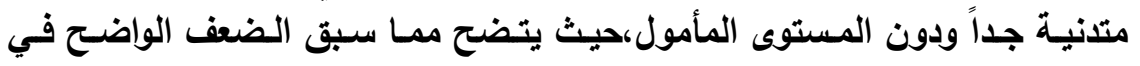

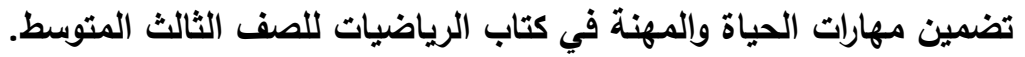

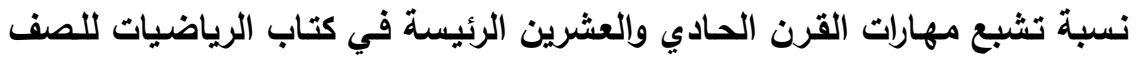

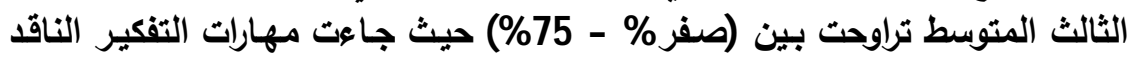

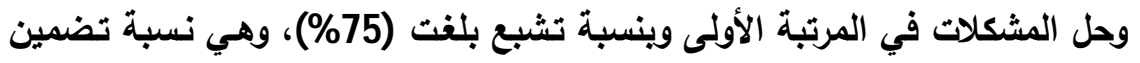

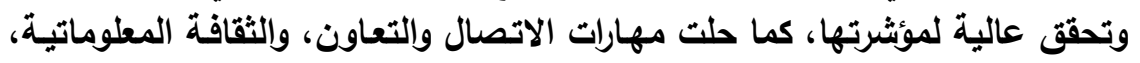

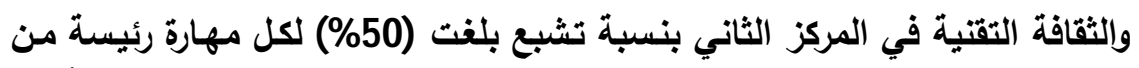

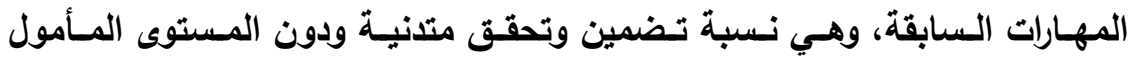


مجلة كلية التريبة، جامعة الأزهر ، العدد: (183، الجزء الأول) يوليو لسنة 2019م

لمؤشرتها، في حين حلت مهارات المرونة والتكيف،والمبادرة والتوجيه الذاتي، والقيادة

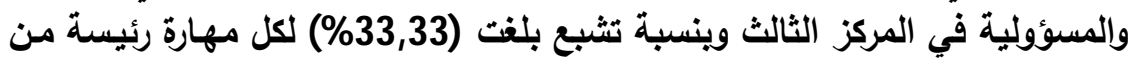
المهارات السابقة، وهي نسبة تضمين وتحقق متدنية ودون المأمول لمؤشيرتها، وحلت

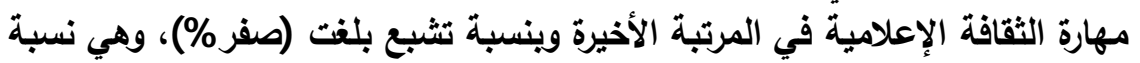
تضمين وتحقق منعدمة لمؤثراتها.

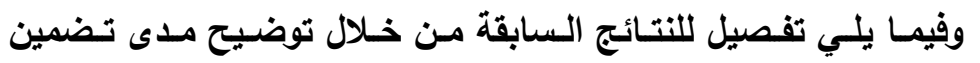

$$
\text { أولاً: مجال التعلم والإبداع: مهار: على حده: }
$$

تم حساب عدد المؤثرات المضمنة لكل مهارة رئيسة وفرعية لمجال التعلم والابداع في

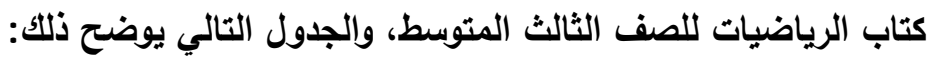

\begin{tabular}{|c|c|c|c|c|}
\hline نسبة تشبع & المؤشثر & المؤشرات الفرعية & الفرعية المهات & الرئيسة \\
\hline \multirow[t]{4}{*}{$\% 50$} & $\sqrt{ }$ & يتيح استخدام التفكير الكلي & \multirow{4}{*}{1 -التفكير } & \multirow{12}{*}{ الناقد وحل التفير } \\
\hline & $\sqrt{ }$ & يساعد على إدرالك العلاقات & & \\
\hline & $\mathbf{x}$ & يتيح تحليل الحجج & & \\
\hline & $\mathbf{x}$ & يحث على تحليل المواقف التعليمية & & \\
\hline \multirow[t]{4}{*}{$\% 100$} & $\sqrt{ }$ & الحجزج والأدلة & \multirow[t]{4}{*}{2 الأحسام 2} & \\
\hline & $\sqrt{ }$ & يوجه إلى تفسير المعلومات & & \\
\hline & $\sqrt{ }$ & يعزز العلاقة بين السبب والنتيجة & & \\
\hline & $\sqrt{ }$ & يضدن مواقف تعليمية تنمي مهارة & & \\
\hline \multirow[t]{4}{*}{$\% 75$} & $\sqrt{ }$ & ومكوناتها الأساسية المشكلات إلى عناصرها & \multirow[t]{4}{*}{ 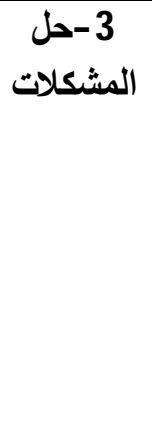 } & \\
\hline & $\mathbf{x}$ & 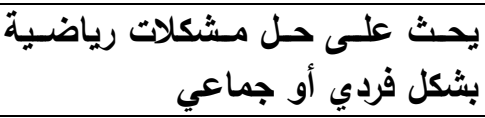 & & \\
\hline & $\sqrt{ }$ & المناسبح الفرصة لحل المشيّار الاستراتيجيات & & \\
\hline & $\sqrt{ }$ & 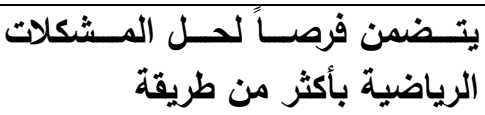 & & \\
\hline
\end{tabular}

جدول (5) المؤشرات الفرعية لمجال التعليم والإبداع المضمنة في مقرر الرياضيات 
مجلة كلية التريبة، جامعة الأزهر ، العدد: (183، الجزء الأول) يوليو لسنة 2019م

\begin{tabular}{|c|c|c|c|c|}
\hline نسبة تشبع & المويثر & المؤشرات الفرعية & الفرعية المهات & الرئيسة \\
\hline \multirow[t]{4}{*}{$\% 25$} & $\mathbf{x}$ & 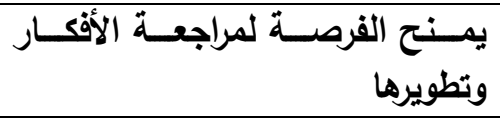 & 4 الإبداعي -(التفير & \multirow{11}{*}{ والإبتكار } \\
\hline & $\sqrt{ }$ & أفكار جديدة فرصاً لتنظيم المطلومـات وفق & & \\
\hline & $\mathbf{x}$ & يمتنح فرصاً لإضـافة تفاصيل جديدة & & \\
\hline & $\mathbf{x}$ & 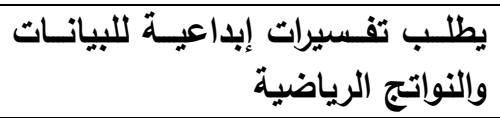 & & \\
\hline \multirow[t]{4}{*}{$\% 25$} & $\mathbf{x}$ & أفكار الآخرين الإبداعية للتواصـل بفاعليـة مـع & \multirow{4}{*}{ 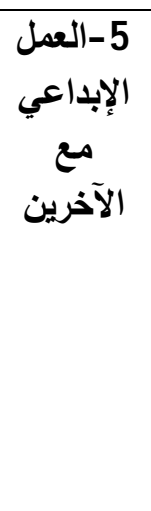 } & \\
\hline & $\mathbf{x}$ & 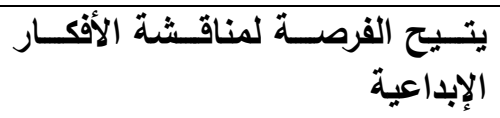 & & \\
\hline & $\sqrt{ }$ & يعزز الأصـالة والإبداع أثناء العـل & & \\
\hline & $\mathbf{X}$ & 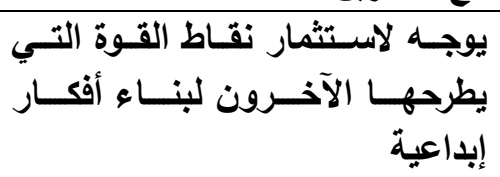 & & \\
\hline \multirow[t]{3}{*}{ صفر\% } & $\mathbf{x}$ & 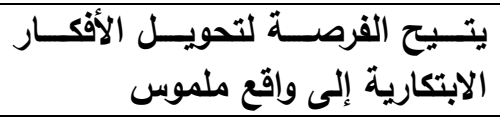 & \multirow[t]{3}{*}{6} & \\
\hline & $\mathbf{x}$ & والأصالة مهام تتسم بالتحـدي والعمـق & & \\
\hline & $\mathbf{x}$ & في تطل على تتفيذ أفكار مبتكرة تسهم & & \\
\hline \multirow[t]{4}{*}{$\% 50$} & $\sqrt{ }$ & ناجــزة تكـوين علاقِـات اجتماعيـة & \multirow{4}{*}{7 -الآحمل 7} & \multirow{4}{*}{ والتعاون } \\
\hline & $\sqrt{ }$ & تيضليمية تنطلب مهام وأنتشاونة بين الجميع & & \\
\hline & $\mathbf{X}$ & يبرز المضاء الفمات الفردية لكل عضو & & \\
\hline & $\mathbf{x}$ & يـدعم تلقِي وتقديم التغذيـة الراجعـة & & \\
\hline
\end{tabular}

- 538- 
مجلة كلية التربية، جامعة الأزهر، العدد: (183، الجزء الأول) يوليو لسنة 2019م

\begin{tabular}{|c|c|c|c|c|}
\hline ن المهارات تشبع & المؤشثر & المؤثرات الفرعية & الفرارية & الرئيسة \\
\hline & & بين أفراد المجموعة & & \\
\hline \multirow[t]{4}{*}{$\% 50$} & $\sqrt{ }$ & 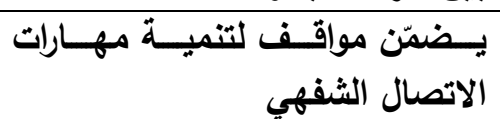 & \multirow[t]{4}{*}{8} & \\
\hline & $\sqrt{ }$ & الاتصـال المكتوب مواقـف لتنميــة مهـــارات & & \\
\hline & $\mathbf{x}$ & ينمي مهارات الاستماع الفعال & & \\
\hline & $\mathbf{x}$ & 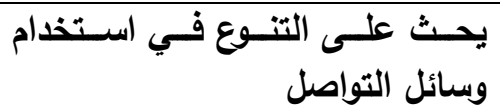 & & \\
\hline$\% 48,39$ & \multicolumn{4}{|c|}{ نسبة تثبع المجال } \\
\hline
\end{tabular}

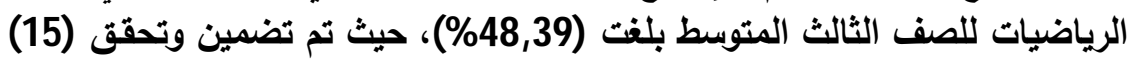

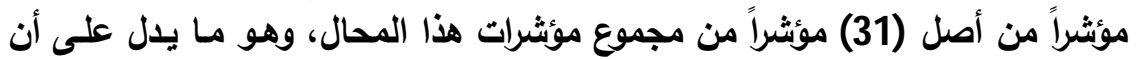

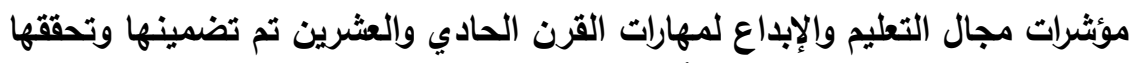
بنسبة متدنية ودون المستوى المأمول .

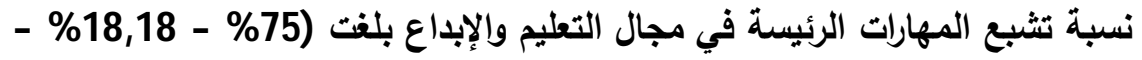

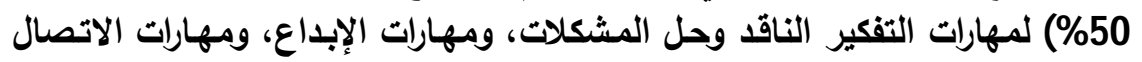

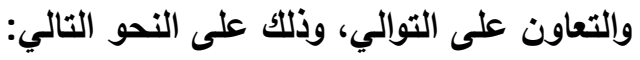

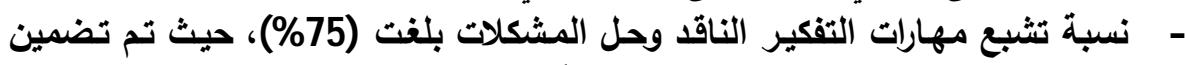

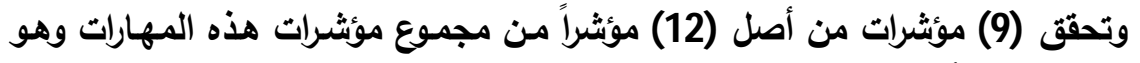

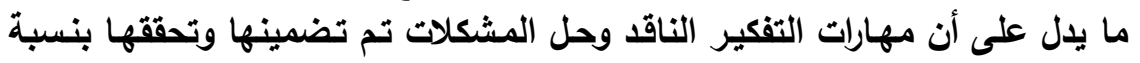
عالية.

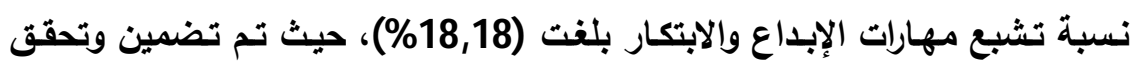

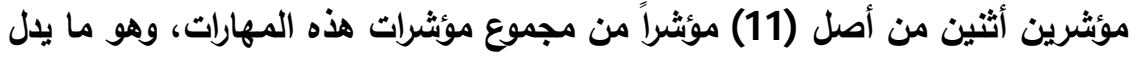

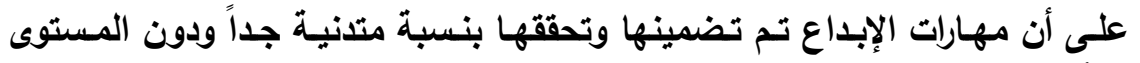

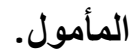

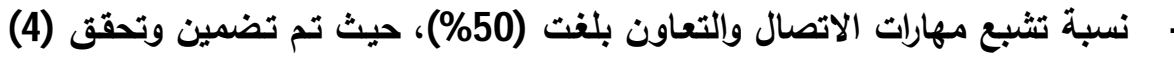

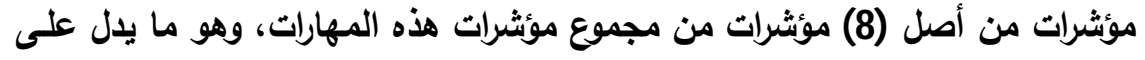

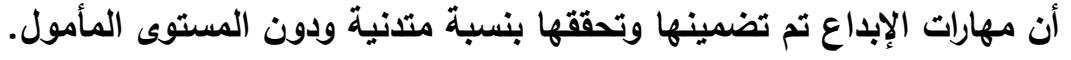

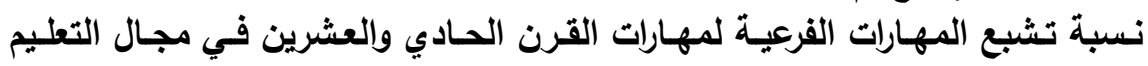
والإبداع تراوحت بين (صفر \% - 100\%) وذلك على النحو التالي: 
- المهارة الفرعية "إصدار الأحكام" التي تتنمي إلى مهارة التفكير الناقد وحل المشكلات

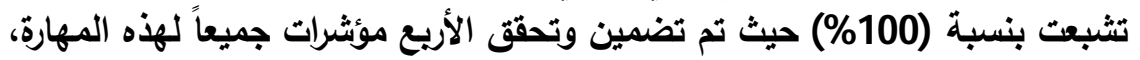

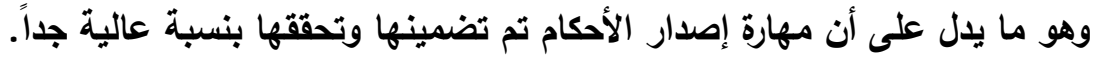

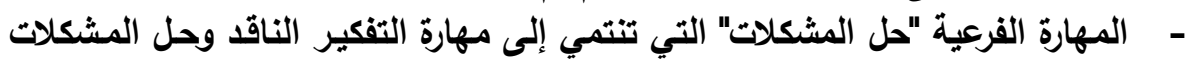

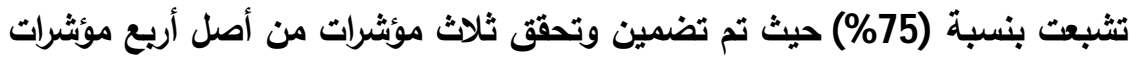

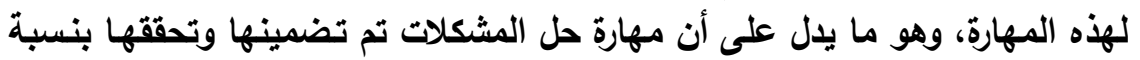

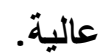
- المهارات الفرعيـة "التفكير الفعال"، و"العمل مـع الآخرين"، و" التواصل الفعال" التي التهي

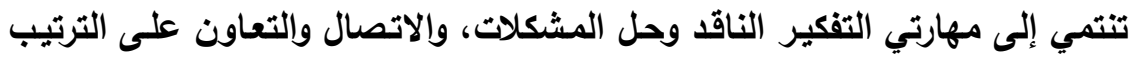

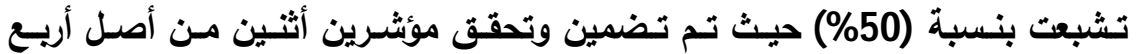

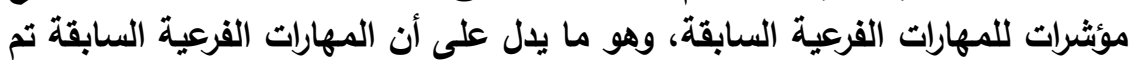

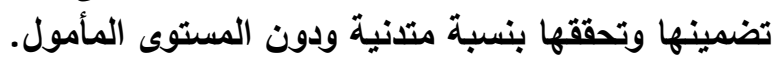

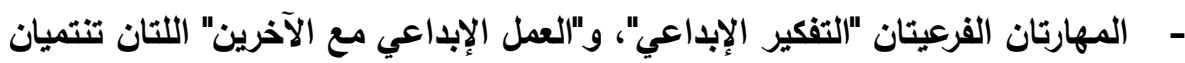

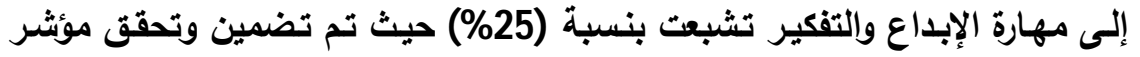

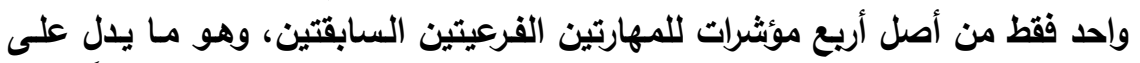

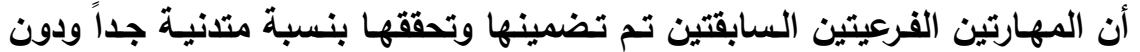

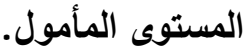

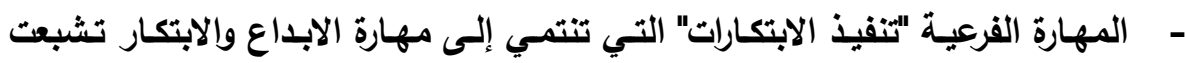

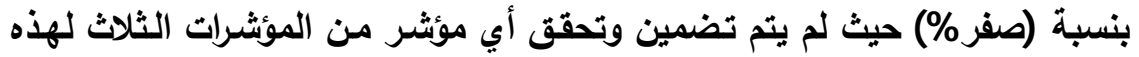

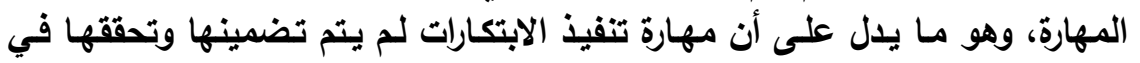

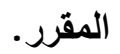
ثانياً: مجال الثقافة المعلوماتية والإعلامية والتقتية: تم حساب عدد المؤثرات المتضمنة لكل مهارة رئيسة وفرعية لمجال الثقافة المعلوماتية

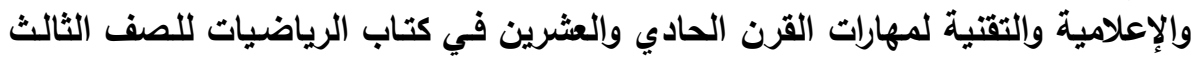
المتوسط، والجدول التالي يوضح ذلكان 
مجلة كلية التريبة، جامعة الأزهر ، العدد: (183، الجزء الأول) يوليو لسنة 2019م

\begin{tabular}{|c|c|c|c|c|}
\hline \multicolumn{5}{|c|}{ جدول (6) المؤثرات الفرعية لمجال الثقافة المعلوماتية والإعلامية والتقتية المضمنة في } \\
\hline ن المبة تشبع & المؤشق & الموئشرات الفرعية & 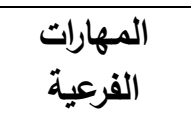 & المهاريسة \\
\hline \multirow[t]{3}{*}{$\% 66,67$} & $\sqrt{ }$ & الموجـهـ نــــو اســتخدام مــصادر & \multirow[t]{3}{*}{ واستخدام } & \multirow[t]{6}{*}{ المعلوماتية } \\
\hline & $\sqrt{ }$ & 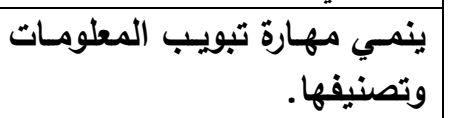 & & \\
\hline & $\mathbf{x}$ & 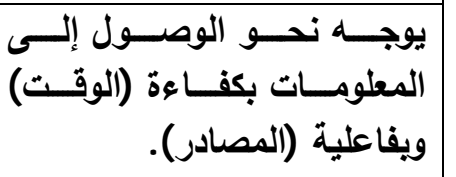 & & \\
\hline \multirow[t]{3}{*}{$\% 33,33$} & $x$ & مصادر المعلى التحقق من مصدات. & \multirow[t]{3}{*}{ إلمعلومات إنقويم } & \\
\hline & $\mathbf{x}$ & نقل المعزل ثقافة الأمانة العلمية عندات وتداولها. & & \\
\hline & $\sqrt{ }$ & بيشجع على نقا المعلومات التي & & \\
\hline \multirow[t]{3}{*}{ صفر\% } & $\mathbf{x}$ & يضمن مواقف تعليمية لتوضيح & \multirow[t]{3}{*}{ استخدام } & \multirow[t]{5}{*}{ الإعلامية الثقافة } \\
\hline & $\bar{x}$ & 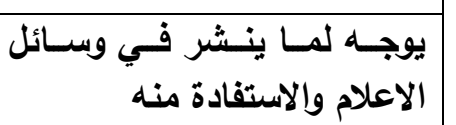 & & \\
\hline & $\mathbf{x}$ & 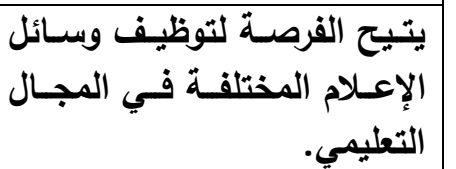 & & \\
\hline \multirow[t]{2}{*}{ صفر\% } & $x$ & 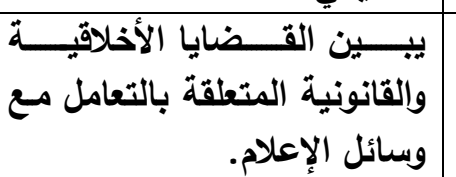 & \multirow[t]{2}{*}{ تحليل وتقويم } & \\
\hline & $\mathbf{x}$ & يتـــيح الفـرص لتحليـل بعـض & & \\
\hline
\end{tabular}


مجلة كلية التريبة، جامعة الأزهر ، العدد: (183، الجزء الأول) يوليو لسنة 2019م

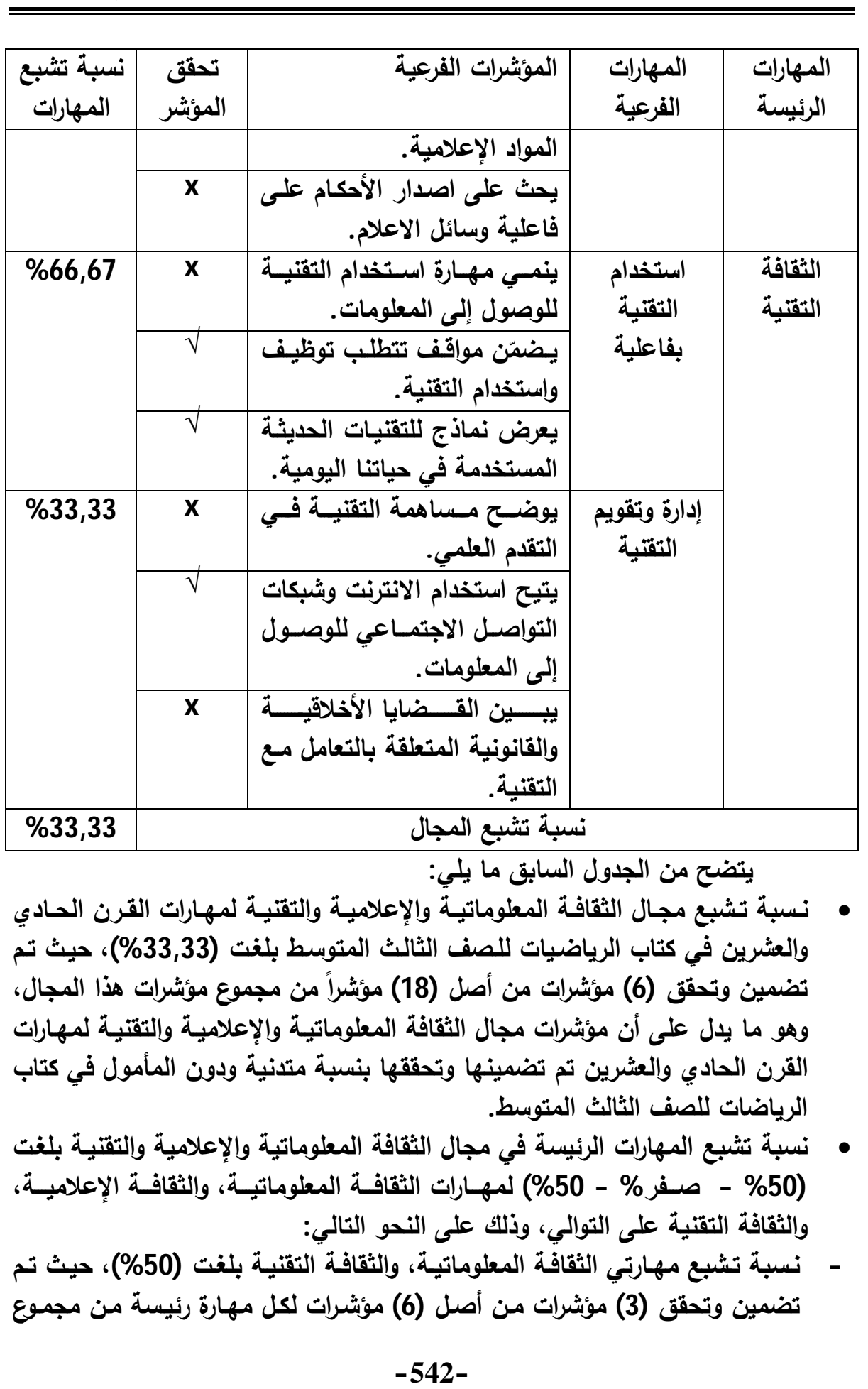


مجلة كلية التربية، جامعة الأزهر ، العدد: (183، الجزء الأول) يوليو لسنة 2019م

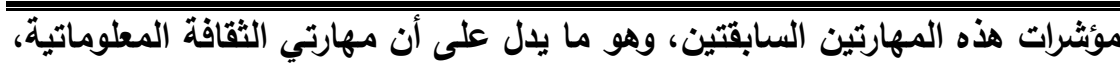

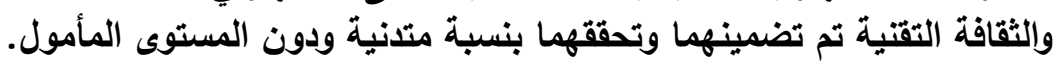

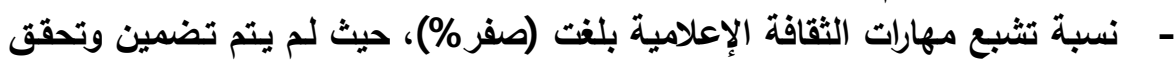

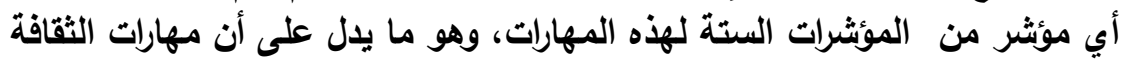
الإعلامية تم تضمينها وتحققها بنسبة منعدمة.

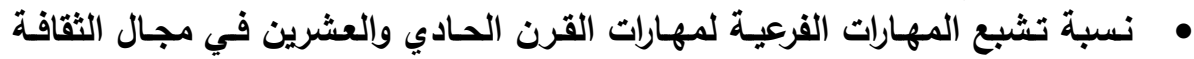

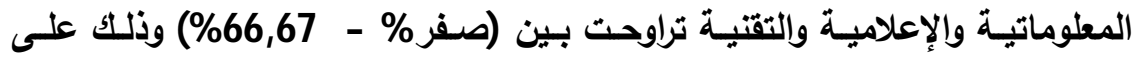

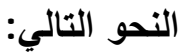

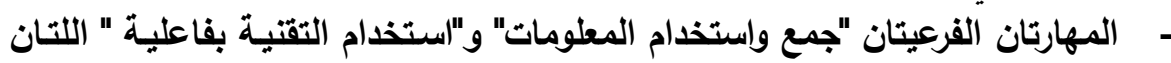

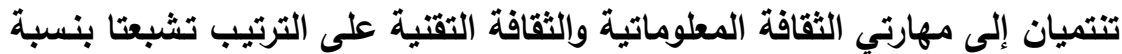

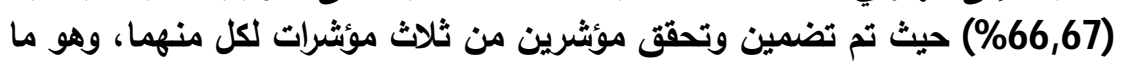

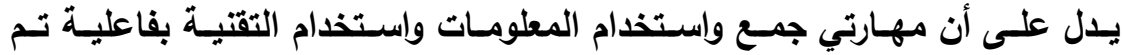

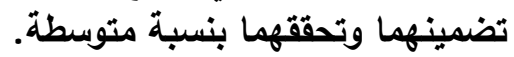

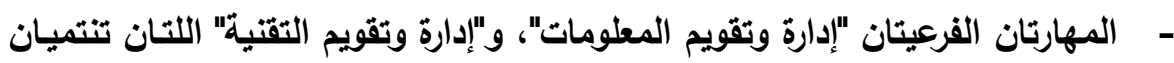

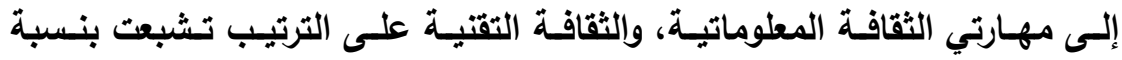

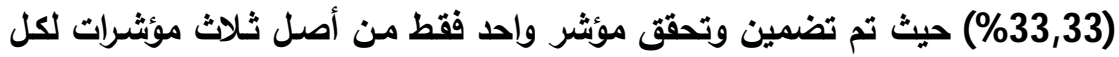

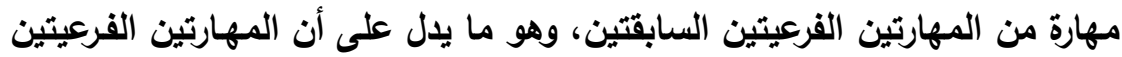

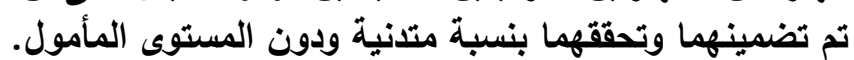

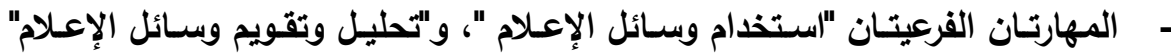

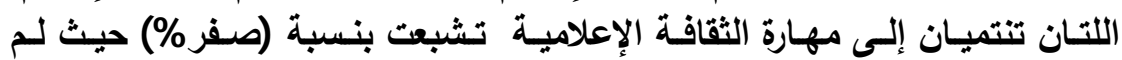

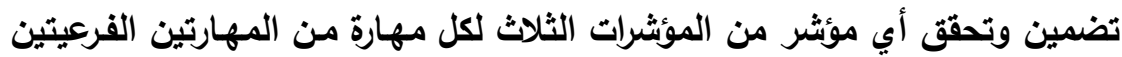

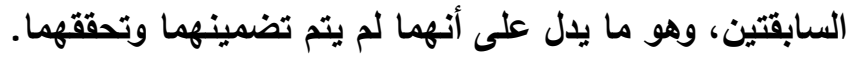

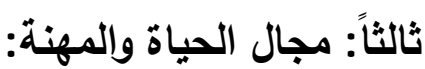

تم حساب عدد المؤثرات المتضمنة لكل مهارة رئيسة وفرعية لمجال الحياة والمهنـة

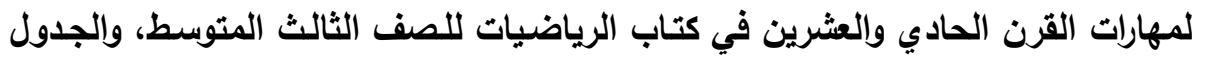
التالي يوضح ذلتك: 
مجلة كلية التريية، جامعة الأزهر، العدد: (183، الجزء الأول) يوليو لسنة 2019م

جدول (7) المؤثرات الفرعية لمجال الحياة والمهنة المضمنة في مقرر الرياضيات للصف الثالث المتوسط

\begin{tabular}{|c|c|c|c|c|}
\hline نسبة تشبع & المؤشق & | المؤشرات الفرعية & الفرارية & الرئيسة \\
\hline \multirow[t]{3}{*}{$\% 33,33$} & $\sqrt{ }$ & يعزز التكيـف لأدوار ومسوؤوليات & \multirow[t]{3}{*}{ التكيف مـع المتيرات } & \multirow[t]{6}{*}{ والتكرونة } \\
\hline & $\mathbf{x}$ & يتسم بمتغيرات متنوعة العمل بفاعلية في مناخ & & \\
\hline & $\mathbf{x}$ & بواعلية إلى استثيف مع المتغيرات التذية الراجعة & & \\
\hline \multirow[t]{3}{*}{$\% 33,33$} & $\mathbf{x}$ & والمعزقات والنقامل بايجابية مـع الثـاء & \multirow[t]{3}{*}{ بالاتصافة } & \\
\hline & $\sqrt{ }$ & 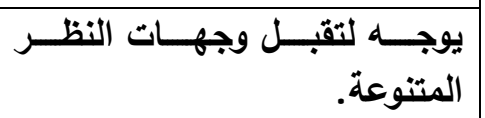 & & \\
\hline & $\mathbf{x}$ & المتنز التعايش مـع وجهات النظر & & \\
\hline \multirow[t]{3}{*}{ صفر\% } & $\mathbf{x}$ & 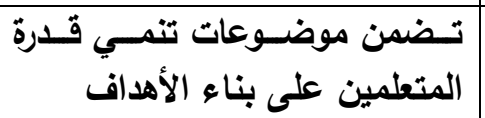 & \multirow[t]{3}{*}{ والأراز الوقدافت } & \multirow{6}{*}{ الألتوجيه } \\
\hline & $\mathbf{x}$ & بطيح الفرصـة للتعبير عن نفسه & & \\
\hline & $\mathbf{x}$ & والمختصنين. & & \\
\hline \multirow[t]{3}{*}{$\% 66,67$} & $\sqrt{ }$ & 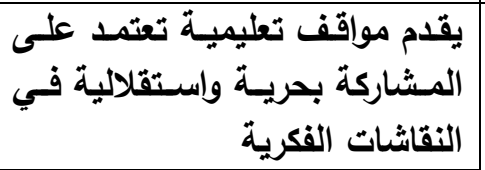 & \multirow[t]{3}{*}{ بالاستقلالية } & \\
\hline & $\mathbf{x}$ & المتضلم المبادرة ماقذاتية تعليمية تنمي لاى & & \\
\hline & $\sqrt{ }$ & يحفز على التساؤل الذاتي & & \\
\hline \multirow[t]{2}{*}{ صفر\% } & $\mathbf{x}$ & 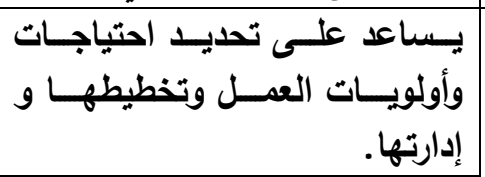 & \multirow[t]{2}{*}{ المشروعات } & \multirow[t]{2}{*}{ والإنتاجية } \\
\hline & $\mathbf{x}$ & يتيح صناعة الأهداف وتحقيقها & & \\
\hline
\end{tabular}


مجلة كلية التريية، جامعة الأزهر ، العدد: (183، الجزء الأول) يوليو لسنة 2019م

\begin{tabular}{|c|c|c|c|c|}
\hline \multirow[t]{3}{*}{ نسبة تشبع } & المؤثق & |المؤشرات الفرعية & الفرارات & المهارات \\
\hline & & حتى في حالة العقبات والضغوط & & \\
\hline & $\mathbf{x}$ & 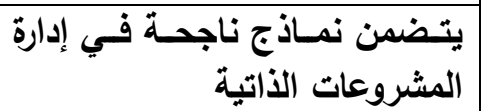 & & \\
\hline \multirow[t]{3}{*}{$\% 33,33$} & $\sqrt{ }$ & تيتضاهم في تنفيذ مهام متعددة. تعليميـة & \multirow[t]{3}{*}{ الوصول إلى نتائج } & \\
\hline & $\mathbf{X}$ & بشكل احترافي المتعلم على تقديم نفسه & & \\
\hline & $\mathbf{x}$ & والثتيحة في الفرصـة للعـشاركة بنـشاط & & \\
\hline \multirow[t]{3}{*}{$\% 33,33$} & $\mathbf{x}$ & وضضمن مواقف تعليمية تقوم على الأدوار وتوزيعها & \multirow[t]{3}{*}{ المسؤولية } & \multirow[t]{6}{*}{ والمسؤولية } \\
\hline & $\sqrt{ }$ & مبدأ تحمل مواقف تعليمية تقوم على & & \\
\hline & $\mathbf{x}$ & 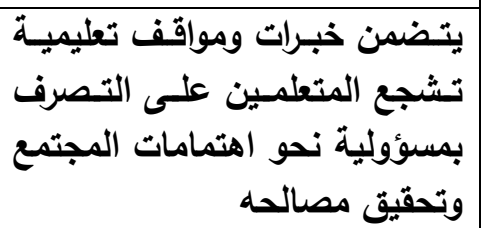 & & \\
\hline \multirow[t]{3}{*}{$\% 33,33$} & $\mathbf{x}$ & | يتضمن توجيهات لأخلاقيات العمل & \multirow[t]{3}{*}{ والقيادة } & \\
\hline & $\mathbf{x}$ & لاى لمتعملمين في تنمية المراقبـة الذاتيـة & & \\
\hline & $\sqrt{ }$ & التضمن مواقف تعليمية تنمي لاى & & \\
\hline$\% 29,17$ & \multicolumn{4}{|c|}{ نسبة تثبع المجال } \\
\hline
\end{tabular}

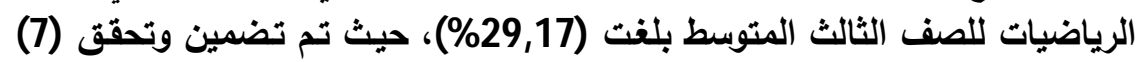

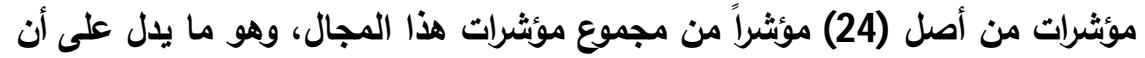

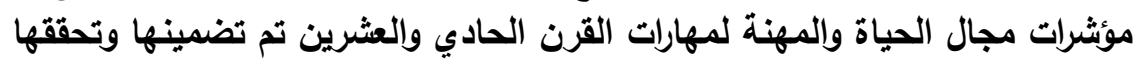
بنسبة متدنية جداً ودون المستوى المأمول. 


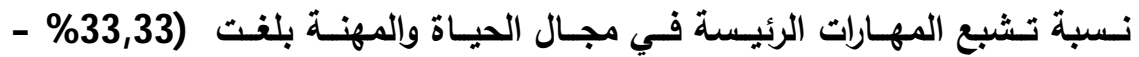

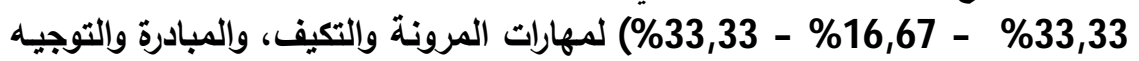
الذاتي، والإنتاجية والمساعلة، والقيادة والمسؤولية على الترتيب، وذلك على النحو

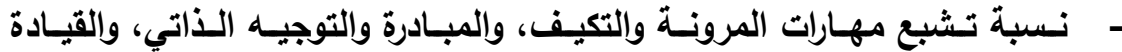

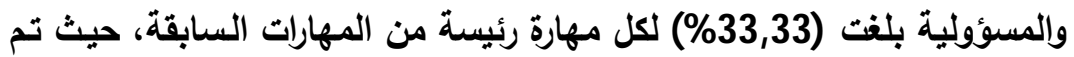

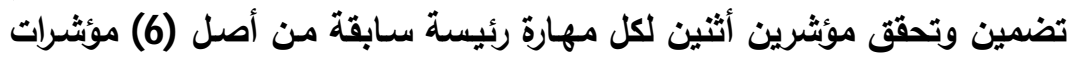

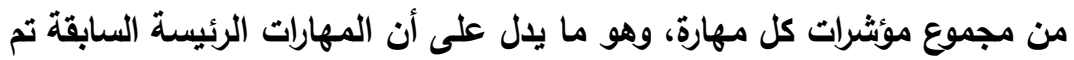

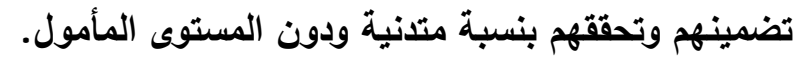

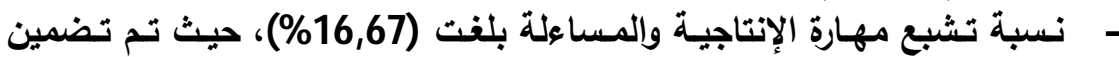

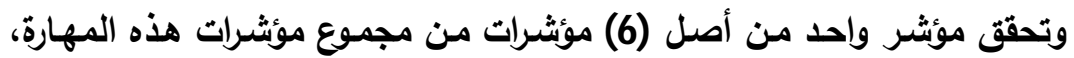

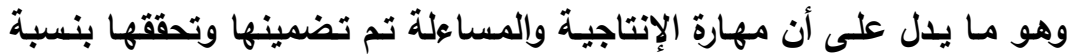

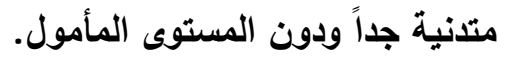

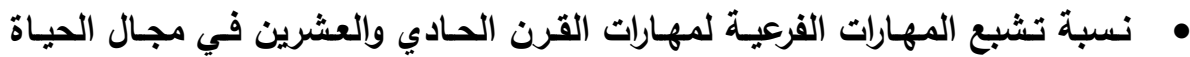

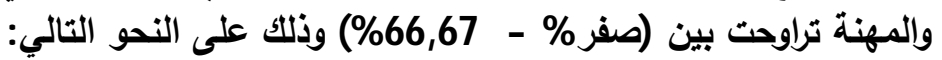

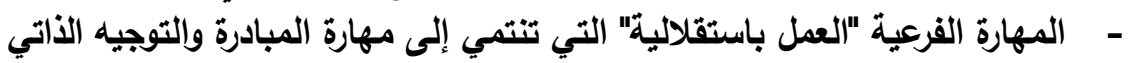

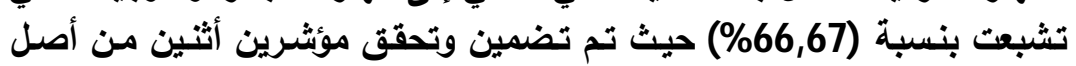

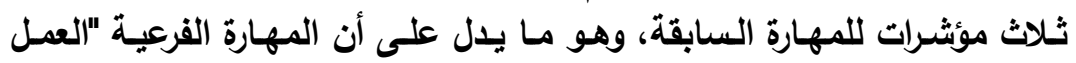

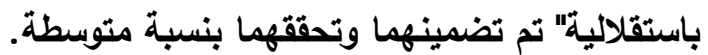

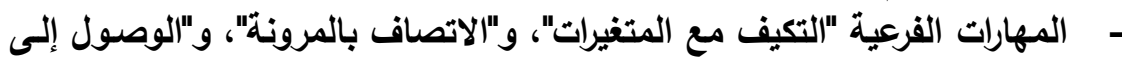

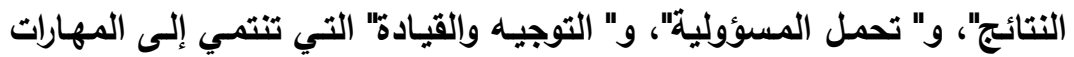

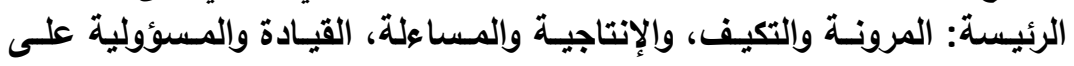

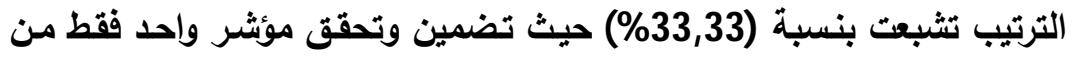

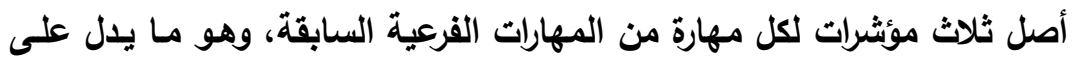

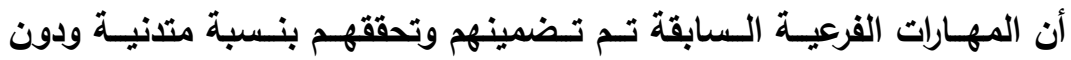

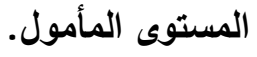

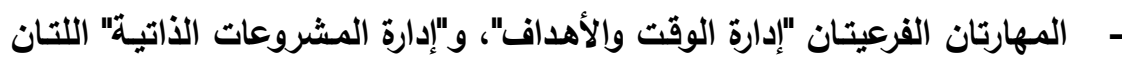

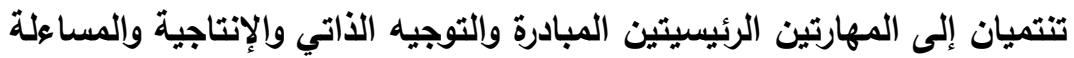

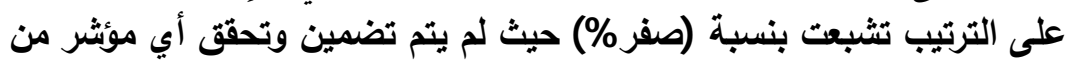

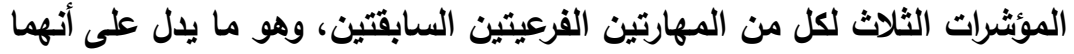

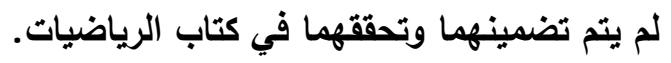


مجلة كلية التريبة، جامعة الأزهر، العدد: (183، الجزء الأول) يوليو لسنة 2019م

مناقشة النتائج وتفسيرها:

• يـل ضعف وتدني تناول كتاب الرياضيات للصف الثالث المتوسط لمهارات القرن

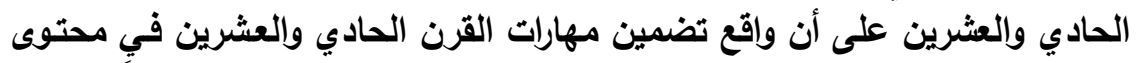

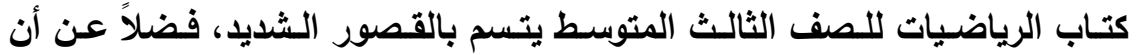

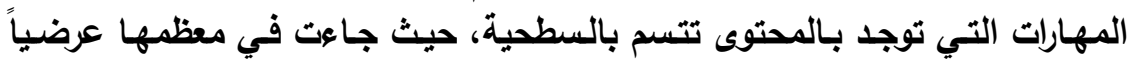

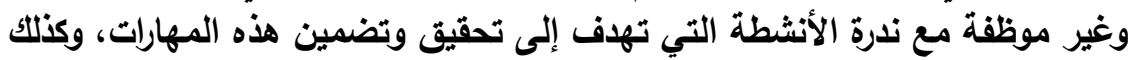
ندرة الأنثطة التقويمية لقياسها.

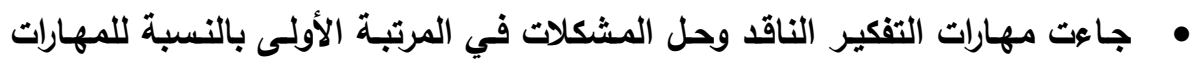

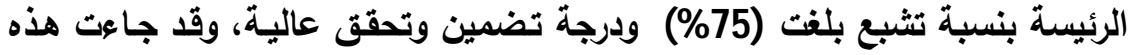

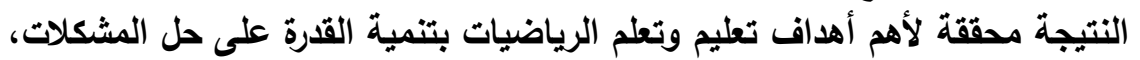

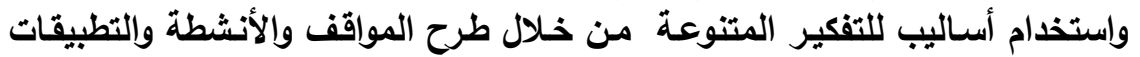
التي تنمي مهارات الترتيب والتصنيف والاستنتاج والاستقصاء والتحليل والتبرير واتخاذ ولاذ

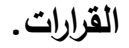

جاعت مهارات الاتصال والتعاون، والثقافة المعلوماتية، والثقافة التقتية في المرتبة

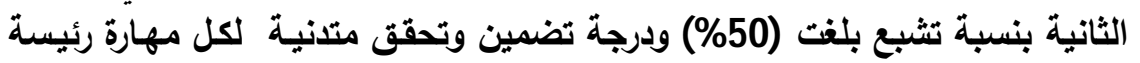

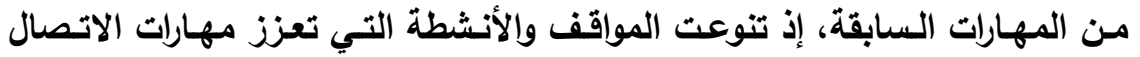

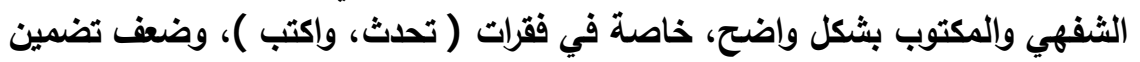

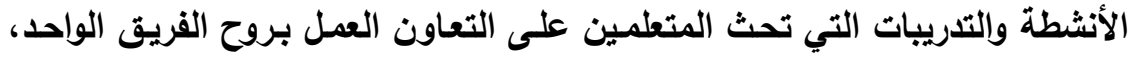

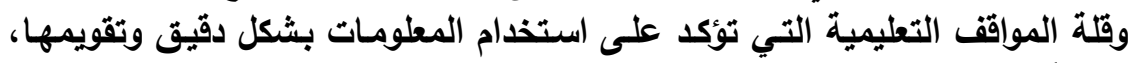

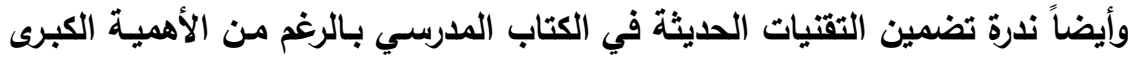
للتقنية في العملية التعليمية.

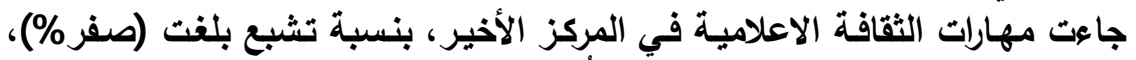

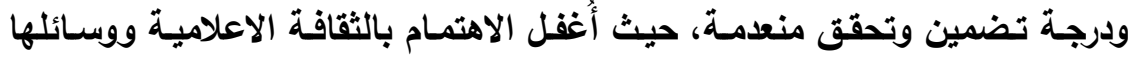

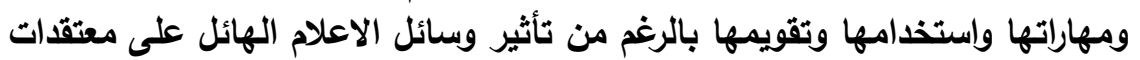
الناس وسلوكياتهم، وتنوع تفسير الأفراد لمضمون الرسائل الاعلامية.

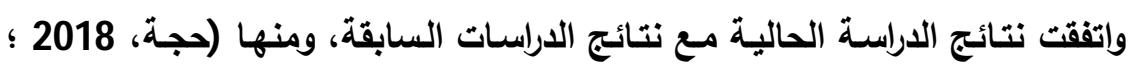

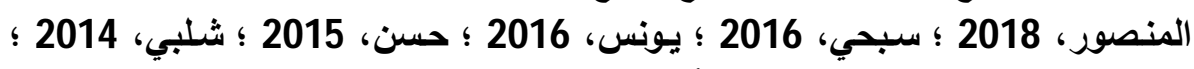

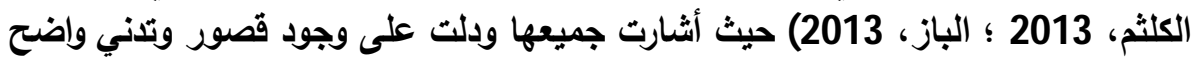

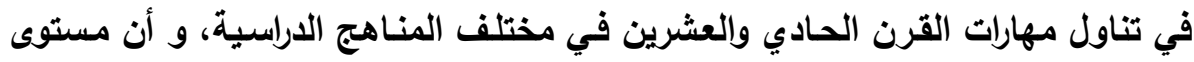

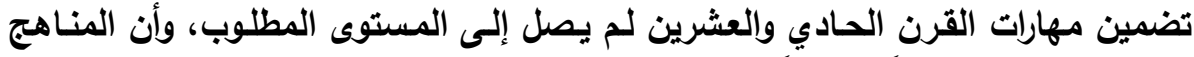

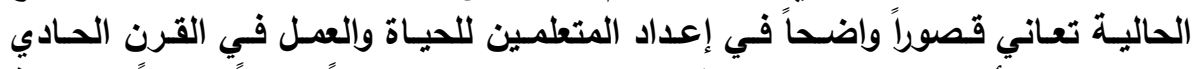

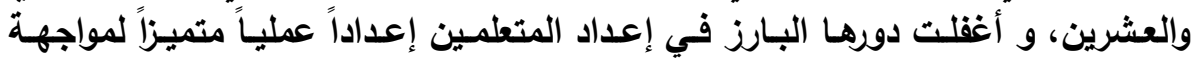


تحدياته، وأن مهارات التفكير الناقد وحل المشكلات يتم تضمينها بلرجة عالية في المناهج

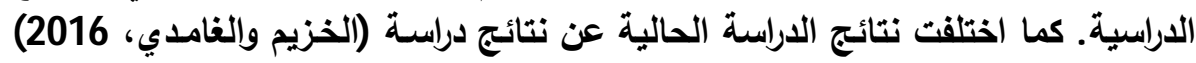

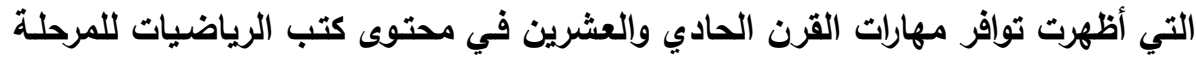
الابتذائية العليا بدرجة متوسطة.

$$
\text { ويعزو الباحث هذه النتائج إلى ما يلي: }
$$

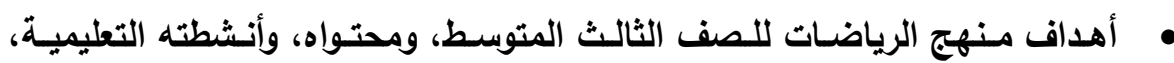

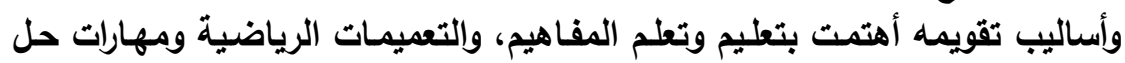

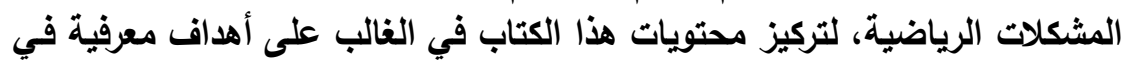

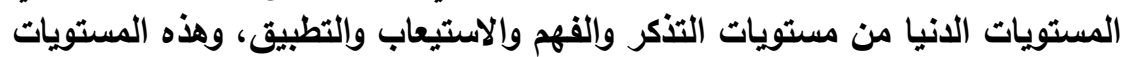

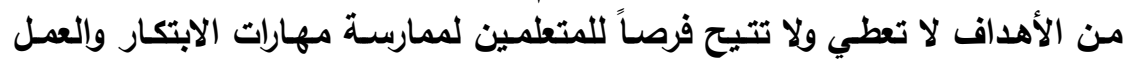

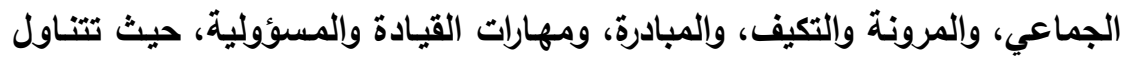

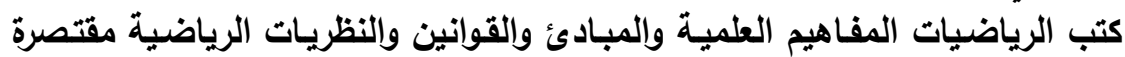
على الحفظ والتفسير والتطبيق.

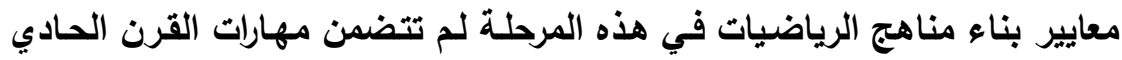

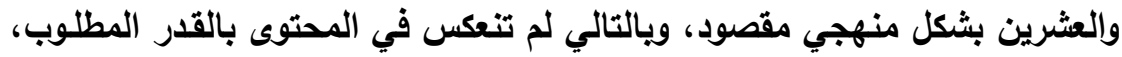

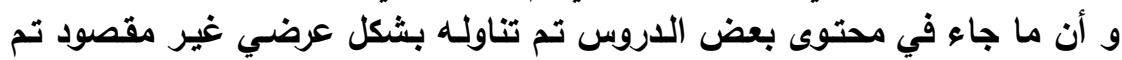

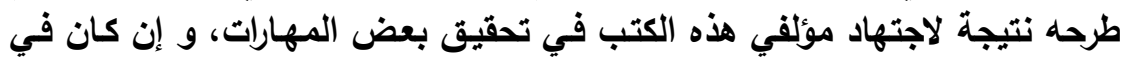
مجمله ضعيف. حداثـة بعض مهارات القرن الحسادي والعشرين مثنل ( مهارات الثقافة المعلوماتيـة

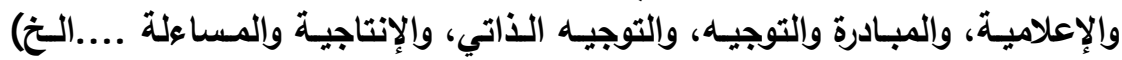

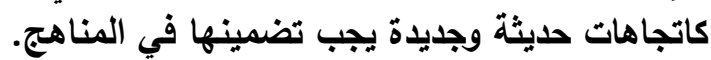

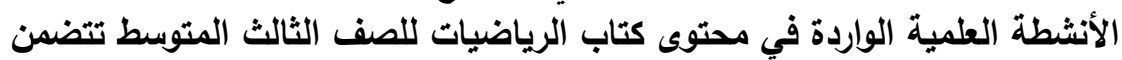

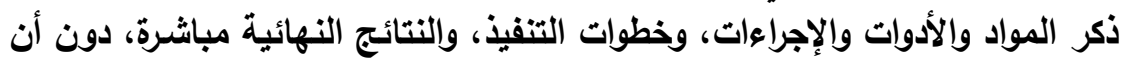

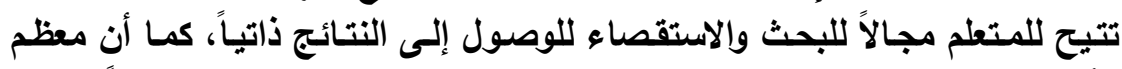

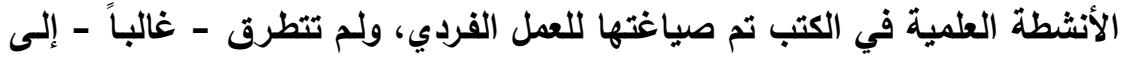

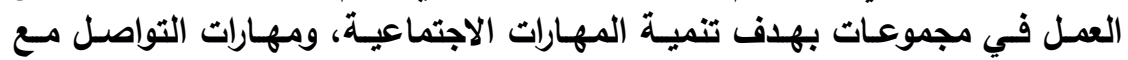
الآخرين، والتوجيه الذاتي،والقيادة والمسؤولية. 


$$
\text { في ضوء نتائج الدراسة، فإنًَ الباحث يوصي بما يلي: }
$$

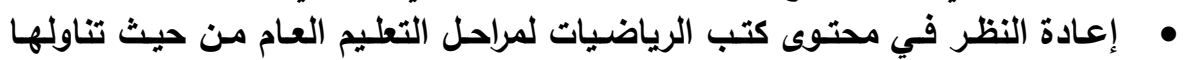

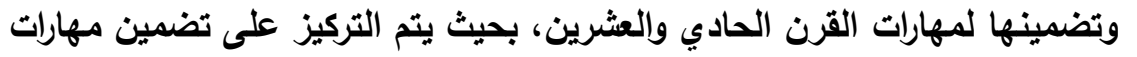

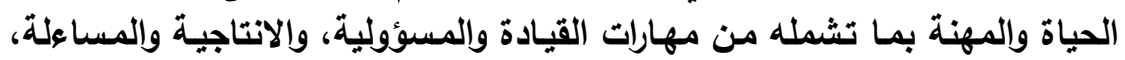
والمبادرة والتوجيه الأتي.

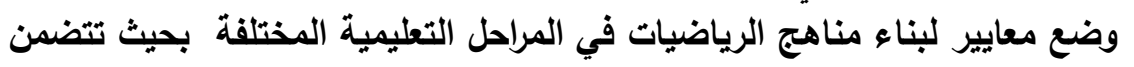

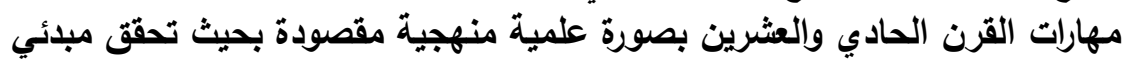
التكامل والاستمرارية. وضع تصور موحد من قبل وزارة التعليم ومسؤولي إعداد وتطوير المناهج لآلية دمج

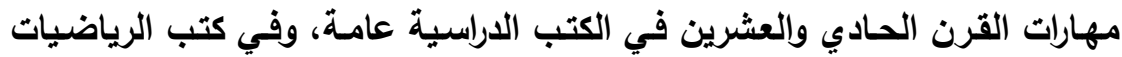
على وجه الخصوص لتوحيد الجهود والعمل.

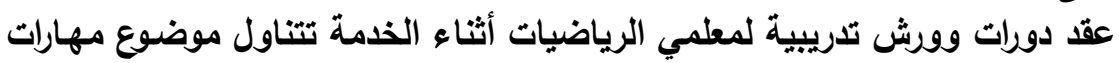
القرن الحادي والعشرين وكيفية تضمينها في مناهي الريات الرياضيات الخديات 
آل كاسي، عبد الله علي وعزام، محمود رمضان (2018) . مستوى تمكن طلاب جامعة

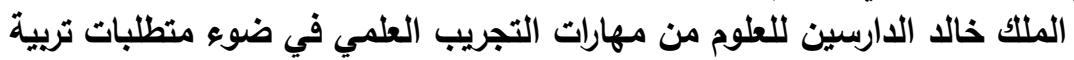

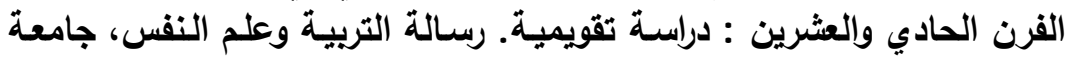

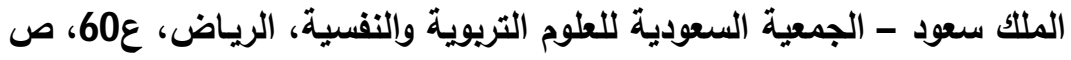

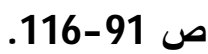

أبو حسن، ياسمين محمد (2015)، تقويم محتوى وأنشطة منـاهج الدراسـات الاجتماعية

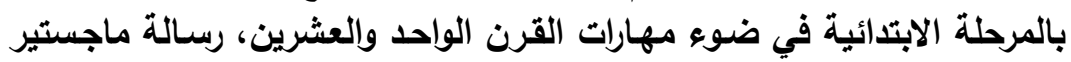

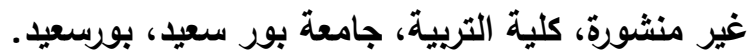

الباز، مروة محمد (2013) . تطوير منهج العلوم للصف الثالث الإعدادي في ضوء مهارات

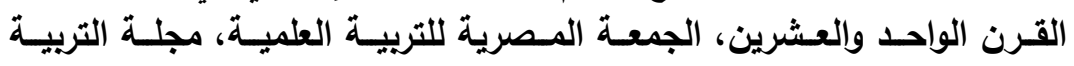

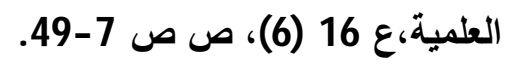
البلوي، عواطف فالح والبلوي،عائشة محمد ( 2019) 2016 ، تصور لبرنـامج تدريبي مقترح

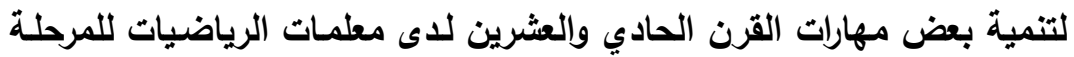

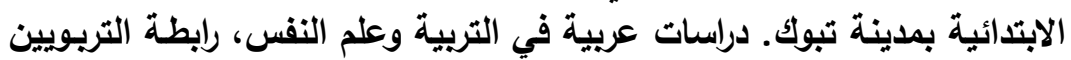

$$
\text { العرب، ع107، ص ص ص } 387 \text { - } 383 \text { - } 433 \text {. }
$$

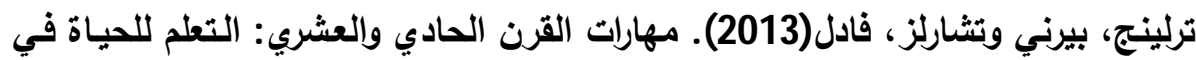

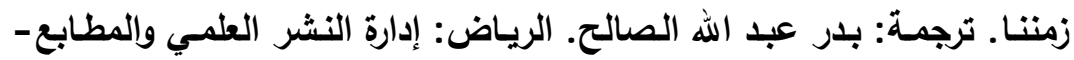
جامعة الملك سعود . ترجئ

حجة، حكم رمضان ( 2018). مدى تضمين كتب العلوم للمرحلة الأساسية العليا لمهارات

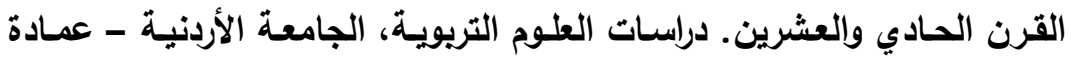

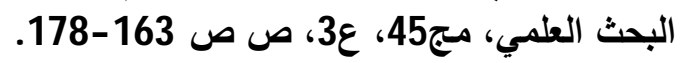

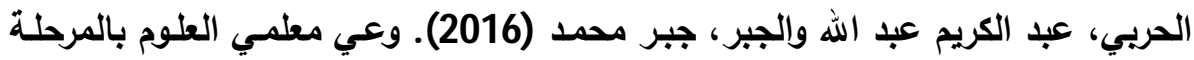

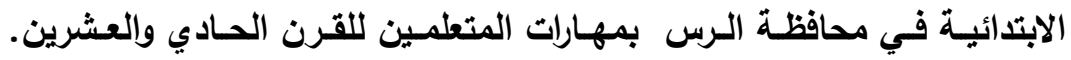

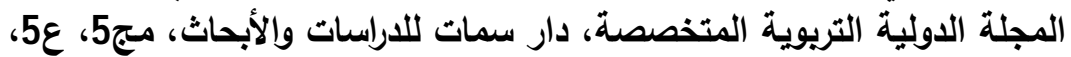
ص ص ص 24 -38. حسن، شيماء محمد ( 2015). تطوير منهج الرياضيات للصف السادس الابتدائي في

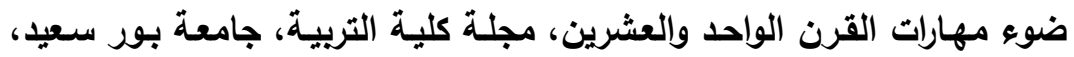

ع ع 18، ص ص صو 297 -345. 
مجلة كلية التربية، جامعة الأزهر، العدد: (183، الجزء الأول) يوليو لسنة 2019م

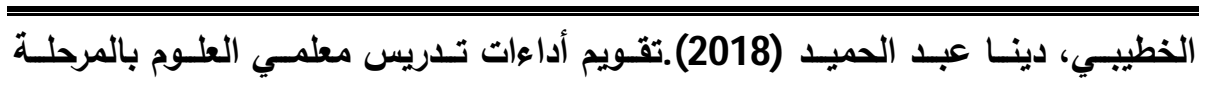

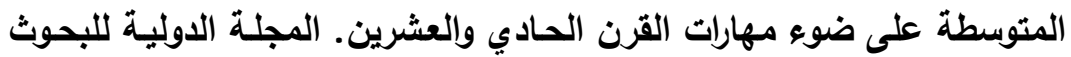

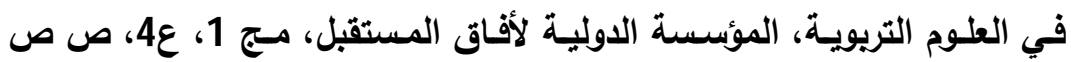

.291- 261

راثند، علي محي الدين عبد الرحمن(2017) . دور تدريس العلوم في تنمية مهارات التعلم

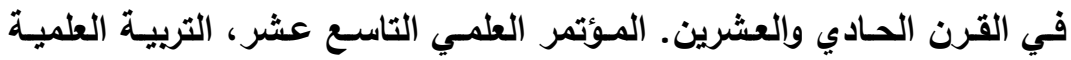

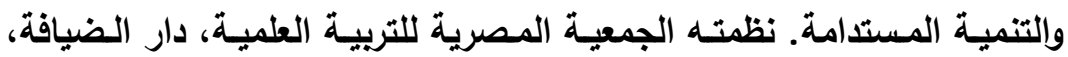

جامعة عين شمس، القاهرة. ص ص 225 -238.

الرياط، بهيرة شفيق (2018),فاعلية الدمج بين استراتيجيات خرائط التفكير ونموذج التعلم

القائم على الموا(قف المزدوجة لتنمية بعض مهارات القرن الحادي والعشرين في

دراسة الهندسة لاى تلاميذ الصف الأول الإعدادي ـ مجلة تربويات الرياضيات، بهنه

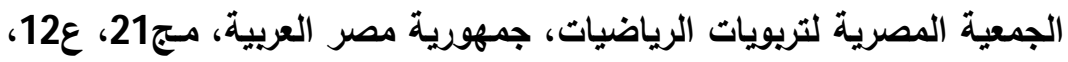

ص ص ص 277 -368.ق

رزق، فاطمة مصطفى محمد (2015) . استخدام مدخل ST EM التكاملي لتعلم العلوم في

تنمية مهارات القرن الحادي والعشرين ومهارات اتخاذ القرار للدى طلاب الفرقة

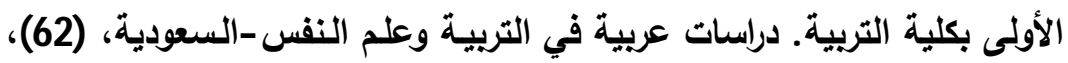

$.128-79$

روفائيل، عصام وصفي ويوسف، محمد أحمد (2001) . تعليم وتعلم الرياضيات في القرن الحادي والعشرين، القاهرة : مكتبة الأنجلو المصرية.

سبحي، نسرين حسن (2016)،مدى تضمين مهارات القرن الحادي والعشرين في مقرر العلوم المطور للصف الأول المتوسط بالمملكة العربية السعودية. مجلة العلوم

التريوية، جامعة الأمير سطام بن عبد العزيز، مج1، عاد، ص ص صالهول 9 -44. 
السعيد، رضا مسعد ( 2018). STEM: مدخل تكاملي حديث متعدد التخصصات للتميز

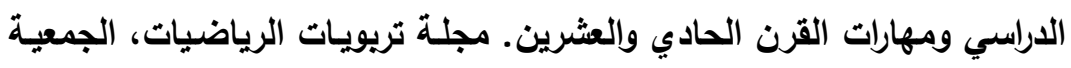

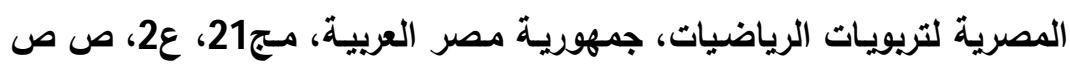
$.42-6$ شلبي، نوال محمد(2014). إطار مقترح لامج مهارات القرن الحادي والعشرين في مناهج

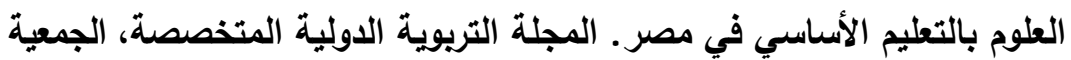

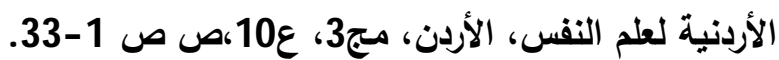
عبد العال، محمد سيد (2018)،فاعلية برنامج معزز بأدوات الويب2 في تنميـة مهارات

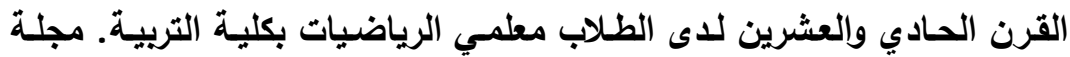

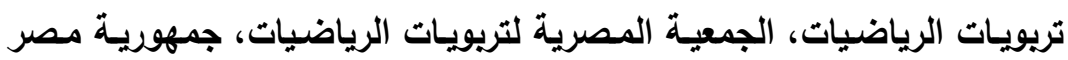

$$
\text { العربية، مج21، ع6، ص ص } 214 \text {-269. }
$$

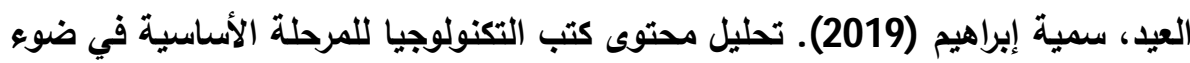
مهارات القرن الحادي والعشرين،ومدى اكتساب طلبة الصف العاشر لها، رسالة

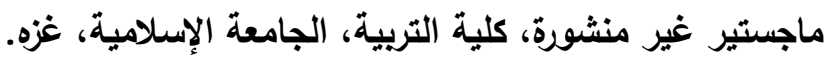

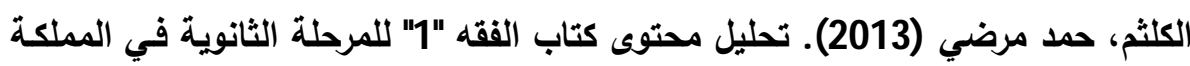

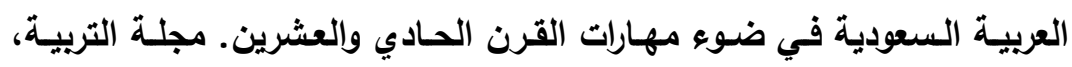

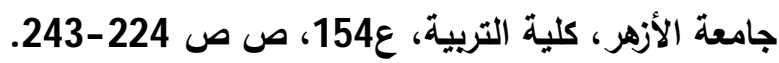

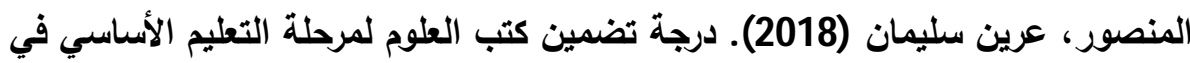

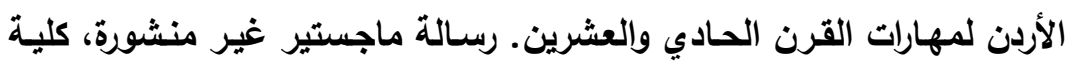
العلوم التربوية،جامعة آل البيت، المفرق، الأردن. الهويش، يوسف محمد (2018). التنمية المهنية لمعلمي المملكة العربية السعودية في الإدنية

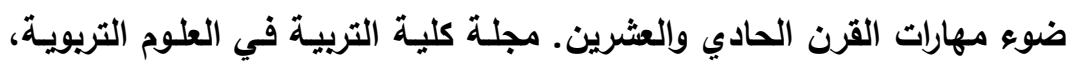

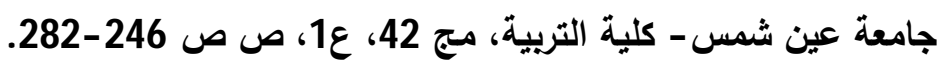


مجلة كلية التربية، جامعة الأزهر، العدد: (183، الجزء الأول) يوليو لسنة 2019م

يونس، إدريس سلطان (2016)، تقويم منهج الجغرافيا بالمرحلة الثانوية العامة في ضوء

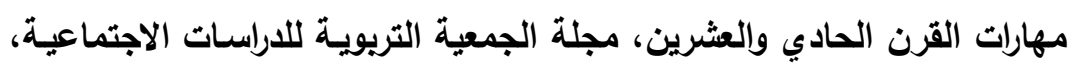

جامعة عين شمس - كلية التربية، القاهرة، ع76، صله ص ص 63 -92.

- 553- 
Kayange، Jaston \& Msiska Masauko ( 2016) Teacher Education In China; training Teachers For The 21st Century، the Online Journal of New Horizons In Education- October 2016 Volume 6، Issue4.

Ken Key(2010) .21st Century Skills; Why They Matter, What They Are, and How we Get There?. http: www . Innovation Iabs. Com psd resourses Ken Kay • pdf .

Miller, Robert D.(2010) ; Developing 21st Century Skills Through the Use of Student Personal Learning Networks, Ed .D . Northcentral University. United States Student Personal Learning Networks, ED. D. Northcentral University . United States .

Scott, Cynthia Luna (2015) . The Futures of learning2: what kind of Learning for The $21^{\text {st }}$ century ?

http: unesdoc . unesco.org images 0024002429242996 pdf .

Sukor, Nur \& Osman, Kamisah \& Abdullah, Maria (2010): 'students Achievement of Malaysian 21st Century Skills in Chemistry', Procedia Social and Behavioral Sciences 9, www.sciencedirect.com

Partnerships for 21st century Skills (2004) . 21st century Skills. (http;//www.21st stcentury Skills.org/ documents / augu st04 NCLB COMMISSIONLETTER- final • pdf) • Retrieved;3/10/2011.

Vogt, J \& Robin,N.( 2012) .A Comparative Analysis of International Frameworks for 21st Century Competences ; Implications for National Curriculum Policies. Journal of curriculum Studies, 44 (3)، 299-321. 